NBSIR 75.692

A Minicomputer-Based System for the Measurement and Analysis of Community Noise

R. L. Fisher, D. S. Blomquist, J. S. Forrer, D. M. Corley

Mechanics Division

Institute for Basic Standards

National Bureau of Standards

Washington, D. C. 20234

May 1975

Final Report

Prepared for

Bioacoustics Division

U. S. Army Environmental Hygiene Agency

Aberdeen Proving Ground, Maryland 21010 

NBSIR 75-692

\section{A MINICOMPUTER-BASED SYSTEM FOR THE MEASUREMENT AND ANALYSIS OF COMMUNITY NOISE}

R. L. Fisher, D. S. Blomquist, J. S. Forrer, D. M. Corley

Mechanics Division

Institute for Basic Standards

National Bureau of Standards

Washington, D. C. 20234

May 1975

Final Report

Prepared for

Bioacoustics Division

U. S. Army Environmental Hygiene Agency

Aberdeen Proving Ground, Maryland 21010

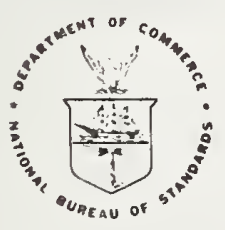

U.S. DEPARTMENT OF COMMERCE, Rogers C.B. Morton, Secretary

NATIONAL BUREAU OF STANDARDS, Richard W. Roberts. Director 

1. Introduction ................. I

2. System Description ............... 2

3. Description of Interface Hardware. . . . . . . . . 4

4. Description of System Software ............ 8

4.1. FORTRAN and Assembly Language Software for the

Minicomputer-Based Community Noise System and

Real-Time Analyzer Interface System. . . . . . . 8

4.1.1. Conversational FORTRAN Programs for Calibration and Use of the Community Noise Mersurement System. 9

4.1.2. Assembly Language Subroutines. ........ 10

4.1.3. Test Programs for the Community Noise/Real-Time Analyzer Interface (Plus Real-Time Analyzer

Subroutine Driver) ............ 13

4.1.4. Typical Output Listings. . . . . . . . . . 14

4.1.5. Procedure for Loading Programs -- "CHECK", "NOISE", "TCLOK" and "TRTAI" . . . . . . . . 19

4.1.6. Interface Software Commands. . . . . . . . 20

4.2. FORTRAN Software for the Analysis of Community Noise Data. 23

4.2.1. Nine-track Tape Translation Program . . . . . 23

4.2.2. Calcomp Plot Program . . . . . . . . . 25

5. Appendix A. Program Listings and Flow Charts for Conversational FORTRAN Calibration and Community Noise Programs. • 26

6. Appendix B. Program Listings for Assembly Language Subroutines. 48

7. Appendix C. Program Listings for Interface Test Programs and Real-Time Analyzer Assembly Language Driver . . . 85

8. Appendix D. FORTRAN Software Listings for the Analysis of Community Noise Data . . . . . . . 97 

A Minicomputer-Based System for the Measurement and Analysis of Community Noise
R. I. Fisher
D. S. Blomquist
J. S. Forrer
D. M. Corley

An operating system for the measurement and analysis of community noise was turned over to the Army for their use in February 1975, thus accomplishing the transfer of technology developed by NBS to the Bioacoustics Division, U. S. Army Environmental Hygiene Agency. This report documents the hardware and software packages prepared by NBS in support of this system.

\section{INTRODUCTION}

The Applied Acoustics Section, Mechanics Division, of the National Bureau of Standards developed a specialized minicomputer-based system for the measurement and analysis of community noise. Since the system originally was developed for in-house use, the hardware and software were in a form that could only be fully utilized by members of the section who were intimately familiar with the operation of the system.

The Bioacoustics Division (BAD) of the U. S. Army Environmental Hygiene Agency, Aberdeen Proving Grounds, required similar measurement and analysis capability to effectively carry out its mission; however, their system would have to be in a form that could be used by personnel not possessing an in-depth familiarity with measurement systems or computer software.

In May 1974, a program was initiated at NBS under BAD sponsorship. The overall objective of this program was the transfer of the technology of measurement and analysis of community noise developed by NBS to BAD. NBS provided the technical expertise in assisting $B A D$ in assembling and documenting such a system and provided the following hardware and software packages: (1) software for sampling community noise levels, (2) software for processing community noise data, (3) utility software programs, (4) community noise interface hardware, and (5) real time analyzer interface hardware and appropriate software driver.

An operating system was turned over to the Army for their use in February 1975. This report documents the hardware and software packages developed by NBS. The documentation includes:

explanation of the hardware and its interaction with the software,

block diagrams to aid understanding of the system and facilitate any future system modifications,

sample calculations for testing and diagnostics,

aser instructions. 


\section{SYSTEM DESCRIPTION}

The community noise measurement system developed by NBS for the Bioacoustics Division was designed to be essentially a "turn-key" data acquisition and analysis system. The hardware portion of the system is comprised of commercially produced analog equipment (microphones, measuring amplifiers, etc.), an interface designed and fabricated by NBS, and an off-the-shelf minicomputer together with its digital peripheral devices.

The input to the present system consists of two microphones which monitor the acoustic environment to be studied and an pptional wind sensor for monitoring wind speed during data acquisition.

Once the proper programs (see Section 4.1. for description of software and loading instructions) are loaded, the minicomputer operates as a hardware controller, sampling and storing the A-weighted sound levels (in decibels re $20 \mu \mathrm{Pa}$ ) for both acoustic data channels every 0.1 second. After a minute of gata (600 samples) has been stored, the minicomputer writes the data on IBM compatible digital magnetic tape for later analysis. It should be noted that a 731.5 metre (2400 foot) digital magnetic tape can store approximately 50 hours of community noise data. Every ten minutes the minicomputer prints out a summary line $\underline{3 f}$ statistical descriptors of the community noise -- $L_{1}, L_{10}, I_{50}$ and $L_{\text {eq }}{ }^{3}$ (for a ten minute interval) -These line summaries which include the tape number, time of day, A-weighted sound levels, etc., are formatted such that they can conveniently serve as the basis for an accurate data log.

The complete data tapes can be processed on a Univac 1108 computer system which utilizes FORTRAN programs (described in Section 4.2.). Once analysis is complete, the community noise data can be produced in tabular and/or graphical form.

I/ The system design provides the capability for expansion to a maximum of eight channels of analog data.

2/ Certain commercial equipment, instruments, or material are identified in this report in order to adequately specify the BAD system. In no case does such identification imply recommendation or endorsement by the National Bureau of Standards, nor does it imply that the material or equipment identified is necessarily the best available for the purpose.

3/ $L_{1}$ is the A-weighted sound level which is exceeded 1 percent of the time. $I_{10}$ is the A-weighted sound level which is exceeded 10 percent of the time. Both $I_{1}$ and $I_{10}$ are often used to represent the higher-level, shorter-duration sounds. $L_{50}$ is the A-weighted sound level which is exceeded 50 percent of the time. $5 \mathrm{~L}_{\text {eq }}$ is the energy equivalent A-weighted sound level. 
Except for brief periods (generally 7 seconds every 10 minutes) while the Teletype is printing out the data line summaries, the A-weighted sound level (in decibels re $20 \mu \mathrm{Pa}$ multiplied by a factor of ten) for either channel 1 or channel 2 (selectable by a switch on the front panel of the interface) is digitally displayed (four digit display) on the front panel of the interface for the convenience of the experimenter. These A-weighted sound levels will typically agree very closely with the analog meter readings of the measuring amplifier for the appropriate channel and therefore provides on the spot confirmation that the procedures for system calibration were correctly followed.

The computer interface designed and fabricated by NBS also contains a time-of-day clock, which the minicomputer interrogates once each minute (and stores the time to the nearest second), and a Brlkel and Kjaer onethird-octave-band real-time-analyzer controller which is functionally independent from the community noise system.

Using a software driver (see Section 4.1.3) the real time analyzer can be sampled to obtain the root mean square ( $\mathrm{rms}$ ) value of the level in each one-third octave band from $12.5 \mathrm{~Hz}$ to $40 \mathrm{kHz}$ (if these filters exist in the real time analyzer), a selected weighted sound level and the overall sound pressure level (linear) at the output of the analyzer in binary coded decimal (BCD) code. A FORTRAN controlling program (not supplied by NBS) could be written to store these data and dump them on to digital magnetic tape for later processing and plotting by a large computer system.

The four digit hexidecimal display on the front panel of the interface which was discussed earlier is independent (hardware wise) from the remainder of the system; therefore, it can be utilized to display up to four hexidecimal digits of information on command from the minicomputer.

Field experience pointed out the necessity for a fast-acting $117 \mathrm{v} \mathrm{A.C.}$ power line conditioner to protect the system from power transients and offset the effect of power brownouts on the computer system. This feature was included in the $B A D$ system. In the event of a longer term (greater than a few milliseconds) power outage that cannot be handled by the conditioner, a power-fail-safe software driver was written by NBS to provide, in conjunction with minicomputer hardware, for orderly shutdown of the central processing unit (CPU) during power failure and a resumption of the program when power is restored. Long term power outages result in the complete shutdown of the minicomputer's digital magnetic tape system. The power-failsafe hardware-software cannot restart the tape system after it shuts down. When the tape unit goes down one must follow the normal manual start up procedures.

The remainder of this report will concentrate on the details of the hardware and software packages developed by NBS. 


\section{DESCRIPTION OF INTERFACE HARDWARE}

The system developed for the Bioacoustics Division has two channels for acoustic data and one channel for wind data. The two acoustic channels have an input impedance of $68 \mathrm{~K} \Omega$ and have a voltage range of 0 to 4.5 volts. The windsensor input has an input impedance of $500 \mathrm{~K} \Omega$ and an voltage range of 0 to 4 volts. The windsensor input has RC integration for smoothing of data. The time constant is 500 milliseconds. The windsensor is a small full wave rectified alternating current generator driven by a conventional 3 bladed anemometer.

Additional channels may be added by inclusion of a buffer amplifier, sample and hold module, timing changes and software changes for each channel added. Maximum expansion of the system -- eight channels -- would also require an expansion of the interface memory capacity.

In addition to the community noise measurement system, the interface also contains the necessary logic to allow a Brllel and Kjaer one-third octave band real time analyzer (model 3347) to be coupled to the minicomputer.

This section contains a simplified explanation of interface operation. For clarity, the minicomputer as well as the commercial analog equipment are shown in the block diagram (Figure 1) describing interface components.

The input signal from the RMS detector $10 \mathrm{~g}$ converter is the logarithm of the A-weighted root mean square (rms) value of the acoustic signal and is buffered by the input amplifier. The buffered signal is fed to a sample and hold module. System timing and control is maintained by a programmable read only memory (PROM). This PROM is addressed by an eight stage counter which is controlled by the crystal controlled oscillator in the time-of-day clock. The PROM strobes the sample and hold module ten times per second. The output of the sample and hold module is fed to a multiplexer (MUX) and then through a buffer amplifier to an analog to digital converter (ADC).

The timing sequence is as follows:

1. The sample and hold module is strobed and the data are held on the storage capacitor.

2. After the data have settled on the hold capacitor (10 RC time constants) the input channels are multiplexed to the ADC.

3. The ADC is strobed to start conversion.

The analog signal is converted to a 10 bit digital word by the ADC. The 10 bit $A D C$ results in a quantization error of $0.05 \mathrm{~dB}$ when the analog signal is sent to a Brllel and Kjaer measuring amplifier type 2607 and the $\log$, dc, output is connected to the interface. The end of conversion pulse from the ADC stores the digitized voltage and a channel number in a 12 bit by 320 word asynchronous first-in/first-out (FIFO) memory. The purpose of the memory is to allow the computer enough time to perform the necessary calculations and "house keeping" without loss of data. The minicomputer is interfaced to the FIFO memory on an interrupt basis. 


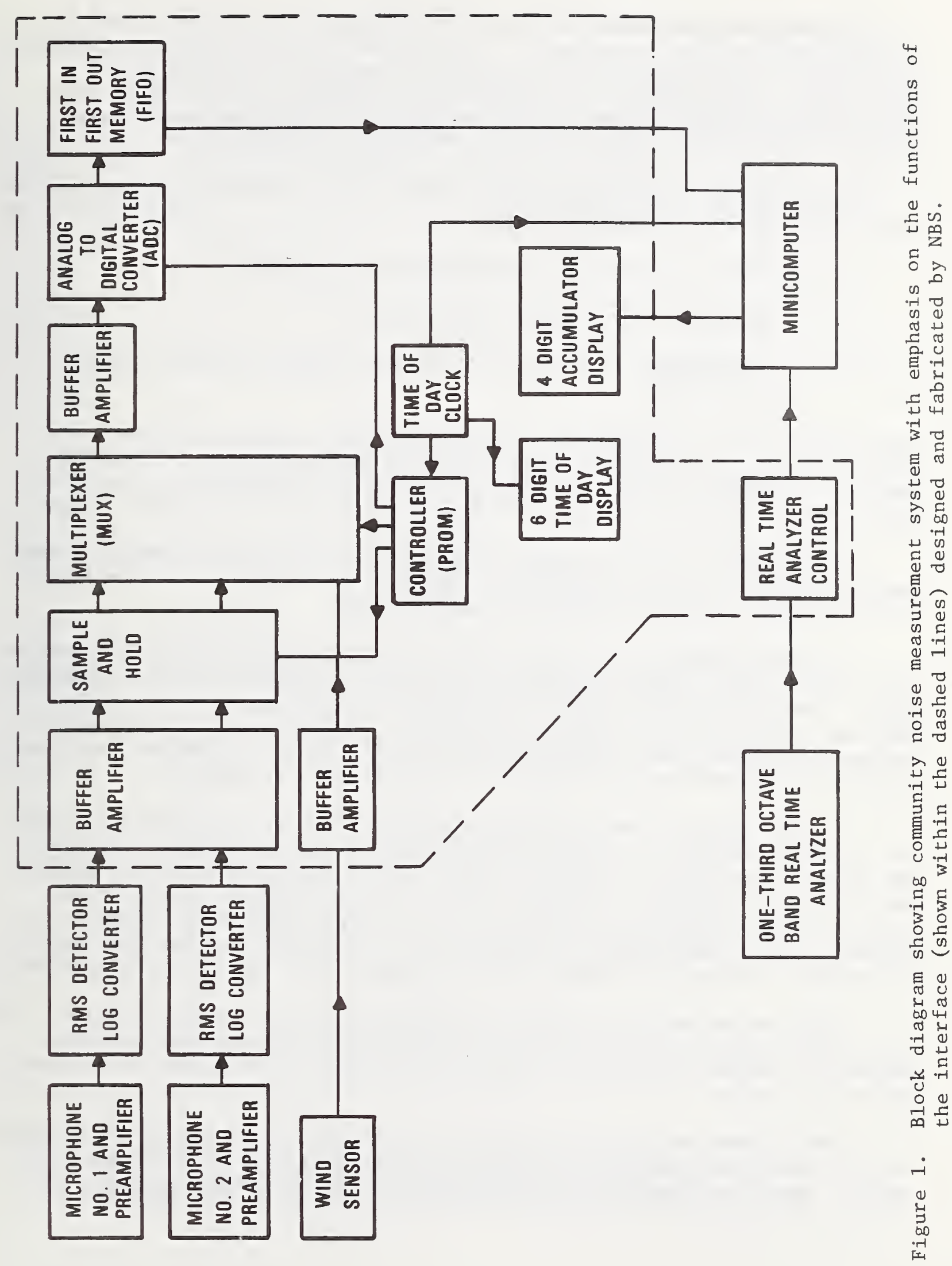


The system also includes a CMOS time-of-day clock, which is read by the minicomputer once each minute. The time base for the clock is crystal controlled. The format of the clock is 24 hours with six BCD digits for hours, minutes and seconds. The clock has a battery powered standby mode which allows for clock operation for a minimum of 1 hour without external power.

The accuracy of the time-of-day clock is governed by the tolerances supplied by the crystal manufacturer:

1. Initial value within 5 ppm (parts per million).

2. Aging per year equals 2 ppm or less.

3. Temperatures from $10^{\circ} \mathrm{C}$ to $40^{\circ} \mathrm{C}$ will cause additional errors up to $8 \mathrm{ppm}$.

Using a worst case assumption for each of the three factors (15 ppm), the total error in one year if the clock were not reset would be 7.9 minutes (about 1.3 seconds per day). After the crystal is one year old, the total drift over a 48 hour period at $20^{\circ} \mathrm{C}$ would be less than 0.6 seconds ( 7 ppm).

In December 1974 the crystal oscillator in the clock in the BAD interface was found, in actual laboratory tests, to be accurate to within 5 ppm of the nominal specified frequency value at $20^{\circ} \mathrm{C}$.

As stated earlier, the system also has the necessary logic for reading out the data from a Brthel and Kjaer one-third octave band real time analyzer (RTA). The 3 l/2 digits from the analyzer are accompanied by two status bits for indicating underrange and overload. In this case, underrange is defined as a level that is less than the RTA's internal reference level while overload is defined as an overload of the analog input amplifier.

On the front of the interface panel there are two displays which allow for operator control -- a time-of-day display and an accumulator display. The time-of-day display shows the time of day in hours, minutes and seconds on a six digit display in 24 hour format. The accumulator display shows the accumulator contents ( 16 bits) on a four digit hexidecimal readout. A single computer instruction is required for the display and the data are set in latches such that the data will be displayed until new data are received.

The time of day is set by use of the hold, slow and fast switches. The hold switch stops the clock, the slow switch advances the clock at a one minute per second rate and the fast switch advances the clock at a one hour per second rate.

Front panel switches also include an external sense switch for computer control and a power switch to disable the battery power for the time-of-day clock. When the computer is to be turned off for more than one hour, the 
battery power should also be turned off to avoid completely discharging the batteries.

There are three switches on the back of the interface. The purpose of these switches is for trouble shooting the hardware and software. All the switches are debounced to eliminate multiple pulses. The Master Reset switch clears the interface memory of all data and resets the PROM to the first location. There are two switches for either shifting data into or out of the memory. 
This section and the appendices document the FORTRAN and SYM II (assembly language for this particular 16-bit minicomputer [Raytheon 704]) assembly language software for the minicomputer-based community noise system and realtime analyzer interface system as well as the FORTRAN software for the analysis of community noise tapes. The documentation includes program listings, overall block diagrams, test programs to be utilized for diagnosis of system problems and typical examples of the output from the main FORTRAN programs.

4.1. Fortran and Assembly Language Software for the Minicomputer-Based Community Noise System and Real-Time Analyzer Interface System.

The operation of the minicomputer-based data acquisition system is discussed from a software point of view in this section. The level of explapgtions assumes familiarity with programming in conversational FORTRAN and SYM II assembly language.

In general, two main FORTRAN programs and their respective subroutines must be loaded into the minicomputer and be operable in order to be able to acquire a possible eight channels of data on digital magnetic tape (for later analysis utilizing a large computer system such as the Univac 1108 at the National Bureau of Standards). It should be noted that substantial changes to both the hardware interface and to the software would be necessary for expanding the present system (2 channels) to a maximum of eight channels.

The first main program is called "CHECK". Once the "CHECK" program is loaded (see Section 4.1.5. for loading procedures) the measuring amplifier (Brthel and Kjaer 2607) provides the output for acoustic data channel 1 and is manually stepped over its entire $50 \mathrm{~dB}$ range and a linear fit is performed on the resulting digital values received by the minicomputer from the community noise interface using the method of least squares. This procedure determines the factor relating analog A-weighted sound levels in decibels ( $r e 20 \mu \mathrm{Pa}$ ) to the digital values transferred to the minicomputer via the community noise interface. The process is repeated for acoustic data channel 2 and a calibration paper tape is automatically punched out for use in the "NOISE" program.

The second main program, called "NOISE", (I) receives and buffers the digital values which are proportional to the output values of the measuring amplifier, (2) converts these values to exact decibel values and (3) writes the community noise data on digital tape. The reference decibel value is maintained in the program by periodic application of a pistonphone calibration on the microphone for each acoustic data channel.

If either of the two main FORTRAN programs malfunction, the Raytheon supplied diagnostic programs -- CPU 30, 31, etc. -- and the system interface 4/"Raytheon 704 Users Manual"

Raytheon Data Systems

1415 Boston-Providence Turnpike

Norwood, Massachusetts 02062

page 8. 12

5/ Raytheon 70' Users Manual, page 8.84 
test programs written by NBS (outlined in Section 4.1.3.) should be run to determine whether the fault lies in the central processing unit (CPU) or the interface.

\subsubsection{Conversational FORTRAN Programs for Calibration and Use of the} Community Noise Measurement System

The measuring amplifier (Brblel and Kjaer 2607) used in the BAD community noise system has a dc output that is directly proportional to the logarithm of the root mean square ( $r m s$ ) input voltage. This dc output is connected to an analog multiplexer (for switching channels) and then to an analog to digital converter in the community noise interface. Therefore, the digital output of the interface is also directly proportional to the logarithm of the rms input voltage of the measuring amplifier. Once the values for $f$ and $c$ in the following equation have been determined, the "NOISE" program will directly compute the A-weighted sound level (SPI) in decibels ( $r e 20 \mu P a$ ) from the raw digital values transferred from the interface to the minicomputer.

$$
\text { SPL }=f D+c
$$

where $\quad D=$ raw digital value from the community noise interface

$f=$ slope of the least squares curve fit discussed in Section 4.1 .

$c=$ constant based on the pistonphone level.

The conversational FORTRAN program called "CHECK" in conjunction with the manual switching of the input attenuator of the measuring amplifier (previously discussed in Section 4.1.) establishes the $f$ values for both acoustic data channels. (See appendices $A$ and $B$ for program listings). The procedure to use is as follows:

1. Load "CHECK" program using one of the methods outlined in Section 4.1.5. of this report.

2. Follow the directions provided by program "CHECK" which are typed on the Teletype.

3. Save the listing produced by the "CHECK" program for future reference. Save the paper tape punched for later use by the "NOISE" program.

The conversational FORTRAN subroutine "ORTH". is a least squares curve fitting routine using orthogonal polynomials. The "CHECK" program calls subroutine "ORTH" to perform a first order (linear) fit on the array of measuring amplifier input values ( 0 to $50 \mathrm{~dB}$ ) versus an array of raw interface value ( 0 to 1023) solving for $c$ and $f$ in equation ( 1 ). The values of $f$ for both acoustic data channel 1 and acoustic data channel 2 are punched on a paper tape (along with the year, day and time) by the "CHECK" program for later use in the "NOISE" program. The values for c are not stored because c will be determined by pistonphone calibration and measuring amplifier gain settings in the "NOISE" program. The flow diagram for the "CHECK" program is presented in Appendix A. 
The "NOISE" program conducts a two-channel community noise survey by sampling the acoustic data channels and the optional wind data channel at a $10 \mathrm{~Hz}$ rate. Once a minute, the noise data (A-weighted sound level in decibels re $20 \mu \mathrm{Pa}$ ) and the maximum wind speed are written on magnetic tape for later analysis.

The procedure for using the "NOISE" program is as follows:

1) Load "NOISE" program into the minicomputer using one of the methods shown in Section 4.1.5. of this report.

2) Follow the directions given by the "NOISE" program in the Teletype printout.

3) After the program is routinely recording data on magnetic tape, a new pistonphone calibration can be initiated by putting sense switch 1 up on the CPU. Similarly putting sense switch 2 up will request a new 2607 gain setting.

4) Save the listing produced by the "NOISE" program as a data log for the data stored on the magnetic tape.

The "NOISE" program will print out $\mathrm{I}_{7}, \mathrm{~L}_{10}, \mathrm{I}_{50}$ and $\mathrm{L}_{\text {eq }}$ every ten minutes on the system Teletype. (These values are not recorded on the magnetic tape). The Teletype printout forms a valuable record of the data recorded on the magnetic tape. $I_{1}$ is a useful guide for determining the proper input attenuator settings for the measuring amplifier. Set the measuring amplifier attenuators so that the value of $I_{1}$ is within $10 \mathrm{~dB}$ of full scale on the measuring amplifier. These $L_{i}$ values (calculated on fixed 10 minute intervals) will not agree exactly with $\mathrm{L}_{i}$ values calculated by a box car averaging method in the program described in Section 4.2. The flow diagram for the "NOISE" program is presented in Appendix A.

"TOGLE" is a conversational FORTRAN subroutine used by both the "CHECK" program and the "NOISE" program to detect sense switch O changes signaling a user response.

\subsubsection{Assembly Language Subroutines}

\section{a. Subroutine "STEM I"}

Main programs such as "CHECK" and "NOISE" and their subroutines can be added to the normal Raytheon systems tape as described in section 4 of the Raytheon Magnetic Tape Operating System Manual- Developing this normal systems tape is time consuming and calling the required programs under "XRAY" control would be a lengthy process. To avoid this problem and in addition avoid operating exclusively with long paper tapes the "STEM I" program was written. (See appendix B for program testing.)

6/ "Magnetic Tape Operating System"

Raytheon Data Systems

1415 Boston-Providence Turnpike

Norwood, Massachusetts 02062 
When called by a conversational FORTRAN program, "STEM 1 " checks to see if sense switches $0, I$, and 2 are up. If these switches are up and the magnetic tape is "write enabled", a small loader and a complete core image dump will be written on magnetic tape thus developing a "special" systems tape. The program on the special systems tape can be called into memory by:

1. Mounting special tape in the magnetic tape drive and bringing the tape to load point (BOT) and on line.

2. Push RESET on the CPU.

3. Push magnetic tape LOAD button $\mathbb{N}$ times where $\mathbb{N}$ equals 1 plus 2 times the number of programs ahead of the desired program on magnetic tape.

4. Push RUN on CPU.

5. Push RUN on CPU.

\section{b. Subroutine "DATA"}

This program establishes interrupt level 5 linkage which allows data to be brought into the computer from the interface. (Subroutine "INTL" must also be called to enable interrupt level 5 thereby starting actual data transfer.) "DATA" makes the instantaneous values of the wind channel, acoustic data channel 1 and acoustic data channel 2 available for use in the main FORTRAN program at a $10 \mathrm{~Hz}$ rate. Program "CHECK" utilizes the "DATA" subroutine to input raw interface data for curve fitting and to send these data to the interface display. Program "NOISE" utilizes the "DATA" subroutine only for pistonphone calibration and does not send any data to the interface display. (Program "NOISE" uses subroutine "DISP" to send A-weighted sound level data to the display.)

\section{c. Subroutine "LFD"}

Program "NOISE" cannot convert raw interface values to actual A-weighted sound levels in decibels ( $r e 20 \mu \mathrm{Pa}$ ) while the Teletype is typing. Therefore, typing time must be minimized. By calling subroutine "LFD", the "NOISE" program can space up to ten lines per second instead of two lines per second when utilizing normal Raytheon formatting. When called by a conversational FORTRAN program, subroutine "IFD" sends a line feed character to the Teletype causing the paper to space up by one line.

\section{d. Subroutine "POWF5"}

This subroutine provides for the orderly shutdown of the central processing unit (CPU) with no program loss in the event of power interruption. When power is restored, "POWF5" sends a master reset signal to the interface and the system returns to the program that was in progress when the power failure occurred. If the power is off for more than a few milliseconds, the magnetic 
tape unit will shut down and manual intervention is required to prepare it for operation. If bit 5 of word $X^{\prime} 4 B^{\prime}$ was set prior to the power failure (by "INTL" subroutine), "POWF5" would reenable interrupt level 5 when power was restored.

\section{e. Subroutine "MULTI"}

The "NOISE" program utilizes subroutine "MULTl" to allow the values for the wind channel and the two acoustic data channels to be transferred from the interface to the minicomputer during actual data collection. (Program "NOISE" utilizes subroutine "DATA" to bring in raw data during pistonphone calibration.) Subroutine "MULTl" fills a 1200 word array -- one minute of data -- with raw data from acoustic data channels 1 and 2. Subroutine "INTL" must be utilized to enable interrupt level 5 before subroutine "MULTl" can transfer data from the interface to the minicomputer.

\section{f. Subroutine "MMON"}

Subroutine "MMON" modifies the Raytheon supplied operating software so that it will not continuously write out MO, MO, ..... on the Teletype when the magnetic tape unit shuts down.

\section{Subroutine "DMAMAG"}

Subroutine "DMAMAG" checks the direct memory access (DMA) magnetic tape unit status and returns the status to the calling conversational FORTRAN program. It is particularly useful for locating end of tape (EOT) and for determining whether or not the magnetic tape is "write enabled".

\section{h. Subroutine "INTL"}

Subroutine "INTL" is used to enable or disable any one of the interrupt levels and to record the enable status of each level in the enable status word in location $X^{\prime} 4 B^{\prime}$. Subroutine "POWF5" uses this status word following a power failure to determine if interrupt level 5 should be reenabled.

\section{i. Subroutine "DISP"}

This subroutine has two modes of operation. In the first mode, "DISP" converts a binary number to binary coded decimal (BCD) format and sends it to the interface display. In the second mode, "DISP" converts the number to $B C D$ and sends it to the interface display only if the external sense switch setting agrees with a calling parameter JCHAN (see program listing in Appendix B). The "NOISE" program calls subroutine "DISP" to display A-weighted sound level data in decibels $(r e 20 \mu \mathrm{Pa}$ ). The person performing the data analysis can elect to display either acoustic data channel 1 or acoustic data channel 2 by placing the external sense switch up or down respectively.

\section{j. Subroutine "LEADR"}

When called by a main conversational FORTRAN program, this subroutine will punch a leader on the Teletype. The "CHECK" program calls subroutine "LEADR" to punch a leader in front of and behind the calibration tape it produces for use in the "NOISE" program. 


\section{k. Subroutine "CLOK"}

When called by a main program, subroutine "CLOK" reads the interface clock until the time agrees for two successive interrogations. The time in hours, minutes and seconds is then utilized by the main program as data.

Program listings for subroutines discussed in this Section are contained in Appendix B.

4.1.3. Test Programs for the Community Noise/Real Time Analyzer Interface (Plus Real Time Analyzer Subroutine Driver)

\section{a. Absolute Binary Routine "MINOSI"I/}

This program is used for system checkout and for performing elementary tests on:

1) interface display

- external sense switch up for a decimal display.

- external sense switch down for a hexidecimal display.

2) wind channel

- sense switches 1 and 2 down to display raw wind values (not corrected to knots).

3) acoustic data channel 1

- sense switch 1 (SSI) up (SS2 down) to display raw channel 1 values (not converted to decibels).

4) acoustic data channel 2

- sense switch 2 (SS2) up (SSl down) to display raw channel 2 acoustic values (not converted to decibels).

5) master reset

- sense switch 3 up to provide a master reset command to the interface after each number is displayed.

6) interrupt level 5 .

Note: Put sense switch $O$ up to halt the CPU after each value is displayed if desired. (Push RUN to continue.)

I/ The program listing for MINOSl and the remaining programs in section 4.1.3. are in Appendix $\mathrm{C}$. 
The "MINOSI" program is loaded into the minicomputer by giving the XRAY directive: AI. If the word FACE remains on the interface display more than a fraction of a second after loading the program, something is wrong with interrupt level 5. Either the interface is not sending an interrupt pulse to the CPU or the interrupt card in the CPU is bad.

\section{b. Conversational FORTRAN Program "TCLOK"}

"TCLOK" is a test program utilized for printing out the current time read from the interface clock. Program "TCLOK" calls subroutine "CLOK" to transfer the hours, minutes and seconds values from the display to the Teletype.

An example of the printout from "TCLOK" is shown in Section 4.1.4.

\section{c. Conversational FORTRAN Program "TRTAI"}

The "TRTAI" program receives values for the sound pressure level in each one-third octave band, a selected weighted sound level and the value for the overall sound pressure level (linear) in BCD format from the output of the real time analyzer (RTA) by calling the RTA driver subroutine "RTAI". The "TRTAI" program prints out these values along with a channel underflow bit on the Teletype. If the underflow bit is a l, that particular channel is at or below the base line value of the real time analyzer. If the underflow bit is a 0 , the value is above the baseline. If the input amplifier of the real time analyzer was overloaded during the time period that data were sampled and sent to the interface, an overload message will be printed out.

An example of "TRTAI" output is shown in Section 4.1 .4 .

\section{a. Subroutine "RTAl"}

When called by a conversational FORTRAN program, subroutine "RTAl" commands the real time analyzer to digitize the values in each one-third octave band, the selected weighted band and the overall (linear) band and to send the values in BCD format to the "RTAI" program as data. Subroutine "RTAl" converts these BCD numbers to binary numbers (decibel times a factor of ten) and sends them to the main conversational FORTRAN program as fixed point integers. Channel underflow bits and the input attenuator overload values are also sent to the FORTRAN main program.

\subsubsection{Typical Output Listings}

This section contains output listings from the "CHECK", "NOISE", "TCLOK", and "TRTAI" programs. 
The portion of the output listing for the "CHECK" program shown below should be kept in a log book since these calibration data establish the system accuracy. The year, date and time of the calibration is printed in the upper right hand corner of the printout and also appears at the beginning of the punched paper tape output which will be read by the "NOISE" program. The first three columns in the middle of the listing show the five step $50 \mathrm{~dB}$ dynamic range of the Brllel and Kjaer measuring amplifier (type 2607), values for acoustic data channel 1 (raw interface numbers) and values for acoustic data channel 2 (raw interface numbers). These data are utilized as the basis for the linear curve fitting routine discussed in Sections 4.1. and 4.1.1. The fourth and fifth columns show the difference in decibels between the 2607 values and the values determined by the curve fitting routine. In the example, the maximum system error was $0.12 \mathrm{~dB}$. The linear equations for acoustic data channels 1 and 2 are printed out and the factor relating raw interface values (ADC values) to 2607 values are also punched out on the special output paper tape that is read by the "NOISE" program.

\section{7 - INTERFACE NOISE SYSTEM LINEARITY CHECK}

\begin{tabular}{|c|c|c|c|c|c|c|c|c|}
\hline & & & & & & & $\begin{array}{l}\text { YEAR } \\
\text { DAY } \\
\text { HOUR } \\
\text { MINUTE }=\end{array}$ & $\begin{array}{rr}= & 1975 \\
= & 58 \\
= & 2 \\
= & 23\end{array}$ \\
\hline 2607 & $\mathrm{CH} !$ & Сห2 & $\mathrm{CH} !$ & СК2 & & & & \\
\hline \multirow{2}{*}{ DS } & $A D C$ & $A D C$ & $D B$ & $D B$ & & & & \\
\hline & VALUE & VALUE & DIFF & DIFF & & & & \\
\hline 0 & 5 & 5 & .11 & -.00 & 60 & DS & VALUE NOT & (USES) \\
\hline 10 & 20.4 & 205 & .07 & .11 & & & & \\
\hline 20 & 400 & 398 & -.12 & -.12 & & & & \\
\hline 30 & 603 & 597 & .03 & -.05 & & & & \\
\hline 40 & 803 & 796 & .03 & .01 & & & & \\
\hline 50 & 1002 & 994 & -.01 & .03 & & & & \\
\hline$H ! D E$ & $=$ CONS & NT + & $02387 E$ & -3 & $A D C$ & VAl & & \\
\hline CH2 DB & $=\operatorname{CONS}$ & NT + & $60568 E$ & -3 & $A D C$ & VALU & JE) & \\
\hline
\end{tabular}

TGRN ON PUNCH, TOGGLE SENSE SWITCH 0

$1975 \quad 58$ 2 $23 \quad 50.02387 E-3 \quad 50.50568 E-3$

TURN OFF PUNCH, TOGGLE SENSE SWITCH O TO RESTART

CHECK OUT IS COMPLETED. USE PAPER TAPE. IN NOISE

PROGRAI IF ABOVE RESULTS ARE SATISFACTORY. 
An example printout of the "NOISE" program is presented on the next page. The second line of the heading contains the page number, magnetic tape number, year, and date and time of the calibration. The time of calibration refers to the time the calibration paper tape was prepared. Below the heading, there are sixteen labeled columns of numbers that make up the main body of the listing and serve as the basis for an accurate data $l o g$ of the noise levels measured as well as certain checks on the minicomputer system. The first four columns give the day of the year and the time (hours, minutes, seconds) corresponding to the end of the 10 minute block of data. The next fofy columns show the $\mathrm{I}_{7}, \mathrm{~L}_{10}, \mathrm{I}_{50}$ and $\mathrm{I}_{\text {eq }}$ values for acoustic data channel 1. - The next four columns show similar gata for acoustic data channel 2. The column labeled WIND shows the highest wind speed (in knots) for the entire 10 minute block. The column labeled AC PFS is a count of the number of ac power failures that occurred during the 10 minute block. The column labeled \# ERR is a count of the number of incorrect channel numbers generated by the interface during the 10 minute block. Finally, the column labeled \# SKIP is a count of the number of missing or skipped channel numbers during the 10 minute block. Non-zero values for either \# ERR or \# SKIP indicate interface malfunction unless AC PFS is also non-zero in the same time block. In the example shown, an attenuator change was made on the measuring amplifier between data blocks 3 and 4 . The new attenuator settings for channels 1 and 2 were .01 volts. A new pistonphone calibration was also made after data block 4. The system drift, in this case, was $0.1 \mathrm{~dB}$.

An example of the printout of the "TCLOK" program is reproduced below. When one pushes the hold button on the interface clock, the clock is stopped and a comparison can be made between the displayed time and the time printed on the Teletype.

HR MIN SEC

$\begin{array}{llll}11 & 6 & 14 \\ 11 & & 6 & 16 \\ 11 & 6 & 17 \\ 11 & & 6 & 19 \\ 11 & 6 & 21 \\ 11 & 6 & 23 \\ 11 & 6 & 24 \\ 11 & & 6 & 26 \\ 11 & & 6 & 28 \\ 11 & 6 & 29 \\ 11 & 6 & 31 \\ 11 & 6 & 33 \\ 11 & 6 & 35 \\ 11 & 6 & 36 \\ 11 & 6 & 38\end{array}$

8/ $I_{1}$ is the A-weighted sound level which is exceeded 1 percent of the time. $I_{10}$ is the A-weighted sound level which is exceeded 10 percent of the time. Both $L_{1}$ and $L_{10}$ are often used to represent the higher-level, shorter-duration sounds. $L_{50}$ Is the A-weighted sound level which is exceeded 50 percent of the time. ${ }^{5} L_{\text {eq }}$ is the energy equivalent $A$-weighted sound level. 
- SAD' EIGITALLY CONTROLLED SOUND LEVEL SURVEY

PAGE I TAPE I YEAR 1975 (2607 CAL $1975 \quad 58223)$

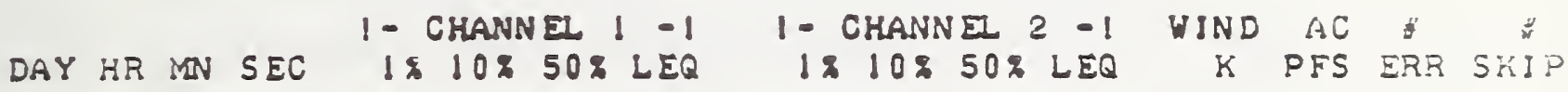

$\begin{array}{lllllllllllllllll}1 & 58 & 2 & 51 & 4 & 74 & 69 & 65 & 67 & 80 & 80 & 79 & 79 & 0 & 0 & 0 & 0 \\ 2 & 58 & 3 & 1 & 4 & 76 & 68 & 65 & 67 & 80 & 79 & 79 & 79 & 0 & 0 & 0 & 0 \\ 3 & 58 & 3 & 11 & 4 & 75 & 69 & 66 & 67 & 80 & 80 & 79 & 79 & 0 & 0 & 0 & 0\end{array}$

( 583 la 4 LAST TAPE RECORE) PUT SS2 DOHI. $\therefore$ WT EUTTON. IN, NORMAL NOISE SIGNAL CONDITIONS. ENTER ATTENUATOR SETTINGS (SOTH ON ONE LINE) $.01 .0 !$

$\begin{array}{lllllllllllll}4 & 58 & 3 & 23 & 0 & 75 & 69 & 66 & 67 & 80 & 79 & 79 & 78\end{array}$ ( 58324 O LAST TAPE RECORD) PUT SSI SS2 COWN SAUE A WT. EUTTON OUT ON SOTH 2607 UNITS. PUT PISTONPHONE ON CH 1 , KAVE METER READ AEOUT $44 \mathrm{ES}$. ENTER ATTENUATOR SETTING WHILE PISTONPHONE IS ON. $\cdot 3 \cdot 3$

PUT PISTONPHONE ON CH 2, HAVE YETER READ ABOUT 44 DE. ENTER ATTINUATOR SETTING WHILE PISTONPHONE IS ON. . 3

CH I ERIFT = -.1O DE CH 2 DRIFT $=0.10 \mathrm{DE}$ A WT SUTTON IN, NORMAL NOISE SIGNAL CONDITIONS. ENTER ATTENUATOR SETTINGS (SOTH ON ONE LINE)

.03 .03 
An example of the printout from the "TRTAI" program is shown below. The listing prints out the sound pressure level (in decibels re $20 \mu \mathrm{Pa}$ ) in each one-third octave band from $12.5 \mathrm{~Hz}$ to $40 \mathrm{kHz}$ (depending on which filters are utilized in the particular RTA), the sound level for the selected weighting network and the overall sound pressure level (linear). As discussed in Section 4.1.3.c., the underflow indicates whether or not the value is above or below the RTA baseline, while the overflow, i.e., an indication of RTA saturation, is indicated by the printing out on the listing -- RTA INPUT AMPLIFIER WAS OVERLOADED -- if saturation occurred.

rUd S\$৫ UR IU BKING IN LAIA rKUM KIA.

KLAL - IIME $1 / 3$ OCTAVE ANALYZEK IYKE $334 \%$ UUTPUI

\begin{tabular}{|c|c|c|c|c|c|}
\hline$\triangle A N D$ & Du & UFLUW & BAVL & DB & UtL \\
\hline$\triangle A \gg E$ L. & $7 v \cdot v$ & 1 & $400 \cdot 0$ & $9 \% .0$ & 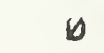 \\
\hline $12 \cdot 5$ & 18.8 & $v$ & sub.u & 98.0 & \\
\hline $16 \cdot 0$ & 85.4 & $v$ & $630 \cdot 1$ & $98 \cdot 2$ & \\
\hline $2 \theta \cdot \theta$ & 89.6 & b & $800 \cdot 0$ & 98.4 & $v$ \\
\hline $25 \cdot 6$ & 97.8 & 0 & 1000.0 & 99.8 & 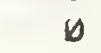 \\
\hline $31 \cdot 5$ & 181.6 & b & 1250.6 & $95 \cdot 6$ & 8 \\
\hline $40 \cdot 0$ & $10 c \cdot 6$ & $\theta$ & 1600.0 & 93.2 & 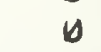 \\
\hline $5 \theta \cdot \theta$ & $9 y .4$ & 0 & evbu.v & 93.2 & 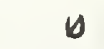 \\
\hline 63.10 & $101 \cdot 0$ & 0 & 2500.0 & 90.4 & 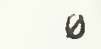 \\
\hline $8 b \cdot b$ & $106 \cdot b$ & $v$ & $3156 \cdot v$ & $88 \cdot 2$ & 0 \\
\hline $16 \theta \cdot b$ & 99.2 & 0 & $4000 \cdot 0$ & 84.8 & b \\
\hline $125 \cdot 0$ & 98.0 & $\theta$ & 5000.00 & $80 . \theta$ & 0 \\
\hline 1618.0 & $98 \cdot 4$ & D & $6300 \cdot 10$ & $7 \% .6$ & 0 \\
\hline $200 \cdot 0$ & $106 \cdot 4$ & $\theta$ & ४⿻心㇒日 & 71.4 & 0 \\
\hline $25 b \cdot 0$ & 102.10 & 0 & $\triangle \triangle D D D . D$ & 70.0 & 1 \\
\hline $315 \cdot 0$ & $98 \cdot 2$ & $\forall$ & 125லb.0 & $76 \cdot 6$ & 1 \\
\hline WEIGHI. & $106 \cdot b$ & $y$ & $10000 \cdot 0$ & 70.6 & 1 \\
\hline LINEAK & 113.6 & $\theta$ & $20 \cup B D \cdot 0$ & 70.0 & $i$ \\
\hline
\end{tabular}



4.1.5. Procedure for Loading Programs -- "CHECK", "NOISE, "TCLOK"
and "TRTAI"

These programs which are written in conversational FORTRAN utilize one or more subroutines which are written in conversational FORTRAN or assembly language. The most efficient procedure for loading any one of these programs (and their subroutines) from paper tape is to utilize a high speed reader (HSR) format. (Copies of "CHECK", "NOISE", "TCLOK", and "TRTAI" have been supplied to BAD in HSR format.)

To run a high speed reader format tape the following procedure should be followed:

1. load XRAY (executive routine)

2. turn on high speed paper tape reader and place paper tape on reader.

3. enter the following command on the Teletype keyboard.

$: 10,1,2 \emptyset$

:EX

Execution will then be automatic.

For reference purposes, steps 1 to 10 explain the punching order necessary to create a HSR tape.

1. Punch the following step 1 commands on paper tape:

line feed :QU,CF carriage return

line feed : EX carriage return

line feed GC carriage return

2. Copy-punch the FORTRAN main program.

3. If there are any FORTRAN subroutines, continue in to step 4 . If there are no FORTRAN subroutines go to step 6.

4. Punch the following command on the paper tape:

line feed GC carriage return

5. Copy-punch the FORTRAN subroutine. Repeat steps 4 and 5 for all FORTRAN subroutines.

6. Punch the following commands on the paper tape:

line feed $E$ carriage return

line feed :QU,CFR carriage return 
7. If there are one or more assembly language subroutines, skip to step 9. If there are no assembly language subroutines proceed to step 8 .

8. Punch the following command on the paper tape:

line feed :EX carriage return

Skip to step 11 .

9. Punch the following command on the paper tape:

line feed :AL carriage return

10. Copy-punch the assembly language subroutines on the paper tape with execution addresses of $X^{\prime} 7^{\prime}$. The last subroutine should transfer to $X^{\prime} 40^{\prime}$.

11. Punch the following command on the paper tape:

line feed G carriage return

To load the "CHECK" and "NOISE" programs from a special magnetic tape the reader is referred to the discussion of subroutine "STEMI" (Section 4.1.2.a.).

\subsubsection{Interface Software Commands}

The Interface Software Command (Table 1) lists all the direct input (DIN) and direct output (DOT) commands that affect the community noise interface and the real time analyzer (RTA). Examples for the 16-bit words are given as an aid in understanding the usage of the commands. This table is mainly for reference because these commands are already used in the software drivers supplied with the community noise and real time analyzer programs. 


\section{Table 1. Interface Software Commands}

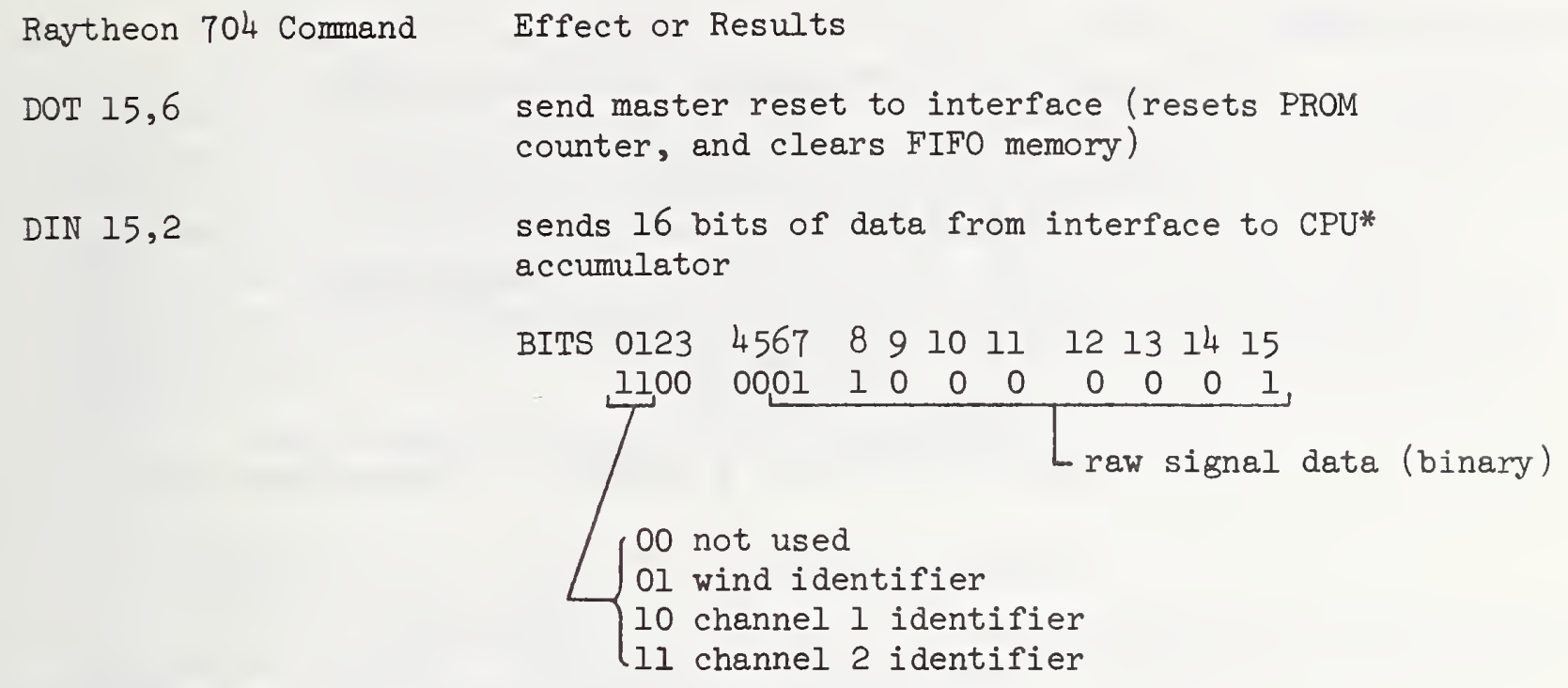

The above example has channel 2 raw data equal to 385.

DOT 15,2

sends 16 bits of data from CPU accumulator to 4 digit hexidecimal display. (Use software to convert binary numbers to decimal BCD** numbers for ordinary base 10 displays)

DIN 15,3

send 16 bits of clock data to $\mathrm{CPU}$ accumulator

Bits $0123 \quad 4567 \quad 8 \quad 9 \quad 1011 \quad 12 \quad 13 \quad 14 \quad 15$

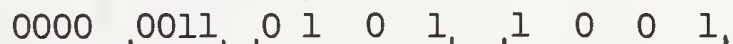

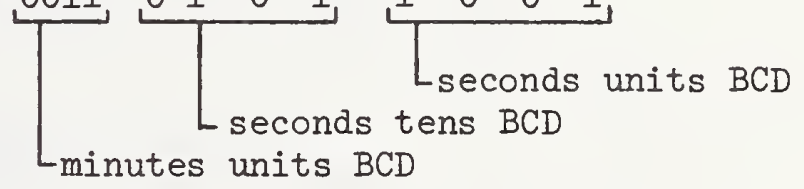

DIN 15,4

send 16 bits of clock data to CPU accumulator

Bits $0123 \quad 4567 \quad 8 \quad 91011 \quad 1213 \quad 14 \quad 15$

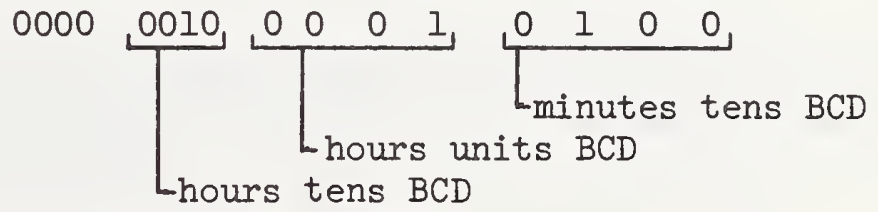

The above time of day example $=21: 43: 59$.

DOT 6,1

send data request to real time analyzer (RTA) 
Table 1 Interface Software Commands (Con't)

Raytheon 704 Command Effect or Results

DIN 6,1

send 16 bits of RTA data to CPU accumulator

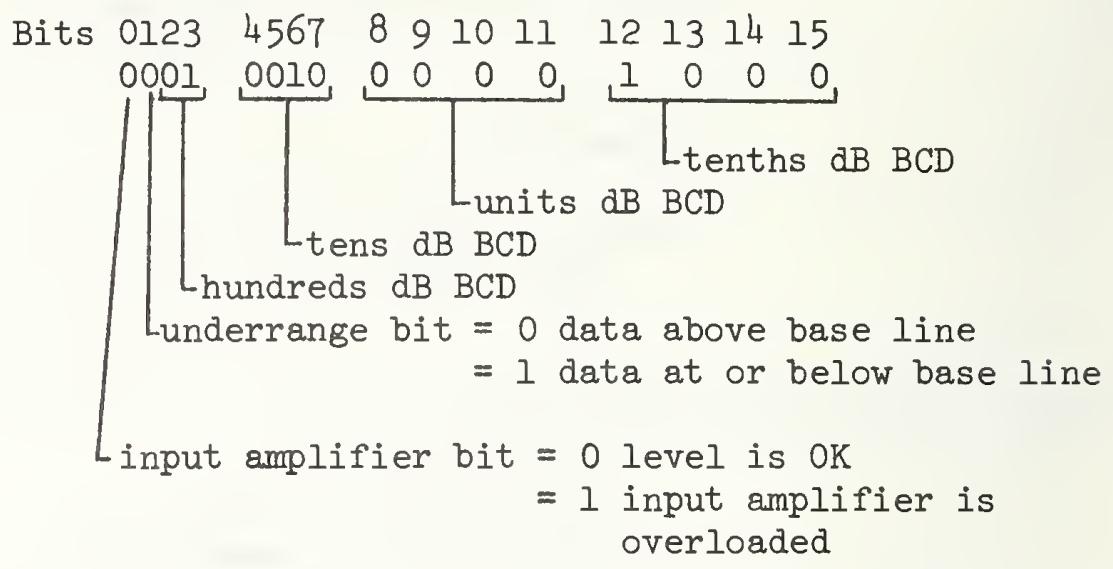

The above example shows $120.8 \mathrm{~dB}$ for the particular channel digitized by the RTA

* CPU stands for Central Processing Unit

**BCD stands for Binary Coded Decimal 
4.2. FORTRAN Software for the Analysis of Community Noise Data

The analysis of the community noise tapes produced by the minicomputerbased data acquisition system is most satisfactorily performed on a large computer system with a high speed printer and digital plotter capability. The main programs and subroutines discussed in this section were specifically written for the Univac 1108 computer system at the National Bureau of Standards but can be adopted for use in almost any large scale system. The software described herein utilizes three utility packages available on the Univac 1108 system, "NTRAN", "AITINT", and "GDS" plotting package, for which detailed documentation was supplied to $B A D$ as part of the operating system.

\subsubsection{Nine-track Tape Translation Program}

\section{a. Purpose}

This program is designed to translate nine-track magnetic tapes written by the 704 Raytheon computer using the Raytheon FORTRAN unformatted write statement. (See program listings in Appendix D.)

In addition to translation of the nine-track tapes, the program also bins the data into selected sound pressure levels with a choice of bin size and range, calculates $I_{1}, I_{10}, I_{50}, I_{90}, I_{9}$ and $I_{e g}$ and $I_{i s t s}$ the results on a line printer. If Is that level Which 1 s exceeded $j$ percent of the time while $\mathrm{L}_{\text {eq }}$ is the equivalent sound level averaged on an energy basis.

$$
L_{\text {eq }}=10 \log _{10}\left(\frac{\sum_{i=1}^{n} 10^{\operatorname{SPL}(i / 10)}}{N}\right)
$$

where SPL(i) are the sound pressure levels and $\mathrm{N}$ is the total number of data points.

If desired all or part of any block of data can be printed for examination.

b. Control Cards

There are a total of three control cards required which allow (a) choice of bin size and range, (b) choice of the portion of the tape to analyze and (c) choice of data to be displayed.

Card 1: IBEG, IEND, IDEL

Format is free, i.e., numbers separated by commas. All formats are of this type unless stated otherwise.

IBEG is the lower bound of range.

IEND is the upper bound of range. 
IDEL is the step size within the range, e.g., 40, 80, 2 means that the data will be binned in 20 bins from 40 to $80 \mathrm{~dB}$ in $2 \mathrm{~dB}$ bins.

Card 2: DAYST, HRST, MINST, DAYFIN, HRFIN, MINFIN

First three are the starting day, hour, minute. Second three are the finishing day, hour, minute. e.g. 209, 19, 1, 209, 19, 2 will result in two blocks of data being read into memory.

Card 3: ICTRL

Legal values are:

0 No listing of the blocks of data.

1 List each control section (1201-1224)

2 List entire 1224 word block

Caution: Use option 2 with care as large amounts of output can be generated.

Note: Each block represents 1 minute of data taken every 0.1 second for two microphones. These 1200 data points are the first 1200 words of the block. In addition there is a 24 word control section at the end of each block giving information pertinent to the block. The output of the program is self explanatory with the exception that each time a read problem occurs (a parity error) -3 is printed and that block is ignored. Also if control word 1207 in the control section is non zero that block is skipped.

c. Subroutines

The program utilizes 3 subroutines for reading, translating and interpolating the data.

1) Reading of the nine-track tapes is accomplished by a routine called RDUNPK which in turn calls the Univac routine NTRAN (described below). RDUNPK $(M, N)$ contains two transfer arguments $(M, N) . M$ is the unit number assigned to the tape at execution. $\mathrm{N}$ is the status word described in the NTRAN guide. This routine uses NTRAN to read blocks of integers from tape (see below). The 16 digit Raytheon integers are unpacked from the 36 digit Univac words. (The Raytheon integers enter the Univac memory sequentially in 8 bit "bytes" two bytes per integer.) This subroutine is listed in Appendix D under the Nine-track Tape Translation Program.

2) NTRAN is a Univac 1108 Fortran library routine used to read blocks of data from tape or drum. 
3) AITINT - is an interpolation program available in the Univac 1108 Math-Pack Library. This program is included with the main program on cards but can be accessed from the fastran drum system at execution time if desired.

\subsubsection{Calcomp Plot Program}

\section{a. Purpose}

Given a specified starting day and hour, this program searches the tape for the starting block; then it calculates $\mathrm{L}_{1}, \mathrm{~L}_{10}, \mathrm{~L}_{50}, \mathrm{~L}_{90}, \mathrm{~L}_{90}$ and $\mathrm{L}$ for a specified number of hours (minimum two hours). The six quantities are plotted as a function of time on a simple graph. Each plot contains the data points connected by solid straight lines. Up to a maximum of 100 hours of data can be plotted.

b. Control Cards

Card 1: IBERG, IEND, IDEL

Same interpretation as in Section 4.2.1.a.

Card 2: DAYST, HRST, NHR

Format I6 and Right Justified

These are the starting day and hour. Calculation begins with first good data block in the specified hour and continues for NHR number of hours.

\section{c. Subroutines}

This program utilizes RDUNPK, NTRAN, and AITINT which are described in Section 4.1.1. In addition the graphical display system (GDS) subroutines are used. These include: GDLILI, NODLIB, NODLIL, TITLEB, TITLEL, TITLEG, PSLILI, SLLILI, NXTFRM, and GDSEND. 
5. APPENDIX A. PROGRAM LISTINGS AND FLOW CHARTS FOR CONVERSATIONAL FORTRAN CALIBRATION AND COMMUNITY NOISE PROGRAMS.

Appendix A contains flow cherts for the "CHECK" and "NOISE" programs. It also contains program listings for the "CHECK", "TOGLE", "ORTH", and "NOISE" programs. 


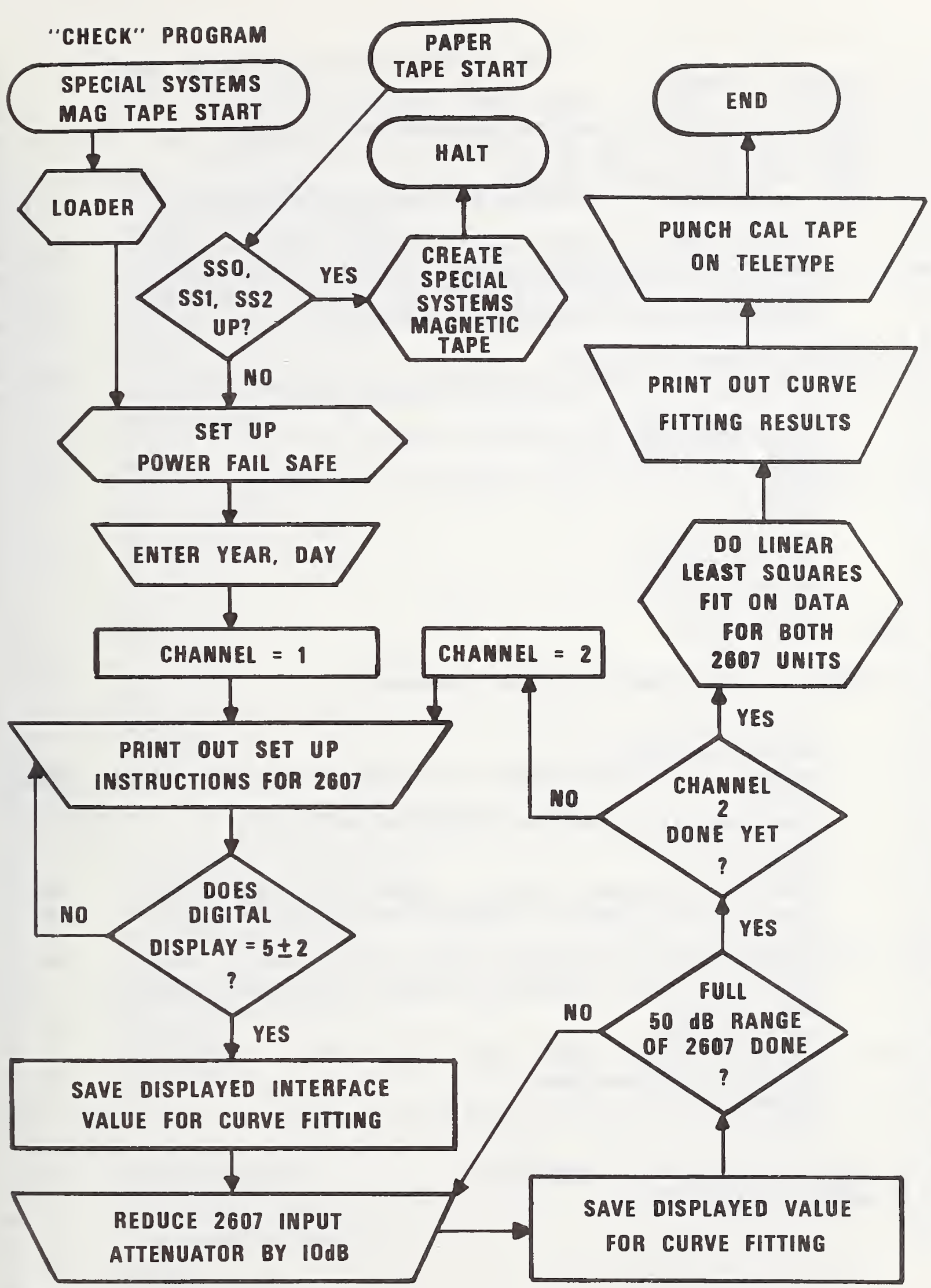

Figure A-1. Flow diagram for "CHECK" program. 


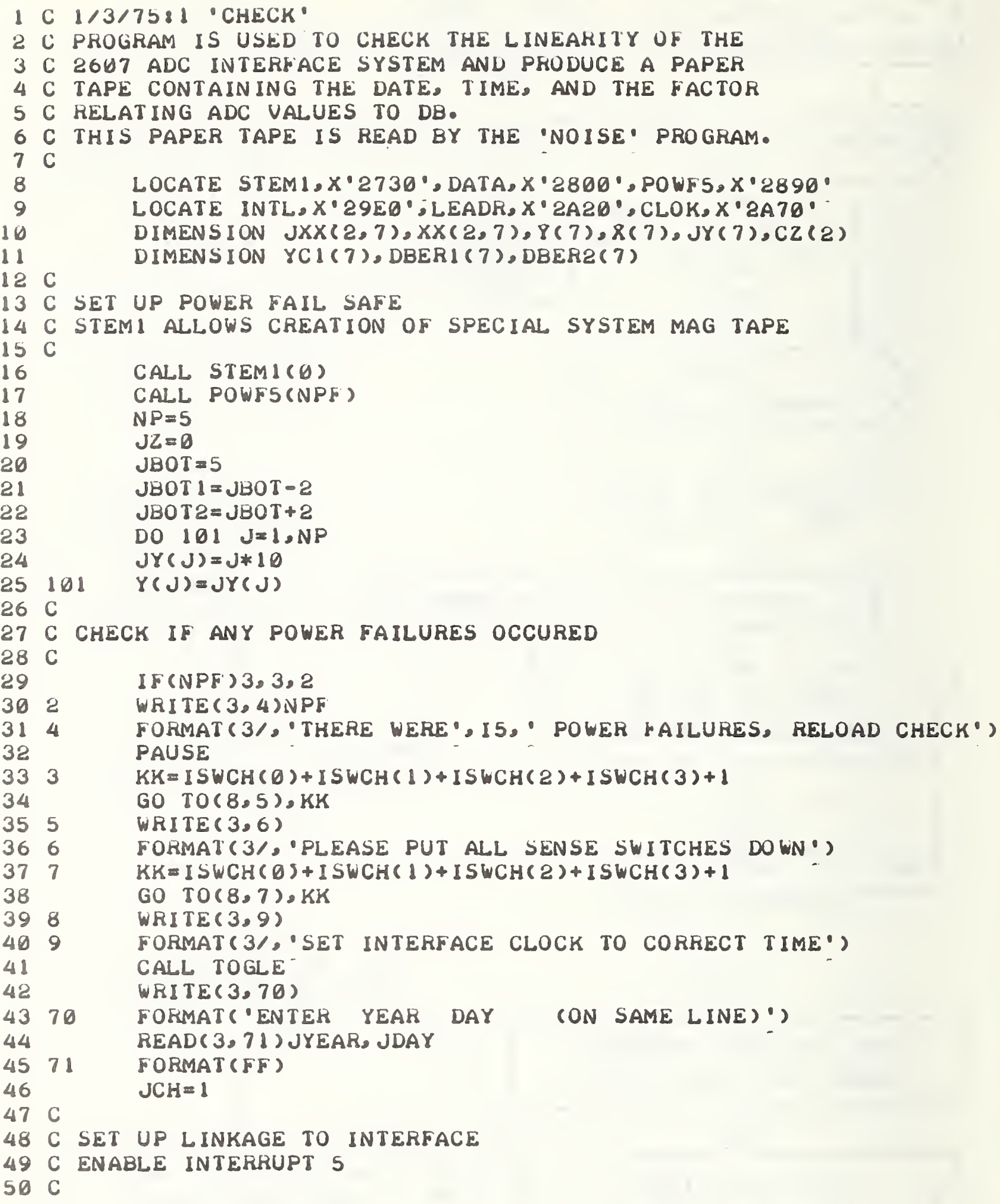


CALL DATA ( JWIND, JRAW I, JRAW2, JCH)

$53 \mathrm{C}$

54 C BEGIN 2607 - INTERFACE SYSTEM CHECK

$55 \mathrm{C}$

5627 WRITE 3,10$) \mathrm{JCH}$

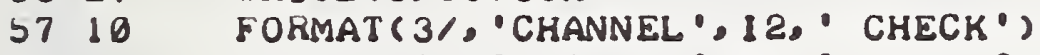

58

IF ( JCH-1) 100, 100, 102

59100 WRITE $(3,11)$

6011

61102

FORMAT('USE 50 MV INTERNAL REFERENCE AS ONLY INPUT TO $2607^{\circ}$ )

6212

WRITE $(3 ; 12)$

63

FORMAT('SET-2607 INPUT ATTENUATOR TO 3.0 VOLTS')

64103

IF $(\mathrm{JCH}-1) 103,103,13$

6595

WRITE (3,95)

66

FORMAT('SET 2607 OUTPUT ATTENUATOR TO XI POSITION')

6796

WRITE $(3 ; 96)$

$68 \quad 13$

FORMATC"SET 2687 OUTPUT SWITCHES TO LOG AND DC')

6914

WRITE ( $3 ; 14)$ JBOT

70 FORMAT ('ADJUST 2607 VARIABLE GAIN SO DIGITAL DISPLAY =", I3)

71 CALL TOGLE

$72 \quad 15$ GO TO $(15,16), \mathrm{JCH}$

73 JR $=$ JRAW $\perp$

74

$A=J R$

75

$J A D C \perp=J R$

$\begin{array}{ll}76 & \text { GO TO } 17 \\ 77 \quad 16 & \text { JR }=\text { JRAW2 }\end{array}$

$X A D C \perp=A$

78

$A=J K$

79

80

8117

$82 \mathrm{C}$

83 C CONTINUE IF DISPLAY IS NEARLY = JBOT

$84 \mathrm{C}$

85

JADC2 $=$ JR

$X A D C 2=A$

$86 \quad 18$

$87 \quad 19$

$J A=A$

88

8920

90

91

9221

93

9422

$95 \mathrm{C}$

$96 \mathrm{C}$

$97 \mathrm{C}$

9823

99

$100 \quad 24$

IF ( JA-JBOT 1) 13,18,18

IF ( JA-JBOT2) 19,19,13

DO $24 \mathrm{~J}=1, \mathrm{NP}$

WHITE (3, 20) JCH

101

FORMAT ('REDUCE 2607 INPUT ATTENUATOR BY 10 DB (CHAN', I2, $\left.{ }^{\circ}\right)^{\circ}$ )

CALL TOGLE

GO TO $(21,22), \mathrm{JCH}$

$A=$ JRAW ।

GO TO 23

$A=$ JRAW2

$102 \quad 25$

SAVE DATA FOR PRINTOUT \& LEAST SQUARES FIT

103

10426

10531

$186 \mathrm{C}$

$J X X(J C H, J)=A$

$X X(J C H, J)=A$

CONT INUE

I F ( JCH - 2) 25, 26, 26

$\mathrm{JCH}=2$

GO TO 27

DO $31 \mathrm{~J}=1, \mathrm{NP}$

$X(J)=X X(1, J)$ 
107 C DO $1 S T$ ORDER FIT ON CHANNEL I DATA

$168 \mathrm{C}$

109

116

11132

112

113

114

115

116

$117 \mathrm{C}$

$118 \mathrm{C}$

119

120

121

122

123

124

125

126

127

128

129

130

131

132

133

13445

135

13646

137

13847

139

14048

141

1 4249

143

14450

145

14651

147

148

149

15052

15153

152

15354

154

15555

156

15740

15880

159

16081

161

$162 \mathrm{C}$

CALL ORTH $(X(1), Y(1), C Z(1), Y C 1(1), E R, 1, J R D, 1,0, N P, 0$, DO $32 \mathrm{~J}=1, N P$

$\operatorname{DBER} \perp(J)=Y C \perp(J)-Y(J)$

FACT $d=C Z(2)$

$\mathrm{CON} 1=\mathrm{CZ}(1)$

DO $33 \mathrm{~J}=1, \mathrm{NP}$

$X(J)=X X(2, J)$

DO 1 ST ORDER FIT ON CHANNEL 2 DATA

CALL ORTH(X(1), Y(1),CZ(1),YC1(1),ER, $1, J R D, 1,0, N P, 0$,

DO $34 \mathrm{~J}=1$,NP

$\operatorname{DBER}(J)=Y C 1(J)-Y(J)$

FACT $2=\mathrm{CZ}(2)$

$\mathrm{CON} 2=\mathrm{CZ}(1)$

$Y D B \downarrow=C O N \downarrow+X A D C \downarrow * F A C T \downarrow$

$Y D B 2=C O N 2+X A D C 2 * F A C T 2$

DETERMINE TIME FHOM CLOCK

CALL CLOK (JH, JM, JS)

BEGIN PRINTOUT OF LINEARITY CHECK

WRITE $(3,45)$

FORMAT $(15 /)$

WRITE $(3,46)$

FORMAT( 2607 - INTERFACE NOISE SYSTEM LINEARITY CHECK')

WRITE $(3 ; 47)$ JYEAR, JDAY

FORMAT $\left(1,53 \mathrm{X},{ }^{\circ} \mathrm{YEAR}=0,15,1,53 \mathrm{X},{ }^{\circ} \mathrm{DAY}=., 15\right)$

WRITE $(3,48) \mathrm{JH}$; JM

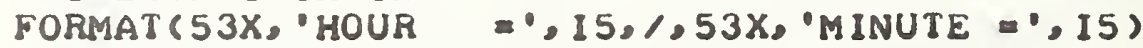

WRITE $(3,49)$

FORMAT $\left(6 \mathrm{X},{ }^{\circ} 2607^{\circ}, 4 \mathrm{X},{ }^{\circ} \mathrm{CH} 1^{\circ}, 5 \mathrm{X},{ }^{\circ} \mathrm{CH} 2^{\circ}, 5 \mathrm{X},{ }^{\circ} \mathrm{CH} l^{\circ}, 5 \mathrm{X},{ }^{\circ} \mathrm{CH}{ }^{\circ}\right)$

WRITE (3,50)

FORMAT ( $\left.7 \mathrm{X},{ }^{\circ} \mathrm{DB} \mathrm{B}^{\circ}, 5 \mathrm{X},{ }^{\circ} \mathrm{ADC} \mathrm{C}^{\circ}, 5 \mathrm{X},{ }^{\circ} \mathrm{ADC}, 5 \mathrm{X},{ }^{\circ} \mathrm{DB} \mathrm{B}^{\circ}, 6 \mathrm{X},{ }^{\circ} \mathrm{DB}{ }^{\circ}\right)$

WRITE $(3,51)$

FORMAT ( $13 \mathrm{X}$, 'VALUE', 3X, 'VALUE', $4 \mathrm{X}$, 'DIFF', $4 \mathrm{X}$, 'DIFF', /)

WRITE ( 3,110$) \mathrm{JZ}, \mathrm{JADC} 1, \mathrm{JADC} 2, \mathrm{YDB} 1, \mathrm{YDBZ}$

FORMAT $\left(4 X, 15,3 X, 15,3 X, 15,59,2,58,2,{ }^{\circ}\right.$

( D DB VALUE NOT USED $)^{\circ}$ )

DO $52 \mathrm{~J}=1, \mathrm{NP}$

WRITE $(3,53)$ JY $(J), J X X(1, J), J X X(2, J), \operatorname{DBER} 1(J), \operatorname{DBER2}(J)$

FORMAT ( $4 \mathrm{X}, 15,3 \mathrm{X}, 15,3 \mathrm{X}, 15,59,2, F 8,2)$

WRITE $(3,54)$ FACT 1

FORMAT $\left(3 /, 6 \mathrm{X},{ }^{\circ} \mathrm{CHI} \mathrm{DB}=\mathrm{CONSTANT}+\circ, \mathrm{E} 13.5,2 \mathrm{X}\right.$, "* $^{\circ}$ (ADC VALUE)')

WRITE $(3,55)$ FACT2

FORMAT $\left(6 \mathrm{X},{ }^{\prime} \mathrm{CH} 2 \mathrm{DB}=\right.$ CONSTANT + $, E 13.5,2 \mathrm{X}$, "* (ADC VALUE)')

WRITE $(3,40)$

FORMAT $\left(3 / 0^{\circ}\right.$ TURN ON PUNCH, TOGGLE SENSE SWITCH $\emptyset^{\circ}$ )

$K K=I S W C H(O)+1$

GO TO $(80,81), K K$

$K K=I S W C H(D)+1$

GO TO $(82,81), \mathrm{KK}$ 
$163 \mathrm{C}$ PUNCH LEADER, PUNCH NUMBERS, PUNCH LEADER

$164 \mathrm{C}$

16582

CALL LEADR

166

16741

WRITE (3, 41) UYEAR, JDAY, JH, JM, FACT 1, FACT'Z

168

FORMAT ( I $5,14,13,13,1 \mathrm{X}, \mathrm{E} 13.5,1 \mathrm{X}, \mathrm{E} 13.5)$

169

17060

CALL LEADR

IF (NPF) $60,60,2$

WRITE $(3,42)$

17142

172

17390

174

FOFMAT('TURN OFF PUNCH, TOGGLE SENSE SWITCH O TO RESTART') WRITE $(3 ; 90)$

17591

17685

177

17886 FORMAT ('CHECK OUT IS COMPLETED. USE PAPER TAPE IN NOISE') WRITE $(3 ; 91)$ FORMAT('PROGRAM IF ABOVE RESULTS ARE SATISFACTORY.',3/) $K K=I S W C H(\emptyset)+1$

GO TO $(85,86), \mathrm{KK}$

$K K=I S W C H(\theta)+1$

179

GO TO $(3,86), \mathrm{KK}$

END 


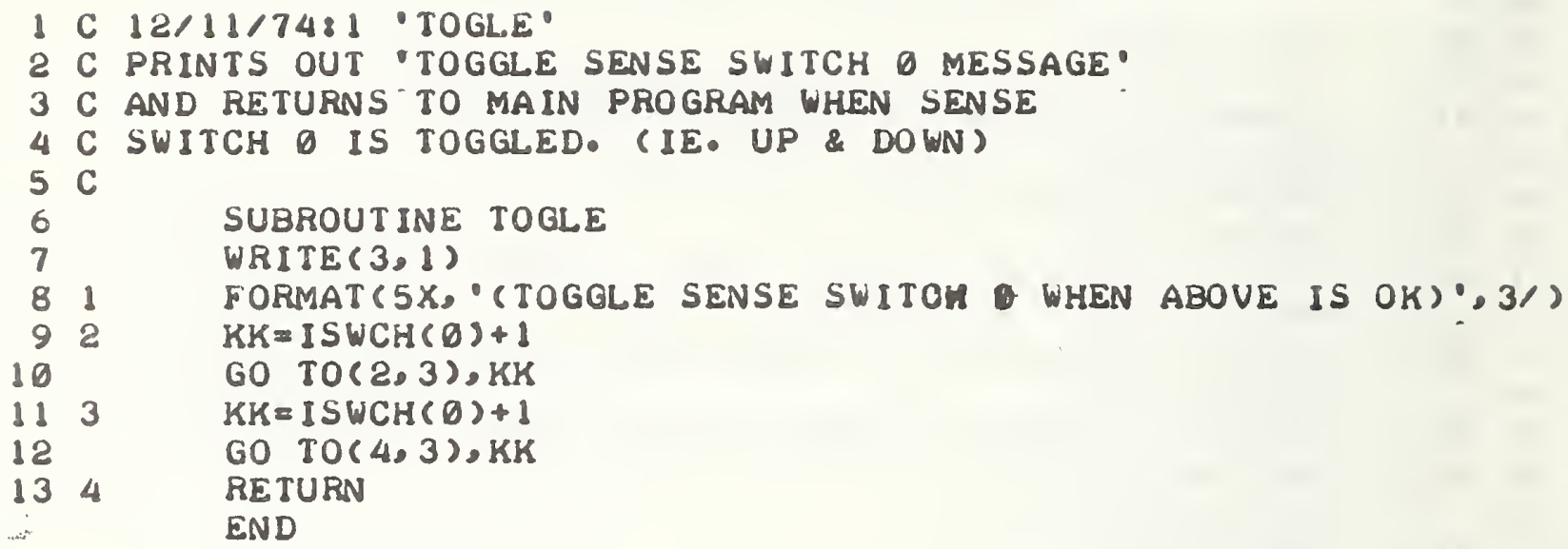


2 C

7 C

8 C ABOUE DIMENSIONS ALLOW FITIING UP TO

9 C $X * \neq 9$ ORDER AND UP TO 50 DATA POINTS.

$10 \mathrm{C}$

il C

$12 \mathrm{C}$

13

14

$15 \mathrm{C}$

$16 \mathrm{C} X$ IS AN ARRAY CONTAINING VALUES OF THE INDEPENDENT VARIABLE.

$17 \mathrm{C} Y$ IS AN ARRAY CONTAINING VALUES OF THE DEPENDENT VARIABLE.

$18 \mathrm{C} \mathrm{CZ}$ IS AN ARRAY CONTAINING CURVE FITTING MONOMIAL COEFFICIENTS.

19 C ERROR IS THE STANDARD DEVIATION OF (YOBSERVED - YFIT)

20 C NHIGH IS HIGHEST FITTING ORDER IF SUBROUTINE IS REQUESTED

$21 \mathrm{C}$ TO DO COMPLETE FIT ON ONE CALL. (IE. KT NOT $=Q$ )

22 C JRD IS PRESENT ORDER OF FIT. ON SINGLE PASS MODE (KT =

$23 \mathrm{C}$ SET JRD $=D$ ON FIRST PASS.

$24 \mathrm{C} K T=\emptyset$ FOR EXIT ON EACH PASS. KT NOT $=\square$ IN MULTIPASS MODE.

25 C NOR $\equiv$ FOR ORDINARY ORTHOGONAL FIT. NOR = I FOR ODD POWER

$26 \mathrm{C}$ ORTHOGNAL FIT. NOR = 2 FOR EVEN POWER ORTHOGONAL FIT.

27 C NP IS THE NUMBER OF DATA POINTS TO BE FITTED.

28 C SG IS DESIRED ERROR OF FIT TEST. IF KT NOT = D THE PROGRAM

29 C EXITS WHEN EITHER JRD = NHIGH OR WHEN ERROR = SG OR LESS.

$30 \mathrm{C} Y \mathrm{YCl}$ IS AN ARRAY CONTAINING POLYNOMIAL VALUES FOR Y (NO NEED

31 C FOR USER TO DIRECTLY EUALUATE TOTAL POLYNOMIAL TO

32 C OBTAIN YFIT)

33 C FOR THE BEST ACCURACY OF FIT THE VALUES OF $X$ SHOULD BE

$34 \mathrm{C}$ BETWEEN -2.0 AND +2.0 (IE. TRANSFORM INDEPENDENT

$35 \mathrm{C}$

$36 \mathrm{C}$

37

38

39

40

41703

42704 IF (JRD-1) 400,301,302

$43 \mathrm{C}$

44 C ZEROING COEFFICIENTS

$45 \mathrm{C}$

46400 DO $54 \mathrm{~J}=1, \mathrm{KORD}$

$47 \quad \operatorname{CPI}(J)=$ ZERO

$48 \quad$ CPZ (J)EZERO

$49 \quad \mathrm{CP} 3(J)=Z E R O$

$50 \quad C P 4(J)=Z E R O$

$51 \quad C Z(J)=Z E R O$

$5254 \quad C X(J)=Z E R O$

53 SEZERO 
$54 \mathrm{C}$

55 C PART I FINDING P OF ORDER ZERO

$56 \mathrm{C}$

57

CP3 1 ( ) $=$ BONE

$58 \quad S 1=Z E R O$

59 DO $56 \mathrm{~J}=1, \mathrm{JJM}$

60 IF (NOR-1) $500.501,500$

$61501 \quad$ PUI $(J)=X(J)$

$62 \quad Z=Y(J) * X(J)$

63 GO TO 502

$64500 \quad$ PVI $(J)=B O N E$

$65 \quad W N=A M$

$66 \quad Z=Y(J)$

$67502 \quad S=S+Z$

$6856 \quad S 1=S 1+Y(J) * Y(J)$

69 IF(NOR-1)503,504,503

$70504 \quad$ S2=ZERO

71 DO $506 \mathrm{~J}=1, \mathrm{JMMl}$

$72506 \quad S 2=S 2+X(J) * X(J)$

$73 \quad \omega N=S 2$

$74503 \quad B=S / W N$

75 DO $325 \mathrm{~J}=1, \mathrm{JJM} 1$

$76325 \quad Y C I(J)=B$

$77 \quad \mathrm{CX}(1)=\mathrm{B}$

78

79

80

81

82

83

84

85

86

87

88

89

90

$91 \mathrm{C}$

92 C PART 2 FINDING $P$ OF ORDER I

$93 \mathrm{C}$

9430

95

$U=S \downarrow-B * B * W N$

$\mathrm{Z}=\mathrm{U} / \mathrm{AM}$

$Z=A B S(Z)$

$\mathrm{SN}=\operatorname{SQRT}(Z)$

$Z=U /(A M-B O N E)$

$Z=A B S(Z)$

$S P O L Y=S Q R T(Z)$

$\mathrm{Z}=\mathrm{SQRT}$ ( WN )

$S C O=S P O L Y / Z$

$J R D=1$

JRDM $1 \approx 0$

$J G O=1$

GO TO 100

96

97

98

99

100

101508

CONT INUE

$\mathrm{S}=\mathrm{ZERO}$

DO $57 \mathrm{~J}=1$, JJM 1

$630 \quad Z=X(J)$

$S=S+Z * Z$

GO TO 57

102

103

104507

$Z \equiv X(J)$

$\mathrm{S}=\mathrm{S}+\mathrm{Z} * \mathrm{Z} * \mathrm{Z} * \mathrm{Z}$

GO TO 57

$S=S+X(J)$

10557

CONT INUE

106

107

$A L=S / W N$

108

$S=Z E K O$

$S 1=Z E R O$

109

CP2 (1) $=C P 3(1)$

110

CP3 (2) $=B O N E$ 


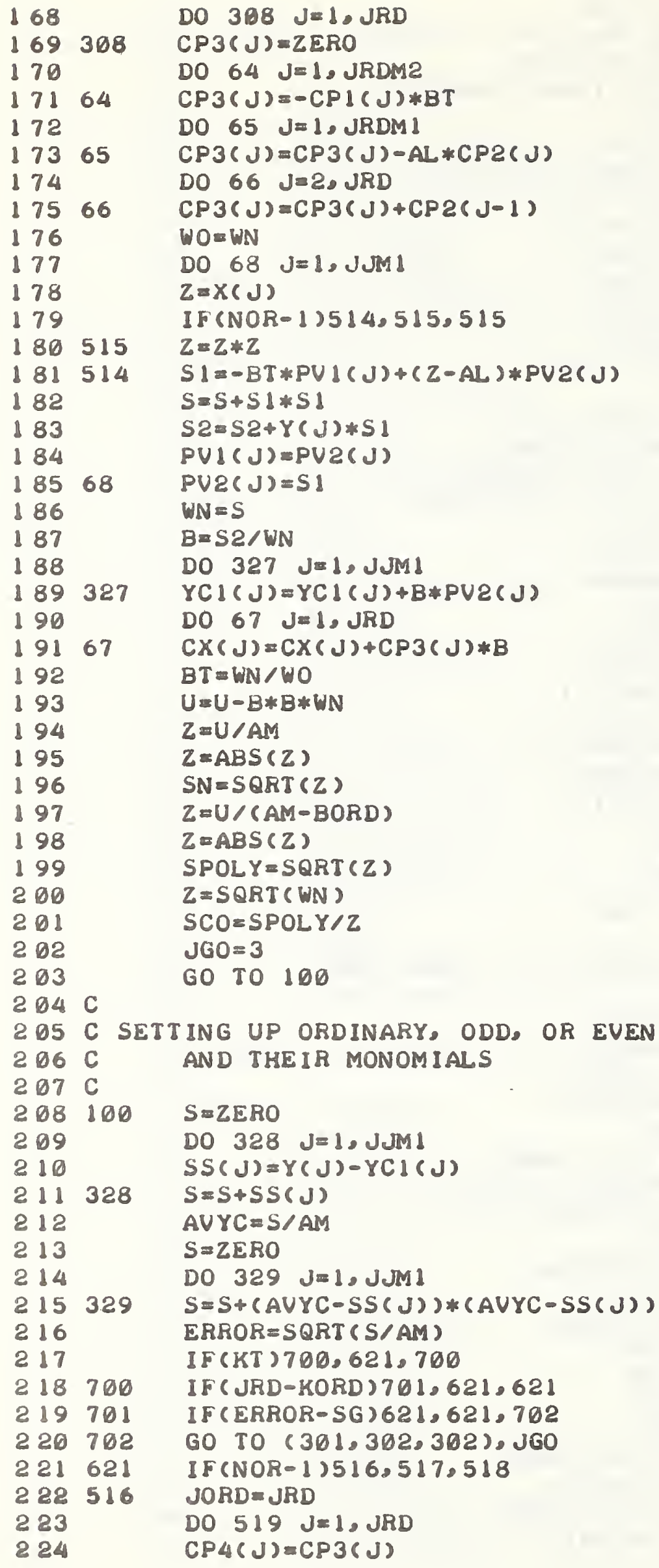

$169308 \quad$ CP3(J)=ZERO

170 DO $64 \mathrm{~J}=1$. JRDME

$17164 \quad \mathrm{CP} 3(\mathrm{~J})=-\mathrm{CP} 1(\mathrm{~J}) * \mathrm{BT}$

172 DO $65 \mathrm{~J}=1$, JRDM 1

$17365 \quad C P 3(J)=C P 3(J)-A L * C P 2(J)$

174 DO $66 \mathrm{~J}=2, \mathrm{JRD}$

$17566 \quad C P 3(J)=C P 3(J)+C P 2(J-1)$

$176 \quad W O=W N$

177 DO $68 \mathrm{~J}=1, \mathrm{~J} \mathrm{~J} 1$

$178 \quad Z=X(J)$

$179 \quad$ IF (NOR-1) $514,515,515$

$180515 \quad Z=Z * Z$

$181514 \quad S \downarrow=-B T * P V \downarrow(J)+(Z-A L) * P V Z(J)$

$182 \quad S=S+S \perp * S 1$

$183 \quad \mathrm{~S} 2=\mathrm{S} 2+\mathrm{Y}(\mathrm{J}) * \mathrm{~S} 1$

$184 \quad$ PVI (J)=PVZ(J)

$18568 \quad$ PVZ(J)=S1

$186 \quad W N=S$

$187 \quad B=S 2 / W N$

188 DO 327 Jæ1. JJMl

$189327 \quad Y C l(J)=Y C d(J)+B * P V Z(J)$

$190 \quad$ DO $67 \mathrm{~J}=1$, JRD

$19167 \quad C X(J)=C X(J)+C P 3(J) * B$

$192 \quad B T=W N / W O$

$193 \quad U * U-B * B * W N$

$194 \quad Z=U / A M$

$195 \quad Z=A B S(Z)$

$196 \quad \mathrm{SN}=\mathrm{SQRT}(\mathrm{Z})$

197

198

199

200

201

202

203

204

205

206

207

208

209

210

2 11

212

213

214

215

216

2 17

2 18700

219701

220702

221621

228516

$Z=U /(A M-B O R D)$

$Z=A B S(Z)$

SPOL $Y=S Q R T(Z)$

$Z=S Q R T$ ( WN )

$S C O=S P O L Y / Z$

$\mathrm{JGO}=3$

GO TO 100

C

C

$100 \quad S=Z E R O$

AND THEIR MONOMIALS

223

224

DO $328 \mathrm{~J}=1, \mathrm{JMM} 1$

$\operatorname{SS}(J)=Y(J)-Y C 1(J)$

$328 \mathrm{~S}=\mathrm{S}+\mathrm{SS}(\mathrm{J})$

$A \cup Y C=S / A M$

$S=Z E R O$

DO $329 \mathrm{~J}=1, \mathrm{~J} M 1$

$3.29 S=S+(A \cup Y C-S S(J)) *(A \cup Y C-S S(J))$

$E R R O R=S Q R T(S / A M)$

IF (KT ) 700, 621,700

IF ( JRD-KORD) 701,621,621

IF (ERROR-SG) $621,621,702$

GO TO ( $301,362,302)$, JGO

IF (NOR-1) $516,517,518$

JORD $=J R D$

DO $519 \mathrm{~J}=1, \mathrm{JRD}$

$\operatorname{CP} 4(J)=\operatorname{CP} 3(\mathrm{~J})$ 


\begin{tabular}{|c|c|c|}
\hline $\begin{array}{l}825 \\
826 \\
227\end{array}$ & 519 & 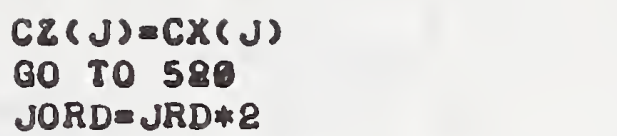 \\
\hline $\begin{aligned} 228 \\
220\end{aligned}$ & & DO $52 \& \mathrm{~J}=1 . \mathrm{JORD}$ \\
\hline 230 & & $\begin{array}{l}K=(J+1) / 2 \\
I F(J-2 *(J / 2)) 522,522,521\end{array}$ \\
\hline $\begin{array}{l}231 \\
232\end{array}$ & $522^{-}$ & $\begin{array}{l}\operatorname{CZ}(J)=\operatorname{CX}(K) \\
\operatorname{CP} 4(J)=\operatorname{CP} 3(K)\end{array}$ \\
\hline 233 & 521 & CONT INUE \\
\hline 234 & & 60 TO 520 \\
\hline 235 & 518 & $J O R D=J R D * 2-1$ \\
\hline 236 & & DO $523 \mathrm{~J} \equiv 1 . \mathrm{JORD}$ \\
\hline 23 & & $I F(J-2 *(J / 2)) 523,523,524$ \\
\hline $\begin{array}{l}239 \\
240\end{array}$ & 524 & $\begin{array}{l}C 2(J)=C X(K) \\
C P 4(J) \equiv C P 3(K)\end{array}$ \\
\hline & 523 & CONT INUE \\
\hline 242 & 520 & $\begin{array}{l}\text { CONT INUE } \\
\text { RETURN }\end{array}$ \\
\hline & & END \\
\hline
\end{tabular}




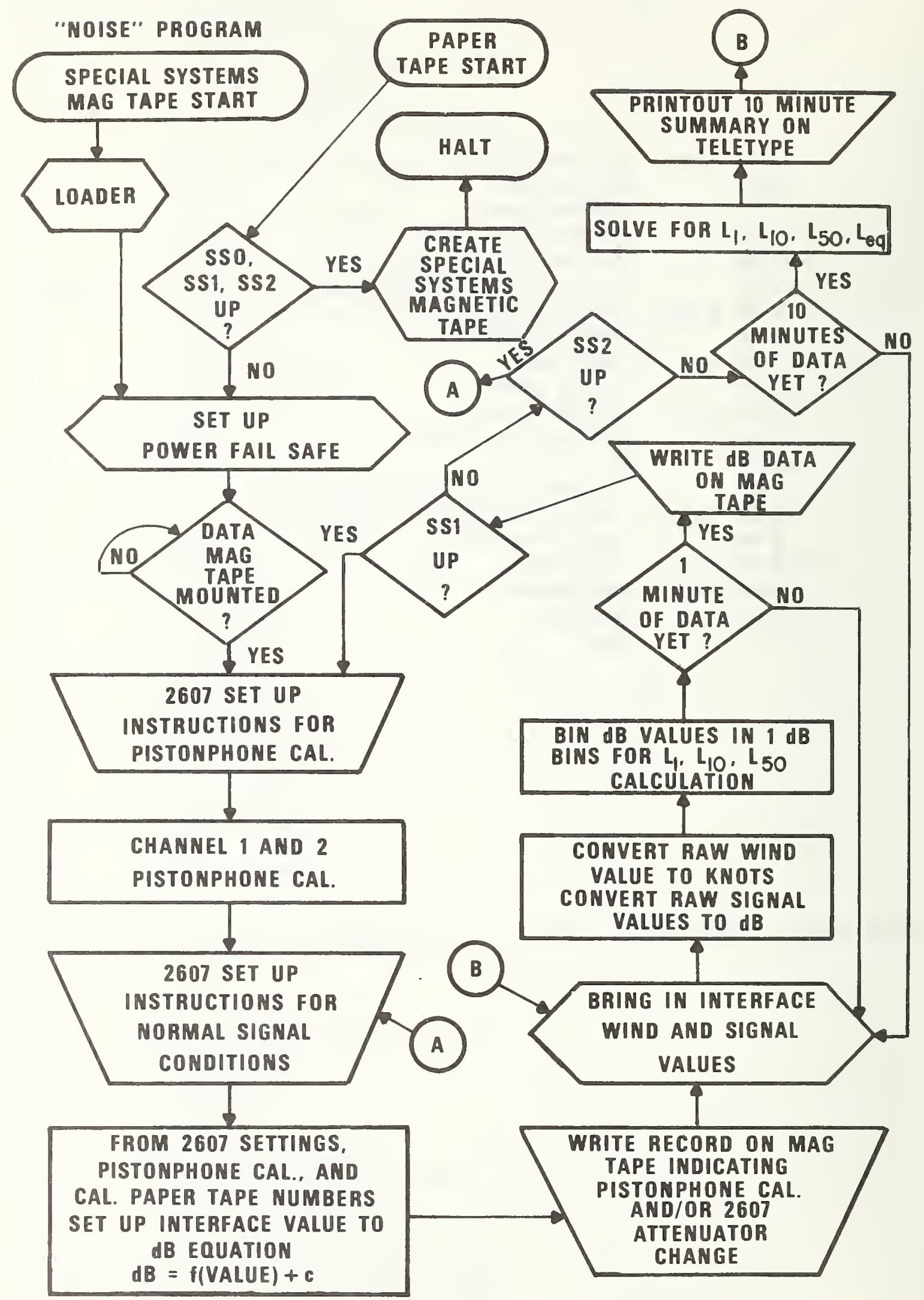

Figure A-2. Flow diagram for "NOISE" program. 
$1 / 23 / 75: 4$ 'NOISE'

2 C THE PROGRAM CONDUCTS A TWO CHANNEL COMMUNITY

3 C NOISE SURUEY BY SAMPLING TWO DATA CHANNELS OF

$\triangle$ C ENUIRONMENTAL NOISE AND A OPTIONAL WIND CHANNEL

5 C AT A 10 HZ RATE. ONCE A MINUTE THE NOISE DATA AND

6 C THE MAXIMUM WIND VALUE ARE DUMPED ON TO THE MAGNETIC

7 C TAPE UNIT FOR LATER ANALYSIS ON A UNIUAC 1108 COMPUTER.

8 C THE PROGRAM WILL PRINTOUT LI, LIO, L50, LEQ,

9 C AND MAXIMUM WIND SPEED EVERY 10 MINUTES ON THE TELETYPE.

$10 \mathrm{C}$

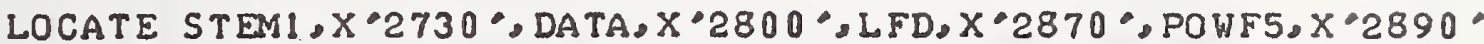
LOCATE MULT1, X'291 B', MMON, X'299B', DMAMAG, X'29C $0^{\circ}$ LOCATE INTL, $X^{\circ} 29 E 0^{\circ} ; D I S P, X * 2 A 20^{\circ} ; C L O K, X^{\circ} 2 A 70^{\circ}$ DIMENSION K(1224), KPA(111);KPB(111)

$19 \mathrm{C} K(1201)=\mathrm{DAY}$

20 C $K(1202)=$ HOUR

$21 \mathrm{C} K(1203)=$ MINUTE

$22 \mathrm{C} \mathrm{K}(1204)=$ SEGOND IMMEDIATELY AFTER RECEIVING \& CONVERTING

$25 \mathrm{C} K(1205)=$ NUMBER OF POWER FAILURES IN JUST THE PAST MINUTE.

$26 \mathrm{C} K(1206)=$ PROGRAM VERSION NUMBER

$27 \mathrm{C} \mathrm{K}(1207)=0$ K ARRAY RECORD ON MAG TAPE CONTAINS REGULAR DB DATA

$28 \mathrm{C} \quad=1$ RECORD ON MAG TAPE INDICATES PISTONPHONE CAL

296

$30 \mathrm{C}$

$=2$

RECORD ON MAG

TAPE INDICATES

\section{CHANGE}

31 C K(1208) = MAG TAPE ID NUMEER

$32 \mathrm{C} \mathrm{K}(1209)=$ HIGHEST WIND SPEED IN KNOTS FOR THE PAST MINUTE.

$33 \mathrm{C} K(1210)=$ NUMBER OF CHANNEL ID ERRORS GENERATED SY INTERFACE.

$34 \mathrm{C} K(1211)=$ NUIAEER OF MISSING DATA VALUES CAUSED EY OVERFLOWING

$35 \mathrm{C}$ FJFO MEMORY.

$36 \mathrm{C} \mathrm{K}(1212)=$ CHANNEL 1 PISTONPHONE VALUE 10 . USING NEXT TO LAST

37 C CAL VALUE. (SHOWS CHANNEL I SYSTEM DRIFT)

38 C K(1213) = CHANNEL 2 PISTONPHONE VALUE * 10. USING NEXT TO LAST

39 C CAL VALUE. (SHOWS CHANNEL 2 SYSTEM DRIFT)

4Q. $C K(1214)=$ YEAR

$41 \mathrm{C} \mathrm{K}(1215)$ TO K(1224) $=0$ (NOT USED)

$42 \quad$ DO $460 \quad \jmath=1215,1224$

$43460 \quad K(J)=0$

$44 \mathrm{C}$

45 C STEM! ALLOWS CREATION OF SPECIAL SYSTEM MAG TAPE. 46 C POWFS SETS UP POWER FAIL SAFE.

$47 \mathrm{C}$ 
$51 \mathrm{C}$

NFIL $=34$

NTIME $=0$

$M=0$

$N=0$

$P C A L=124$.

$J P G=1$

WRITE $(3,220)$

FORMAT( $3 /$ "PUT SSI UP FOR PISTONPHONE CAL. (NOT NOW)') WRITE $(3,25)$

FORMAT( 'PUT SSZ UP TO CHANGE 2607 SETTINGS. (NOT NOW)') $K K=I S W C H(0)+I S W C H(1)+I S W C H(2)+I S W C H(3)+1$

GO TO $(340,341), \mathrm{KK}$

WRITE $(3,342)$

FORMAT( $3 / \%$ "PLEASE PUT ALL SENSE SWITCKES DOWN.")

$K K=I S W C H(0)+I S W C H(1)+I S W C H(2)+I S W C H(3)+1$

GO TO $(340,343), K K$

$$
\text { JWAY }=0
$$

WRITE (3,73)

FORMAT(2/, 'SET INTERFACE CLOCK TO CORRECT TIME.")

CALL TOGLE

WRITE 3,138$)$

FORMAT( ENTER YEAR DAY TAPEA ( 3 NUMBERS ON ONE LINE)')

READ ( 3,4 ) JYEAR, JDAY,NTAPE

FORMAT (FF)

$K(1208)=$ NTAPE

$K(1214)=J Y E A R$

CALL CLOK(JHR, JMIN, JSEC)

JHOLD $=$ JKR

WRITE( 3,270$)$

FORMAT $3 /$. TURN ON HIGH SPEED PAPER TAPE READER. ") WRITE(3,271)

FORMAT ("PUT CAL TAPE (FROM CHECK PROGRAM) IN READER.")

CALL TOGLE

READ CAL TAPE TO OBTAIN SLOPE OF LINEAR TRANSFER FUNCTION RELATING DB TO ADC VALUE.

READC 4, 4) JYRC, JDC, JHC. JMC, FACTI, FACT2

WRITE $(3,272)$

FORMAT ( TURN OFF HIGH SPEED PAPER TAPE READER.")

WRITE $(3 ; 7)$

FORMAT(3/. MOUNT DATA TAPE \& BRING TO LOAD POINT \& ON LINE.") CALL DMAMAG(MAG)

$M A G G=M A G$

IF $(M A G-3) 207,135,207$

WRITE $(3,240)$

FORMAT(3/.'DO THE FOLLOWING FOR BOTH 2607 UNITS.") 
102

103241

104

105242

106

107243

108

109244

110

111280

112

113

114

115

116246

117

118248

119

$120 \quad 247$

121

122

123

124

125

126

127

128

129251

130

131

132

133

134

135

136

137

138

139252

140

$141 \quad 253$

142

143

144

145

146

1.47

148

1.49

150

151

$152 \quad 262$

153

WRITE $(3,241)$

FORMAT( $3 x$, ,SET VARIABLE GAIN CONTROL TO CAL POSITION.")

WRITE $(3,242)$

FORMAT( $3 X$, 'SET OUTPUT ATTENUATOR TO XI POSITION.")

WRITE $(3,243)$

FORMAT( $3 X$, "A VT. BUTTON SHOULD BE OUT.')

WRITE $(3,244)$

FORMAT ( $3 X$, "50 MV INTERNAL REFERENCE BUTTON SHOULD BE OUT.")

WRITE $(3,280)$

FORMAT ( $3 X$, 'SET 2607 OUTPUTS TO LOG, DC, RMS, \& I SEC. ')

CALL TOGLE

WRITE(3,245)

FORMAT( 'PUT PISTONPHONE ON CHANNEI $1 .{ }^{\circ}$ )

WRITE 3,246$)$

FORMAT("OBTAIN 44 DB METER READING BY ADJUSTING")

WRITE $(3,248)$

FORMAT ( $3 X$, 'INPUT ATTENUATOR \& SENSITIVITY SCREW. ')

WRITE 3,247$)$

FORMAT('REPEAT ABOVE FOR CHANNEI $\left.2 \bullet^{\circ}\right)$

CALL TOGLE

WRITE 3,281$)$

281 FORMAT("HAVE A WT. BUTTON OUT ON BOTH 2607 UNITS.")

WRITE $(3 ; 250)$

FORMAT (PUT PISTONPHONE ON CH 1 , HAVE METER READ ABOUT 44 DB. I

CALL DATA (JXX, JRAW1, JRAW2, 3)

CALL INTL $(5,2)$

WRITE(3,251)

FORMATC'ENTER ATTENUATOR SETTING WHILE PISTONPHONE IS ON.')

READ $(3,4)$ PSET 1

AJRI = JRAU!

$K(1207)=1$

$O C O N \perp=C O N \perp$

CON $1=P C A L-F A C T I * A J R \perp$

$D B=C O N 1+F A C T 1 * A J R I$

$K K D A=D B * 10$.

CALL DISP(KKDA, 0$)$

WRITE( 3,252$)$

FORMAT (PUT PISTONPHONE ON CH 2, HAVE METER READ ABOUT 44 DB.Y WRITE( $3 ; 253)$

253 FORMAT (ENTER ATTENUATOR SETTING WHILE PISTONPHONE IS ON.")

READ $(3,4)$ PSET2

AJR2 = JRAW2

OCON $2=$ CON2

CON2 $=$ PCÁL - FACT2 2 AJR2

$D B=C O N 2+$ FACT2*AJR2

$K K D B=D B * 10$.

CALL DISP $(K K D B, 0)$

$K(1212)=K K D A$

$K(1213)=K K D B$

IF (JWAY) 262, 263,262

DBLDI = OCON $1+$ FACT 1 *AJRI

DBLD2 $=0$ CON2 +FACT2 *AJR2 


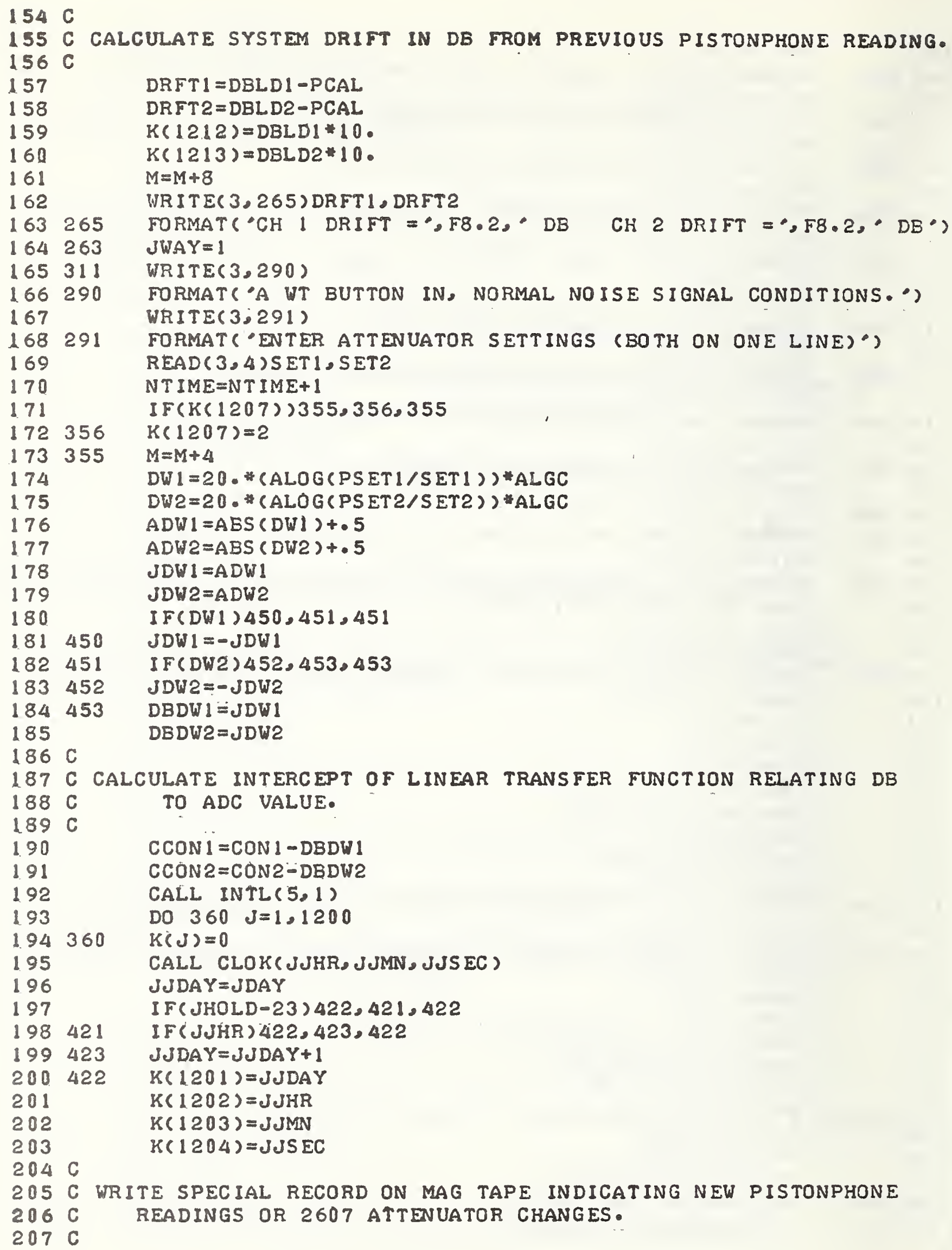




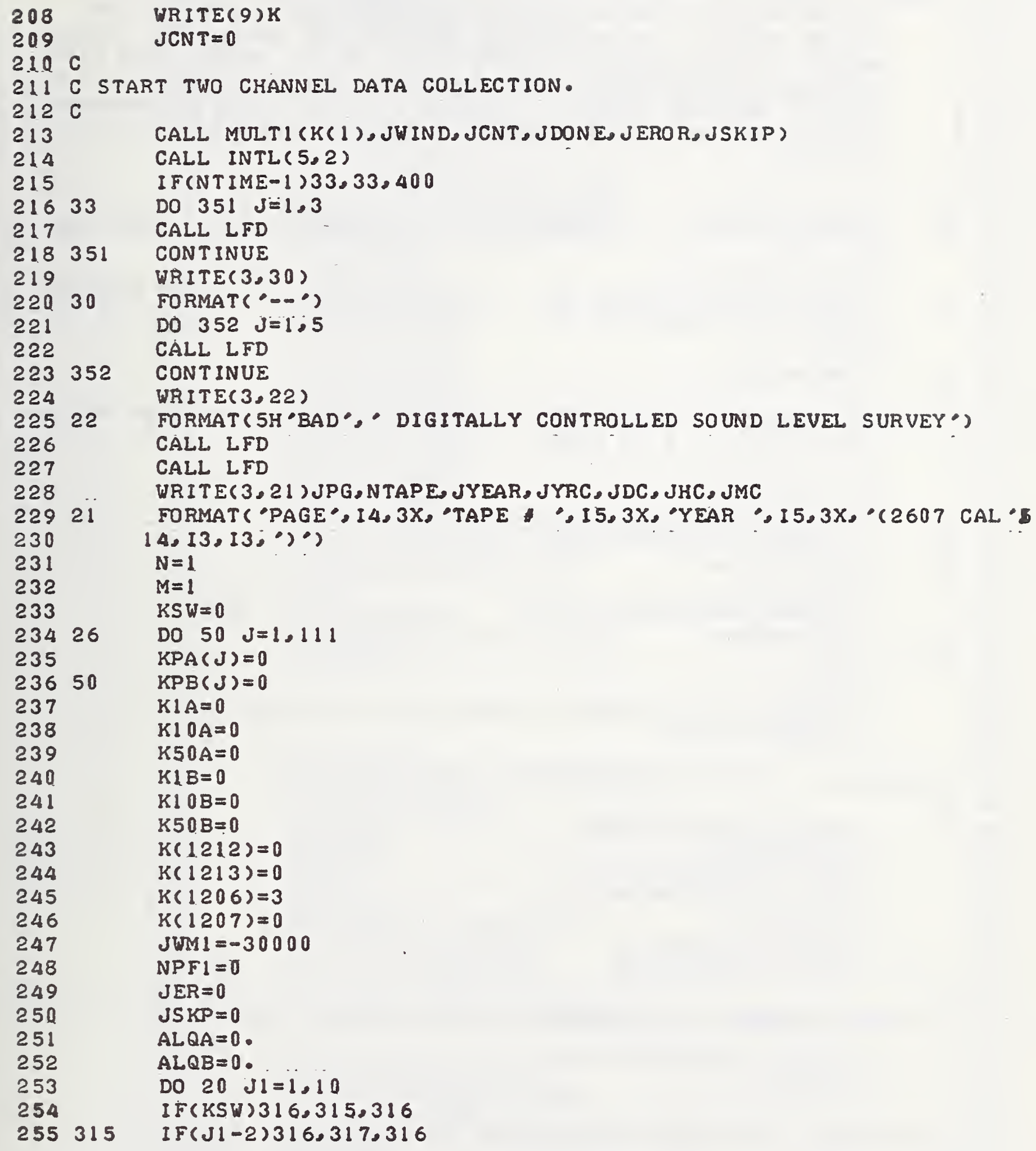


THE HEADING IS LONG AND TO ALLOU DNOUGH TIME FOR ADC VALUE TO DE CONVERSION (CONVERSION HALTS DURING TTY PRINTOUT) THE" SECOND HALF OF THE HEADING IS PRINTED OUT DURING THE SECOND MINUTE OF DATA COLLECTION. BRINGING IN ADC VALUES FROM FIFO MEMORY (VIA INTERRUPT LEVEI 5) IS HALTED ONLY WHEN THE MAG TAPE IS WRITING (ABOUT - 5 SECOND) OR WHEN A NEW PISTONPHONE CALIBRATION OR 2607 ATTENUATOR CHANGE IS REQUESTED BY SSI OR SS2.

WRITE $(3,23)$

LOOP WHERE ADC VALUES ARE CONVERTED TO DB AND WHERE DB VALUES ARE BINNED IN 1 DB STEPS.

$$
\text { DO } 8 \quad J=1,1200
$$

IF $(J C N T-J) 80,147,147$

IF $(J C N T-1200) 100,41,41$

CALL INTL $(5,1)$

283

$284 \quad 126$

AN VAL $=K(J)$

285125

IF (JWMAX-JUIND) $125,125,126$

286 JWMAX $=$ JWIND

290 C CHANNEL I ADC DATA CONUERSION TO DB 
$314 \mathrm{C}$

315 C BINNING CHANNEL 2 DB VALUES IN 1 DB STEPS.

$316 \mathrm{C}$

$31762 \quad K P B(K P 1-19)=K P B(K P 1-19)+1$

3188

$K(J)=D B A=10$.

319

$320 \quad 120$

CALL CLOK(JHR, JMIN, JSEC)

$321 \quad 123$

IF (JHOLD-23) 122, 123,122

$322 \quad 124$

IF ( JHR ) I $22,124,122$

$323 \quad 122$

$J D A Y=J D A Y+1$

324

325

JHOL $D=J K R$

$K(1201)=J D A Y$

$K(1202)=J H R$

326

$K(1203)=J M I N$

327

328

329

330

331

332

333

334

335

$336 \quad 150$

$K(1204)=J S E C$

$\mathrm{K}(1.205)=\mathrm{NPF}$

$K(1210)=J E R O R$

$J E R=J E R+J E R O R$

$K(1211)=J S K I P$

AJWMX $=$ JWMAX

VOLT $=-.00821541 * A J W M X+4.22168$

$J W M=12.5815 * V Q L T+3.53$

337

IF (JWM-5) $150,151,151$

338

JWM $=0$

$K(1209)=J K M$

$339 \quad 12$

IF (JWMI-JWM) 127,128,128

$340 \mathrm{C}$

341 C WRITE DATA FOR CURRENT MINUTE ON MAG TAPE.

$342 \mathrm{C}$

343128 WRITE(9)K

344

345

346

347

348

349

350

351

352320

NPF $1=N P F 1+N P F$

$J S K P=J S K P+J S K I P$

$J S K I P=0$

$J E R O R=0$

$N P F=0$

JCN $T=0$

$\mathrm{KK}=\operatorname{ISWGH}(1)+1 \mathrm{SWCH}(2)+1$

GO TO $(160,320), \mathrm{KK}$

$353 \mathrm{C}$

354 C HALT DATA COLLECTION IF MAG TAPE IS FULL. (EOT)

$355 \mathrm{G}$

356160 CALL DMAMAG(MAG)

$357 \quad$ IF $(M A G-17) 401,402,402$

358401 CALL INTL $(5,2)$

35920

36028

361

362

CONT INUE

$N \perp P A=60$

N1 OPA $=600$

N $50 P A=3000$

363

N $1 P B=60$

364

N $10 P B=600$ 


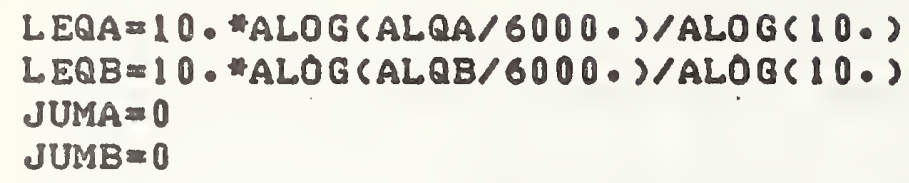

DO LOOP TO ADD UP DB BINS AND DETERMINE 1\%, $10 \%, 50 \%$ LEVELS.

$$
\begin{aligned}
& \text { DO } 6 Q \quad J 2=1,111 \\
& \text { J3 }=112-J 2 \\
& \text { JUMA }=\text { JUMA +KPA (J3) } \\
& \text { JUMB = JUMB +KPB (J3) } \\
& \text { IE (JUMA-N } 1 \text { PA }) 45,46,46
\end{aligned}
$$$$
N \perp P A=30000
$$$$
K 1 A=J 3+19
$$$$
\text { IF ( JUMA-N } 1 \text { OPA }) 47,48,48
$$$$
\text { N } 10 P A=30000
$$$$
K 10 A=J 3+19
$$$$
\text { IF (JUMA-N 50PA) } 52,51,51
$$

$N 50 P A=30000$

$K 50 A=J 3+19$

IF ( JUMB-N I PB ) 54,55, 55

$N \perp P B=30000$

$$
K 1 B=J 3+19
$$

IF (JUMB-N 1 OPB ) 56,57,57

$N 1 O P B=30000$

$\mathrm{KI} O \mathrm{OB}=\mathrm{J} 3+19$

IF (JUMB-N $50 P B) 60,59,59$

$N 50 P B=30000$

$K 50 B=J 3+19$

CONTINUE

OUTPUT DATA TO TTY EVERY 10 MINUTES.

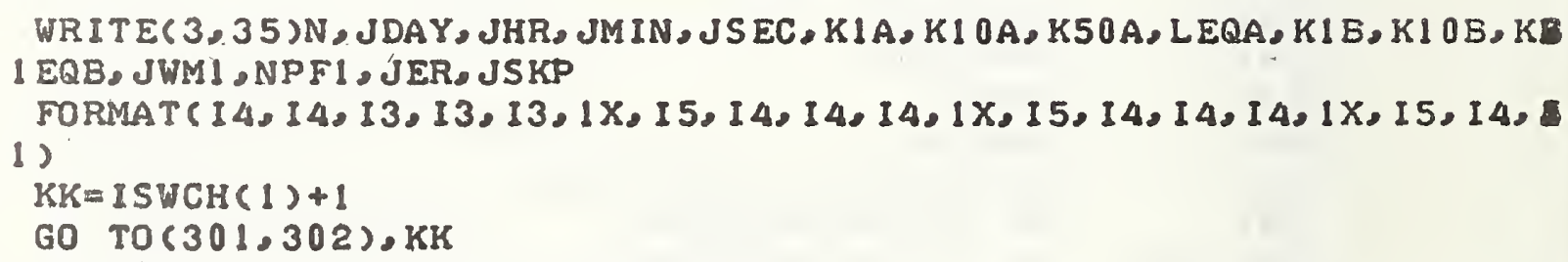




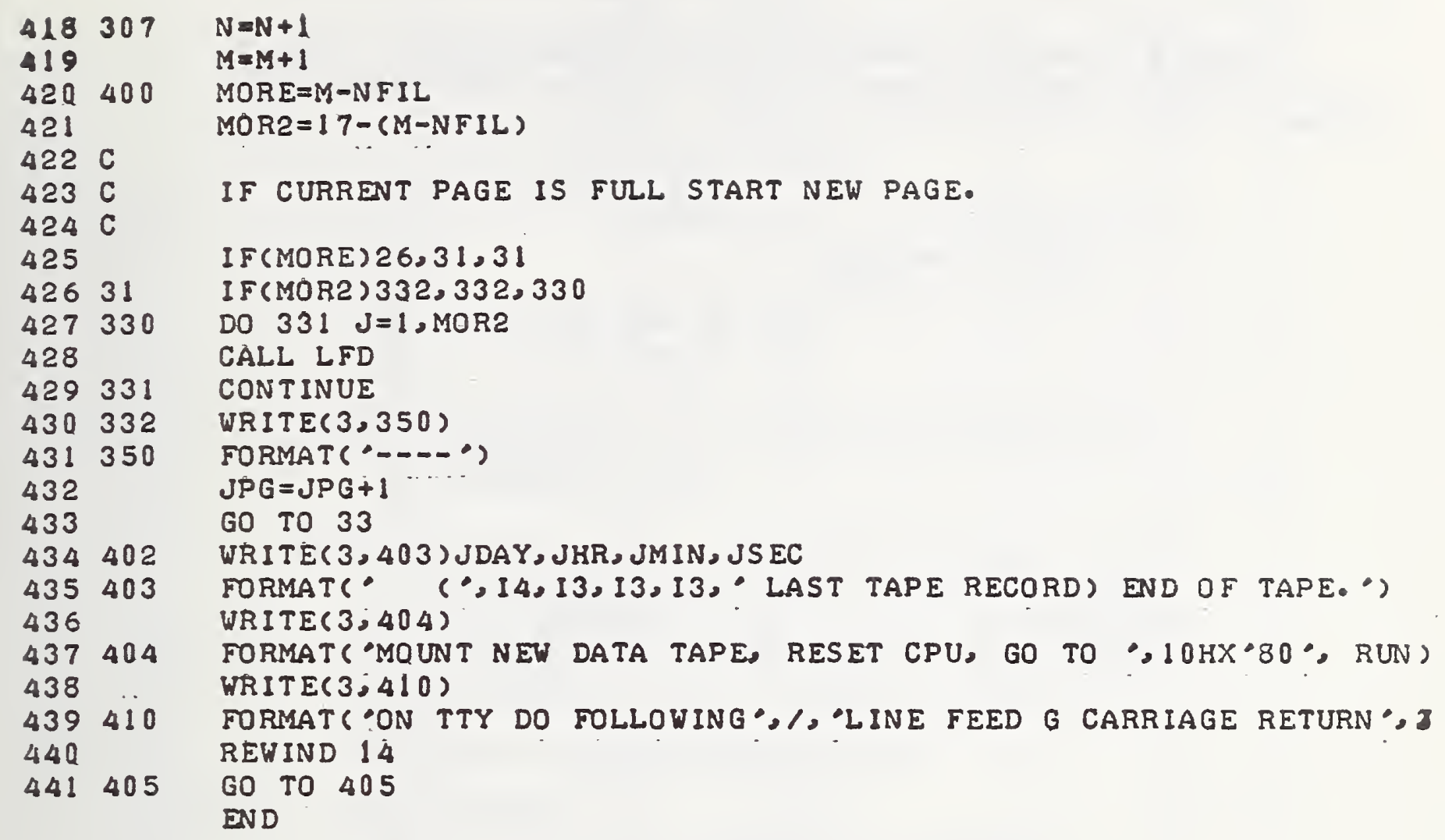


6. APPENDIX B. PROGRAM LISTINGS FOR ASSEMBLY LANGUAGE SUBROUTINES

Appendix B contains program listings for "STEMI", "DATA", "LFD", "POWF5", "MULTII", "MMON", "DMAMAG", "INTL", "DISP", "LEADR", and "CLOK" programs. 
$2730 \quad 0082$

27310000

27320080

27339059

27348801

2735 F7E5

$2736 \quad 0860$

$2737 \quad 173 \mathrm{~A}$

$2738 \quad 8756$

27397801

273A $Q 8 \mathrm{CO}$

$273 B \quad 173 D$

$273 \mathrm{C} \perp 7 \mathrm{CA}$

273D 08DO

273E 1740

$273517 \mathrm{CA}$

$274 Q$ Q $8 E 0$

$2741 \quad 1743$

$2742 / 7 \mathrm{CA}$

27430080

$2744805 \mathrm{C}$

$274577 \mathrm{~EB}$

2746 A7 E2

$2747 \quad 7704$

$2748 \quad 0220$

2749 OALD

274A 0820

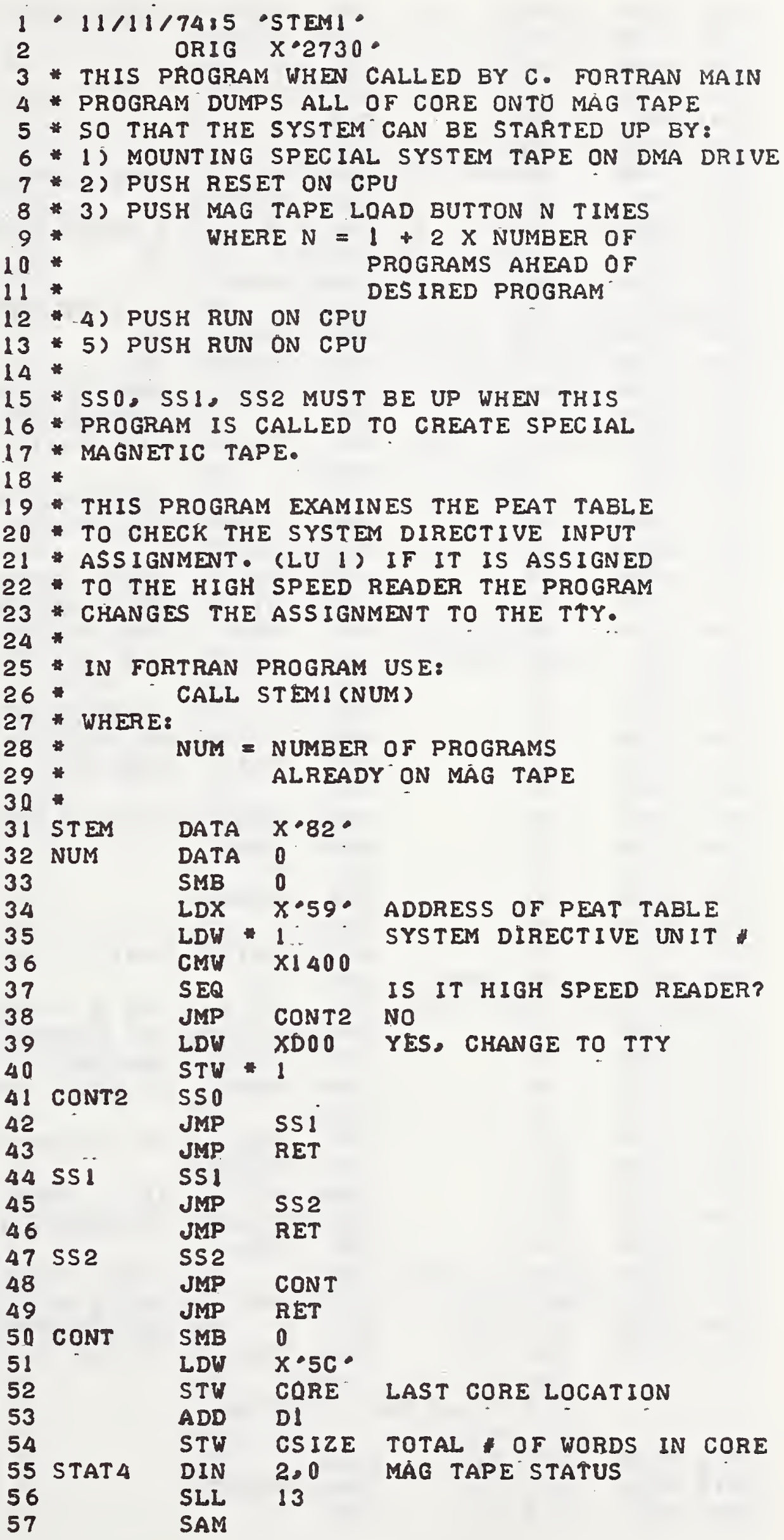

ORIG X.2730.

* THIS PROGRAM WHEN CALLED BY C FORTRAN MAIN

4 * PROGRAM DUMPS ALL OF CORE ONTO MÁg TAPE

5 * SO THAT THE SYSTEM CAN BE STARTED UP BY:

6 * 15 MOUNT ING SPECIAL SYSTEM TAPE ON DMA DRIVE

* 2) PUSH RESET ON CPU

8 * 3) PUSH MAG TAPE LOAD BUTTON $N$ TIMES

40

41

42

43

45

46

47

49

5

\section{2}




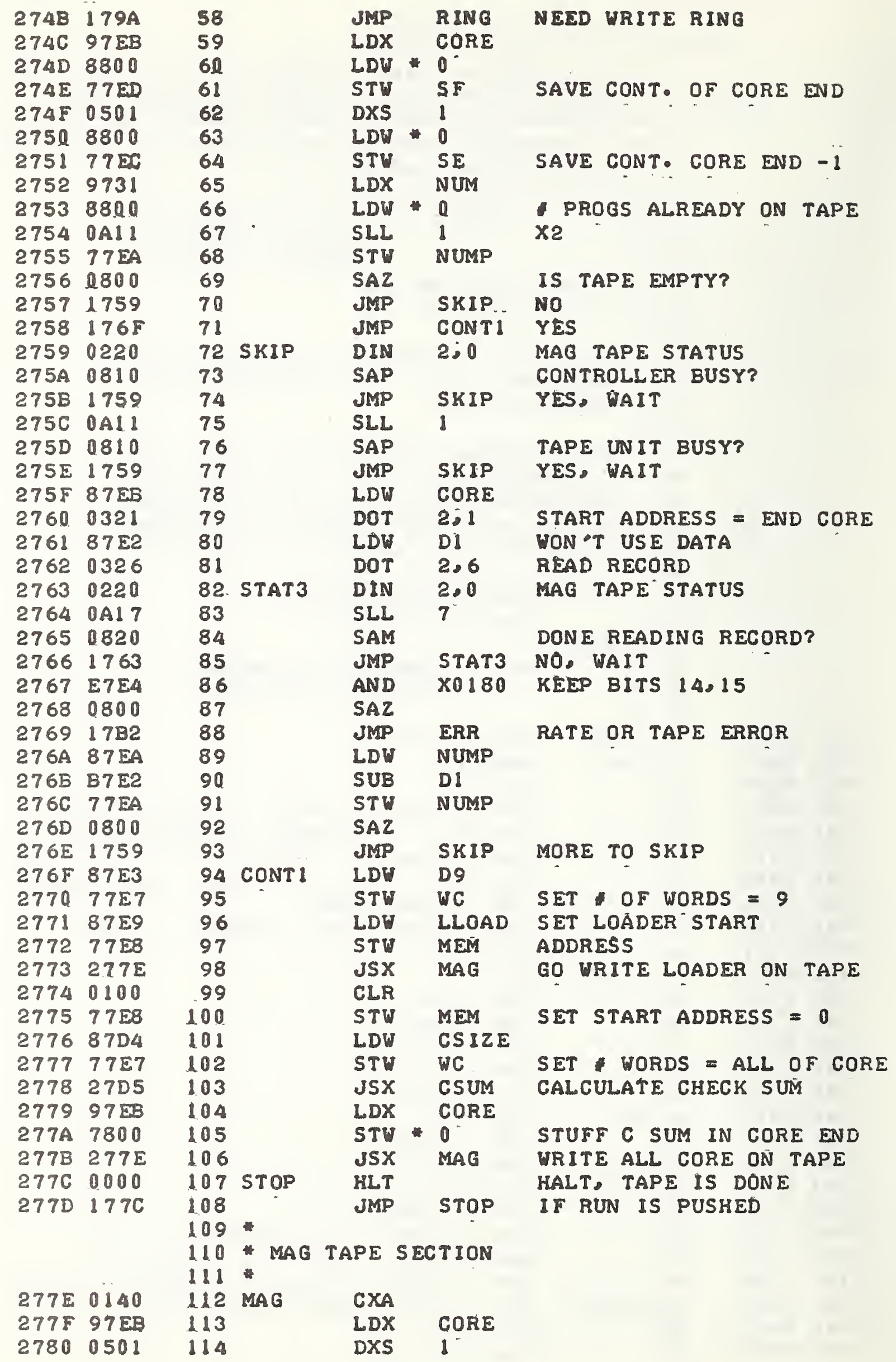




\begin{tabular}{|c|c|c|c|c|c|c|}
\hline 2781 & 7800 & 115 & & STW & 0 & SAVE RETURN \\
\hline 2782 & 0220 & 116 & STAT 1 & DIN & 2,0 & MAG TAPE STATUS \\
\hline 2783 & 0.810 & 11.7 & & SAP & & CONTROLLER BUSY? \\
\hline 2784 & 1782 & 118 & & JMP & STAT I & YES, WAIT \\
\hline 2785 & $0 A\lfloor!$ & 119 & & SLL & 1 & \\
\hline 2786 & Q810 & 120 & & SAP & & TAPE UNIT BUSY? \\
\hline 2787 & 1782 & 121 & & JMP & STAT I & YES, WAIT \\
\hline 2788 & $0 A 13$ & 122 & & SLL & 3 & \\
\hline 2789 & 0810 & 123 & & SAP & & IS TAPE REWINDING? \\
\hline $278 A$ & 1782 & 124 & & JMP & STAT 1 & YES, WAIT \\
\hline $278 B$ & $87 E 8$ & 125 & & LDW & MEM & \\
\hline $278 C$ & $032 !$ & 126 & & DOT & $2 \cdot 1$ & SET MEMORY START ADDRESS \\
\hline 2780 & $87 E 7$ & 127 & & LDW & WC & NUMBER OF WORDS \\
\hline $278 E$ & 0324 & 128 & & DOT & 2,4 & SET WORD COUNT, WRITE REC. \\
\hline $278 \mathrm{~F}$ & 0220 & 129 & STAT2 & DIN & $2 ; 0$ & MAG TÅPE STATUS \\
\hline 2790 & OAl 7 & 130 & & SLL & 7 & \\
\hline 2791 & Q820 & 131 & & SAM & & DONE WRITING A RECORD? \\
\hline 2792 & $178 \mathrm{~F}$ & 132 & & JMP & STAT2 & NO, WAIT \\
\hline 2793 & E7E4 & 133 & & AND & $\times 0180$ & KEEP BITS 14,15 \\
\hline 2794 & Q800 & 134 & & SAZ & & \\
\hline 2795 & $17 \mathrm{B2}$ & 135 & & JMP & ERR & RATE OR TAPE ERROR \\
\hline 2796 & $97 \mathrm{EE}$ & 136 & & LDX & CORE & \\
\hline 2797 & 0501 & 137 & & DXS & 1 & \\
\hline 2798 & 9800 & 138 & & LDX * & 0 & GET RETURN \\
\hline 2799 & 1800 & 139 & & JMP & 0 & DO THE RETURN \\
\hline $279 A$ & 0080 & 140 & RING & SMB & 0 & \\
\hline $279 B$ & $206 E$ & $|\Delta|$ & & JSX & $X \cdot 6 E^{\circ}$ & \\
\hline $279 C$ & C EC 5 & 142 & & TEXT & NEED" & \\
\hline 2790 & C5C4 & & & & & \\
\hline $279 E$ & 0080 & 143 & & SMB & 0 & \\
\hline $279 \mathrm{~F}$ & $206 E$ & 144 & & $j 5 x$ & $X^{\circ} 6 E^{\circ}$ & \\
\hline $27 A 0$ & D7D2 & 145 & & TEXT & 'WRIT' & \\
\hline $27 \mathrm{Al}$ & C 9D4 & & & & & \\
\hline $27 A 2$ & 0080 & 146 & & SMB & 0 & \\
\hline $27 A 3$ & $206 E$ & 147 & & JSX & $X^{\circ} 6 E^{\circ}$ & \\
\hline $27 A 4$ & D2C 9 & 148 & & TEXT & 'RING' & \\
\hline $27 A 5$ & $\mathrm{CEC} 7$ & & & & & \\
\hline $27 \mathrm{~A} 6$ & 0.000 & 149 & & HLT & & MOUNT TAPE, PUSH RUN \\
\hline $27 A 7$ & 1748 & 150 & & JMP & STAT 4 & \\
\hline $27 A 8$ & 0080 & 151 & C ERR & SMB & 0 & \\
\hline $27 A 9$ & $206 E$ & 152 & & $J S X$ & $X \cdot 6 E^{\circ}$ & \\
\hline $27 A A$ & $\mathrm{C} 2 \mathrm{Cl}$ & 153 & & TEXT & - BAD - & \\
\hline $27 A B$ & C $4 A 0$ & & & & & \\
\hline $27 A C$ & 0080 & 154 & & SMB & 0 & \\
\hline $27 A D$ & $206 E$ & 155 & & JSX & $X^{\circ} 6 E^{\circ}$ & \\
\hline 27AE & C3D3 & 156 & & TEXT & 'CSUM" & \\
\hline $27 A F$ & D5CD & & & & & \\
\hline 2780 & 0000 & 157 & & HLT & & REDO MAG TAPE \\
\hline 2761 & $17 \mathrm{AB}$ & 1.58 & & JMP & C ERR & IF RUN IS PUSHED \\
\hline $27 B 2$ & 0080 & 159 & ERR & SMB & 0 & \\
\hline 2783 & $206 E$ & $16 Q$ & & JSX & $X^{\circ} 6 E^{\circ}$ & \\
\hline 2754 & D4C I & 161 & & TEXT & "TAPE" & \\
\hline $27 B 5$ & DOC 5 & & & & & \\
\hline 2786 & 0080 & 162 & & SME & 0 & \\
\hline $27 \mathrm{B7}$ & $206 E$ & 163 & & JSX & $X^{\circ} 6 E^{\circ}$ & \\
\hline $\begin{array}{l}27 B 8 \\
27 B 9\end{array}$ & $\begin{array}{l}\text { C 5D2 } \\
\text { C FD2 }\end{array}$ & 164 & & TEXT & 'EROR. & \\
\hline
\end{tabular}




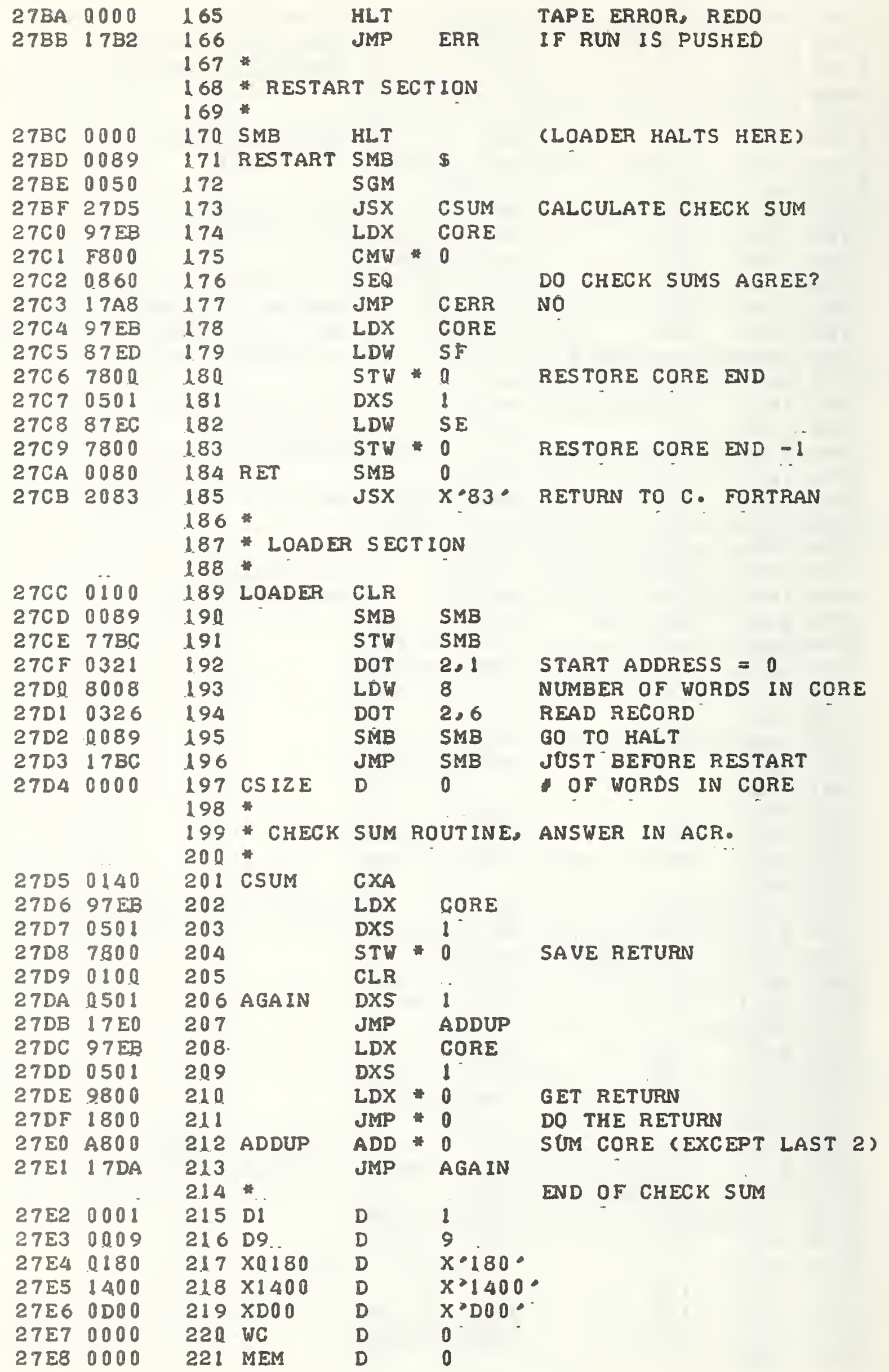




\section{$11 / 11 / 7485$ 'STE1}

$\begin{array}{llllll}27 E 9 & 27 C C & 222 & \text { LLOAD } & \text { D } & \text { LOADER } \\ 27 E A & 0000 & 223 & \text { NUMP } & \text { DATA } & 0 \\ 27 E B & 0000 & 224 & \text { CORE } & \text { D } & 0 \\ 27 E C & 0000 & 225 & \text { SE } & \text { D } & 0 \\ 27 E D & 000 & 226 \text { SF } & \text { D } & 0 \\ & & 227 & \text { END } & \end{array}$

NO ERRORS 


$\begin{array}{llllllll}\text { ADDUP. } & 27 E 0 & \text { AGAIN } & 27 D A & \text { CERR } & 27 A 8 & \text { CONT } & 2743 \\ \text { CONT1 } & 276 F & \text { CONT2 } & 273 A & \text { CORE } & 27 E B & \text { CSIZE } & 27 D 4 \\ \text { CSUM } & 27 D 5 & \text { DI } & 27 E 2 & \text { D9 } & 27 E 3 & \text { ERR } & 27 B 2 \\ \text { LLOAD } & 27 E 9 & \text { LOADER } & 27 C C & \text { MAG } & 277 E & \text { MEM } & 27 E 8 \\ \text { NUM } & 2731 & \text { NUMP } & 27 E A & \text { RESTART } & 27 B D & \text { RET } & 27 C A \\ \text { RING } & 279 A & \text { SE. } & 27 E C & \text { SF } & 27 E D & \text { SKIP } & 2759 \\ \text { SMB } & 27 B C & \text { SS1 } & 273 D & \text { SS2 } & 2740 & \text { STAT1 } & 2782 \\ \text { STAT2 } & 278 F & \text { STAT3 } & 2763 & \text { STAT4 } & 2748 & \text { STEM } & 2730 \\ \text { STOP } & 277 C & \text { WC } & 27 E 7 & \text { XO180 } & 27 E 4 & \text { X1400 } & 27 E 5 \\ \text { XDOO } & 27 E 6 & & & & & & \end{array}$




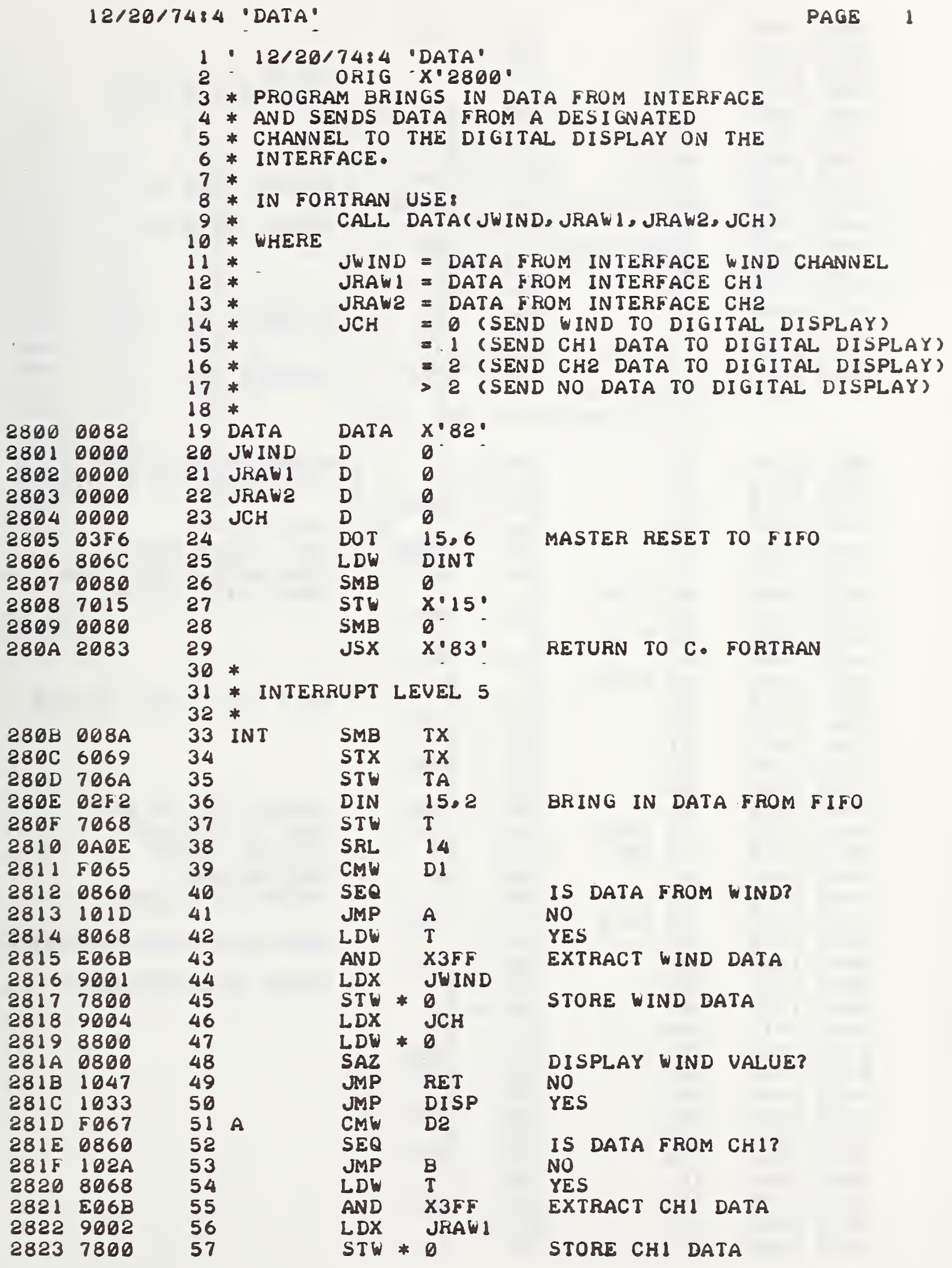




\begin{tabular}{|c|c|c|c|c|c|c|}
\hline 2824 & 9004 & 58 & & LDX & $\mathrm{JCH}$ & \\
\hline 2825 & 8800 & 59 & & LDW & $* 0$ & \\
\hline 2826 & 5065 & 60 & & CMW & D1 & \\
\hline 2827 & 0860 & 61 & 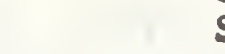 & SEQ & & DISPLAY CHI DATA? \\
\hline 2828 & 1047 & 68 & & JMP & RET & NO \\
\hline 2829 & 1033 & 63 & & MPP & DISP & YES \\
\hline $282 A$ & 8068 & 64 & $\mathrm{~B}$ & L DW & $\mathrm{T}$ & \\
\hline $282 B$ & ED6B & 65 & & AND & $\times 3 F F$ & EXTRACT CH2 DATA \\
\hline $282 C$ & 9003 & 66 & & LDX & JRAWR & \\
\hline 288D & 7800 & 67 & & STW & $* 0$ & STORE CH2 DATA \\
\hline 2825 & 9004 & 68 & & LDX & JCH & \\
\hline 2825 & 8800 & 69 & & LDW & $* B$ & \\
\hline 2830 & 5067 & 70 & & CMW & D2 & \\
\hline 2831 & 9860 & 71 & & SEQ & & DISPLAY CHZ DATA? \\
\hline 32 & 1047 & 72 & & JMP & RET & NO \\
\hline 33 & 8068 & 73 & DISP & LDW & I & \\
\hline 34 & ED6B & 74 & & AND & $\times 3 F 5$ & EXTRACT DATA \\
\hline & & 75 & * & & & \\
\hline & & $\begin{array}{l}76 \\
77\end{array}$ & * CONUERT & IT TO & $B C D$ & \\
\hline 2835 & 0810 & 78 & & SAP & & NEGATIVE VALUE? \\
\hline 28 & 0110 & 79 & & CMP & & YES, ABSOLUTE VALUE \\
\hline 2837 & 5066 & 80 & & CMU & D9999 & \\
\hline 2838 & 0890 & 81 & & SLE & & TOO BIG? \\
\hline 2839 & 8066 & 82 & & LDW & D9999 & YES, LIMIT VALUE \\
\hline $283 A$ & $204 A$ & 83 & & JSX & $R M \perp B$ & REMAINDER SUBROUT INE \\
\hline 2838 & 0000 & 84 & $D I G 4$ & $\mathbf{D}$ & 0 & LEAST SIG. DIGIT \\
\hline $283 C$ & $204 A$ & 85 & & JSX & RM 10 & \\
\hline 283D & $0 D D O$ & 86 & DIG3 & D & 0 & \\
\hline $283 E$ & $204 A$ & 87 & & $J S X$ & $R M 10$ & \\
\hline $283 F$ & 0000 & 88 & DIG2 & D & $\boldsymbol{D}$ & \\
\hline 2840 & $0 A 14$ & 89 & & SLL & 4 & MOST SIG. DIGIT IN ACR \\
\hline 2841 & CO35 & 90 & & ORI & DIG2 & \\
\hline 2842 & $0 A 14$ & 91 & & SLL & 4 & \\
\hline 28 & CO3D & 92 & & ORI & DIG3 & \\
\hline 2844 & DA 14 & 93 & & SLL & 4 & \\
\hline 2845 & $\mathrm{CO} 3 \mathrm{~B}$ & 94 & & ORI & DI G4 & PACKED BCD IN ACR \\
\hline 2846 & 0352 & 95 & SEND & DOT & 15,2 & SEND TO DISPLAY \\
\hline 8847 & 9069 & 96 & RET & LDX & $T X$ & RESTORE INDEX \\
\hline 2848 & $806 A$ & 97 & & LDW & TA & RESTORE ACR \\
\hline 2849 & 0015 & 98 & & INR & 5 & INTERRUPT RETURN \\
\hline $284 \mathrm{~A}$ & 7063 & 99 & $R M \perp B$ & STW & ASAV & \\
\hline $284 B$ & 0800 & 100 & & SAZ & & CHECK FOR ZERO NUMERATOR \\
\hline $284 \mathrm{C}$ & 1045 & 101 & & $M M P$ & $s+3$ & \\
\hline 284D & 7800 & 182 & & STV $*$ & $* 0$ & STUFF ZERO REMAINDER \\
\hline $284 E$ & 1801 & 103 & & MPP. & $* 1$ & \\
\hline 28 & BA11 & 104 & & SLL & 1 & 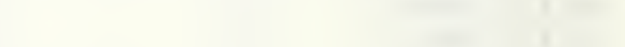 \\
\hline 28 & $A D 63$ & 105 & & $A D D$ & ASAV & 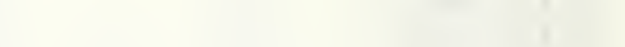 \\
\hline 28 & 7064 & 106 & & STW & TSAV & \\
\hline 28 & $9 A B 4$ & 107 & & SRL & 4 & \\
\hline 28 & AD6 64 & 108 & & ADD & TSAV & $x_{1}$ \\
\hline 28 & DAO4 & 109 & & SRL & 4 & \\
\hline & $A D 64$ & 110 & & ADD & TSAV & \\
\hline & $9 A B 4$ & 111 & & SRL & 4 & \\
\hline & $A D 64$ & 118 & & ADD & ISAV & \\
\hline & A065 & 113 & & ADD & DI & \\
\hline & DAO5 & 114 & & SRL & 5 & \\
\hline
\end{tabular}




\section{$12 / 20 / 7484{ }^{\circ}$ DATA'}

PAGE 3

\begin{tabular}{|c|c|c|c|c|c|c|}
\hline $\begin{array}{l}285 A \\
285 B \\
285 \mathrm{C} \\
285 \mathrm{D} \\
285 \mathrm{E} \\
285 \mathrm{~F} \\
2860 \\
2861 \\
2862 \\
2863 \\
2864 \\
2865 \\
2866 \\
2867 \\
2868 \\
2869 \\
286 A \\
286 B\end{array}$ & $\begin{array}{l}7064 \\
0 A 13 \\
A 964 \\
A 964 \\
0110 \\
A 063 \\
7800 \\
8064 \\
1801 \\
0000 \\
0000 \\
0001 \\
2705 \\
0002 \\
0000 \\
0000 \\
0000 \\
93 F 5 \\
280 B\end{array}$ & $\begin{array}{l}115 \\
116 \\
1117 \\
118 \\
119 \\
120 \\
121 \\
122 \\
123 \\
124 \\
125 \\
126 \\
127 \\
128 \\
129 \\
130 \\
131 \\
132 \\
133 \\
134\end{array}$ & $\begin{array}{l}\quad- \\
\text { ASAV } \\
\text { TSAV } \\
\text { DI } \\
\text { D9999 } \\
\text { D2 } \\
\text { T } \\
\text { TX } \\
\text { TA } \\
\text { X3FF } \\
\text { DINT }\end{array}$ & $\begin{array}{l}\text { STW } \\
\text { SLL } \\
\text { ADD } \\
\text { ADD } \\
\text { CMP } \\
\text { ADD } \\
\text { STW * } \\
\text { LDW } \\
\text { JMP } \\
\text { D } \\
D \\
D \\
D \\
D \\
\text { DATA } \\
\text { D } \\
\text { D } \\
D \\
\text { D } \\
\text { END }\end{array}$ & $\begin{array}{l}\text { TSAV } \\
3 \\
\text { TSAU } \\
\text { TSAV } \\
\text { ASAV } \\
0 \\
\text { TSAU } \\
1 \\
0 \\
0 \\
1 \\
9999 \\
2 \\
0 \\
0 \\
0 \\
X \cdot 3 F F^{\circ} \\
\text { INT }\end{array}$ & $\begin{array}{l}\text { - 10*QUOTIENT } \\
\text { REMAINDER } \\
\text { QUOTIENT IN ACR }\end{array}$ \\
\hline
\end{tabular}

N O ERRORS 


$\begin{array}{llllllll}\text { A } & 281 D & \text { ASAV } & 2863 & \text { B } & 282 A & \text { DI } & \text { 3865 } \\ \text { DE } & 2867 & \text { D9999 } & 2866 & \text { DATA } & 2800 & \text { DIGE } & 8835 \\ \text { DIG3 } & 283 D & \text { DIG4 } & 283 B & \text { DINT } & 286 C & \text { DISP } & 2833 \\ \text { INT } & 280 B & \text { JCH } & 2804 & \text { JRAWI } & 8802 & \text { JRAWE } & 2803 \\ \text { JWIND } & 2801 & \text { RET } & 2847 & \text { RMID } & 284 A & \text { SEND } & 8846 \\ \text { T } & 2868 & \text { TA } & 286 A & \text { TSAV } & 2864 & \text { TX } & 8869\end{array}$

$\times 3 F F$

PAS?

$286 \mathrm{~B}$ 


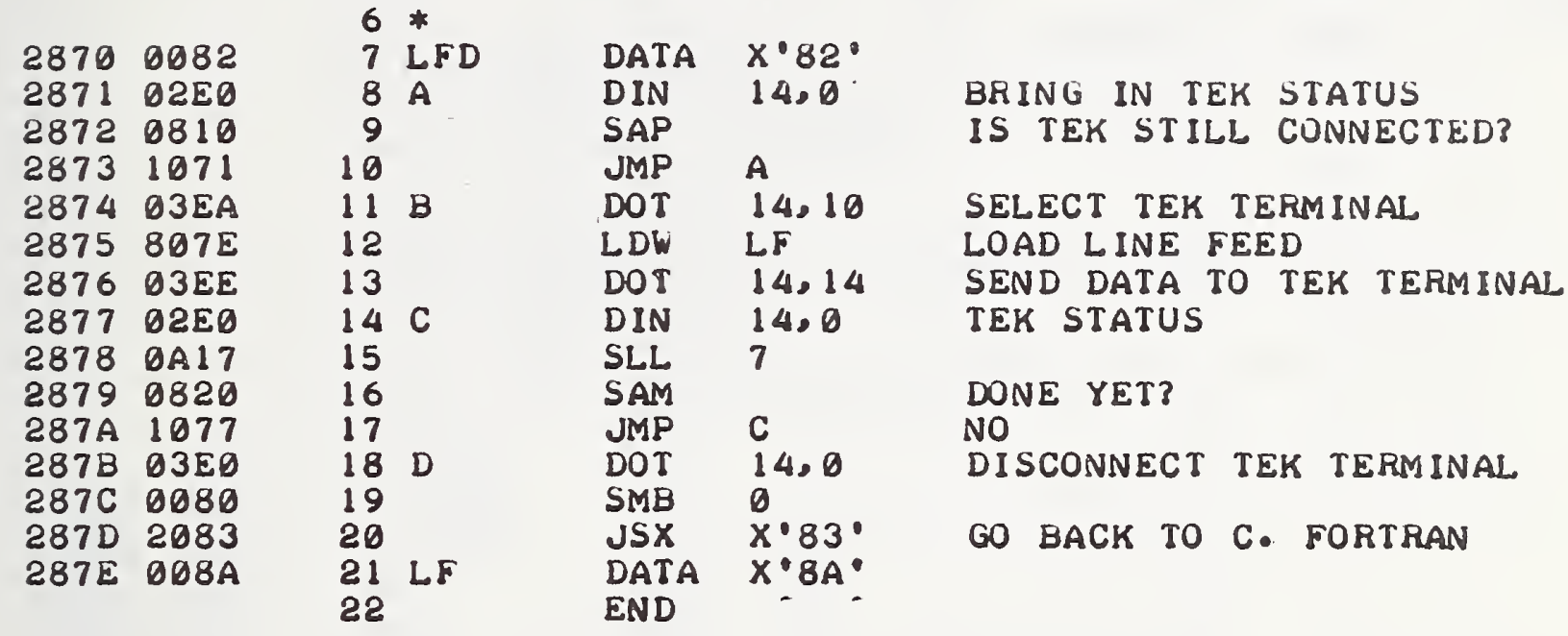


$12 / 20 / 7483^{\circ} L F D$ '

PAGE 2

A

$2871 \quad B$

287E LFD

$2874 \mathrm{C}$

2870

2877 D

$887 B$

PAS? 


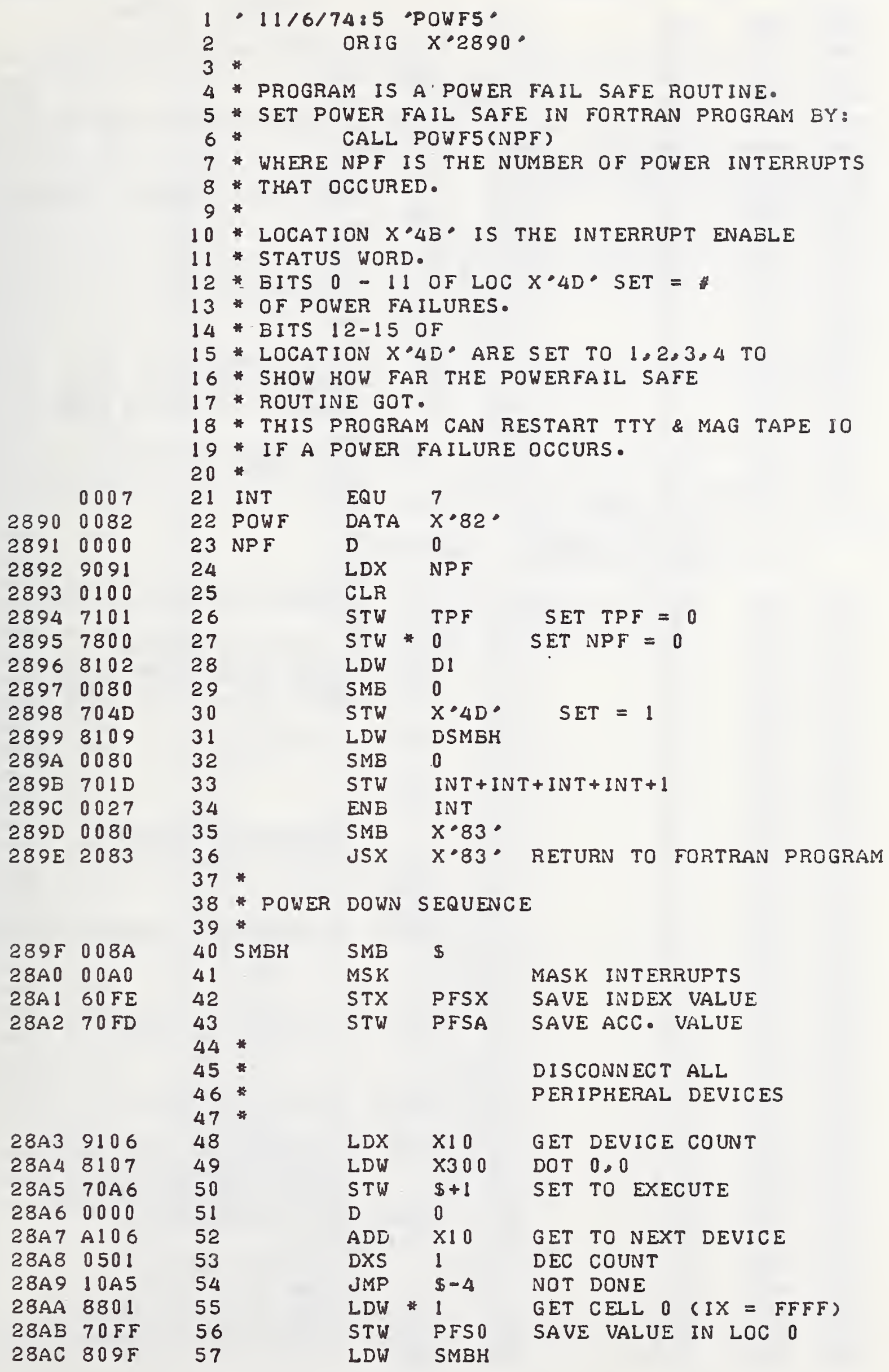




\begin{tabular}{|c|c|c|c|c|c|c|}
\hline $28 A D$ & 0080 & 58 & & SMB & 0 & \\
\hline 28AE & 7070 & 59 & & STW & $X \bullet 7 D \cdot$ & PUT SMB IN LOC $X^{\circ} 7 D^{\circ}$ \\
\hline 28AF & $80 \mathrm{Cl}$ & 60 & & LDW & JMPH & \\
\hline 28B0 & 0080 & 61 & & SMB & 0 & \\
\hline $28 B 1$ & $707 E$ & 62 & & STW & $X \bullet 7 E^{\bullet}$ & PUT POWER UP JMP IN LOC $X^{\circ} 7 E^{\circ}$ \\
\hline $28 B 2$ & 8108 & 63 & & LDW & $\times 107 D$ & \\
\hline $28 B 3$ & 0080 & 64 & & SMB & 0 & \\
\hline 28B4 & 7000 & 65 & & STW & 0 & STORE JMP TO $X^{*} 7 D^{\circ}$ IN LOC 0 \\
\hline 2855 & 9091 & 66 & & LDX & NPF & \\
\hline 2856 & 8800 & 67 & & LDW & $* 0$ & \\
\hline $28 B 7$ & A 102 & 68 & & $A D D$ & DI & \\
\hline $28 B 8$ & 7800 & 69 & & STW & $* 0$ & $N P F=N P F+1$ \\
\hline 2889 & 8101 & 70 & & LDW & TPF & \\
\hline 28BA & A 102 & 71 & & $A D D$ & D! & \\
\hline 28BB & 7101 & 72 & & STW & TPF & $T P F=T P F+1$ \\
\hline 28BC & $0 A 14$ & 73 & & SLL & 4 & MOVE 4 BITS TO LEFT \\
\hline 28BD & A 103 & 74 & & $A D D$ & D2 & SHOWS PFS GOT TO HERE \\
\hline $28 B E$ & 0080 & 75 & & SMB & 0 & \\
\hline $28 B \mathrm{~F}$ & $704 \mathrm{D}$ & 76 & & STW & $x \cdot 4 D^{\circ}$ & RESTORE PF STATUS \\
\hline $28 \mathrm{CO}$ & 0000 & 77 & & HLT & & WAIT FOR A.C. POWER UP \\
\hline \multirow[t]{4}{*}{$28 \mathrm{Cl}$} & $10 \mathrm{C2}$ & 78 & JMPH & JMP & $\$+1$ & \\
\hline & & 79 & * & & & \\
\hline & & 80 & * POWER & UP & S EQU ENCE & \\
\hline & & 81 & * & & & \\
\hline $28 C 2$ & 0027 & 82 & & ENB & INT & ENABLE POWER FAIL SAFE \\
\hline $28 \mathrm{C3}$ & 0080 & 83 & & SMB & 0 & \\
\hline $28 C 4$ & $804 D$ & 84 & & LDW & $X \cdot 4 D \cdot$ & LOAD PF STATUS \\
\hline $28 C 5$ & EIOA & 85 & & AND & $X F F F O$ & KEEP OF POWER FAILS \\
\hline $28 \mathrm{C} 6$ & A 104 & 86 & & $A D D$ & D3 & SHOWS PFS GOT TO HERE \\
\hline $28 \mathrm{C} 7$ & 0080 & 87 & & SMB & 0 & \\
\hline $28 C 8$ & $704 D$ & 88 & & STW & $X^{\circ} 4 D^{\circ}$ & $S E T=3$ \\
\hline 2809 & 0050 & 89 & & SGM & & \\
\hline $28 \mathrm{CA}$ & $80 \mathrm{FF}$ & 90 & & LDW & PFSO & \\
\hline $28 \mathrm{CB}$ & 0080 & 91 & & SMB & 0 & \\
\hline $28 \mathrm{CC}$ & 7000 & 92 & & STW & 0 & RESTORE LOCATION O \\
\hline $28 C D$ & 0356 & 93 & & DOT & 15,6 & MASTER RESET FIFO \\
\hline $28 C E$ & 0080 & 94 & & SMB & $x \cdot 4 B^{\circ}$ & \\
\hline $28 \mathrm{CF}$ & $804 B$ & 95 & & LDW & $x^{\circ} 4 B^{\circ}$ & \\
\hline 28D0 & $E \perp O B$ & 96 & & AND & $\times 400$ & EXTRACT INT. ENABLE 5 STATUS \\
\hline 28D1 & 0800 & 97 & & SAZ & & \\
\hline 28D2 & 0025 & 98 & & ENB & 5 & \\
\hline 2803 & 0080 & 99 & & SMB & 0 & \\
\hline $28 D 4$ & $905 \mathrm{C}$ & 100 & & LDX & $x \cdot 5 c$ & FIND END OF CORE \\
\hline 28D5 & 0507 & 101 & & DXS & 7 & \\
\hline 28D6 & 8804 & 102 & & LDW & * 4 & \\
\hline 28D7 & $710 \mathrm{C}$ & 103 & & STW & IORET & SAVE IO RETURN \\
\hline 28D8 & 9800 & 104 & & $\operatorname{LDX}$ & $* 0$ & \\
\hline 28D9 & 6100 & 105 & & STX & SAVE & SAVE LOC OF LAST FIOT \\
\hline 28DA & 8800 & 106 & & LDW & $* 0$ & WORD 0 OF FIOT \\
\hline $28 D B$ & 0820 & 107 & & SAM & & POHER DOWN DURING IO? \\
\hline 28DC & 1054 & 108 & & JMP & INRR & NO, NORMAL INR \\
\hline 28DD & E\OD & 109 & & AND & $\times 7 F F F$ & YES \\
\hline 28DE & 7800 & 110 & & STW & $* 0$ & SET BUSY BIT $=0$ \\
\hline 28DF & 8802 & 111 & & LDW & $\Rightarrow 2$ & WORD 2 OF FIOT \\
\hline $28 E 0$ & 7111 & 112 & & STW & WORD2 & SAVE WORD 2 OF FIOT \\
\hline $28 \mathrm{El}$ & E $10 \mathrm{E}$ & 113 & & AND & $X \perp F 0$ & EXTRACT UNIT NUMBER \\
\hline 28E2 & $F 112$ & 114 & & $\mathrm{CMW}$ & XDO & \\
\hline
\end{tabular}




\begin{tabular}{|c|c|c|c|c|c|c|}
\hline $28 E 3$ & 0860 & 115 & & $S E Q$ & & WAS DEVICE = TTY? \\
\hline $28 E 4$ & $10 F 0$ & 116 & & JMP & RETURN & No \\
\hline $28 E 5$ & 8111 & 117 & & LDW & WORD2 & \\
\hline $28 E 6$ & $E \perp 0 F$ & 118 & & AND & $X \perp F F$ & KEEP BITS 6-15 \\
\hline 28E7 & A 110 & 119 & & $A D D$ & $\times 1800$ & PUT DISCONNECT IN JMP CODE \\
\hline $28 \Sigma 8$ & 7802 & 120 & & STW & $* 2$ & CHANGE WORD 2 OF FIOT \\
\hline $28 E 9$ & 0020 & 121 & & ENB & 0 & ALLOW TTY TO INTERRUPT \\
\hline 28EA & 8113 & 122 & & LDW & CR & \\
\hline $28 E B$ & $03 E E$ & 123 & & DOT & 14.14 & SEND CARRIAGE RETURN \\
\hline 28EC & $02 E 0$ & 124 & WAIT & DIN & 14,0 & TTY STATUS \\
\hline 28ED & OAI 7 & 125 & & SLL & 7 & \\
\hline 28EE & 0820 & 126 & & SAM & & \\
\hline $28 E F$ & $10 \mathrm{EC}$ & 127 & & JMP & WAIT & \\
\hline $28 F 0$ & $910 \mathrm{C}$ & 128 & RETURN & LDX & IORET & PRETEND IO WAS FINISHED \\
\hline $28 \mathrm{Fl}$ & 0501 & 129 & & DXS & 1 & \\
\hline $28 F 2$ & OA 0 & 130 & & NOP & & \\
\hline $28 F 3$ & 1800 & 131 & & JMP & $* 0$ & GO BACK TO DOIO \\
\hline $28 F 4$ & 0080 & 132 & INRR & SMB & 0 & \\
\hline $28 F 5$ & $804 \mathrm{D}$ & 133 & & LDW & $X \cdot 4 D$ & LOAD PF STATUS \\
\hline $28 F 6$ & EIOA & 134 & & AND & $X F F F O$ & KEEP $\#$ OF POWER FAILS \\
\hline 2857 & A 105 & 135 & & $A D D$ & D4 & SHOWS IO WAS NOT IN PROGRESS \\
\hline $28 F 8$ & 0080 & 136 & & SMB & 0 & WHEN THE POWER FAILED \\
\hline $28 F 9$ & $704 D$ & 137 & & STW & $X \cdot 4 D^{\circ}$ & \\
\hline $28 F A$ & $90 \mathrm{FE}$ & 138 & & LDX & PFSX & RESTORE INDEX \\
\hline $28 \mathrm{FB}$ & $80 F D$ & 139 & & LDW & PFSA & RESTORE ACC. \\
\hline $28 F C$ & 0017 & 140 & & INR & INT & \\
\hline $28 \mathrm{FD}$ & 0000 & 141 & PFSA & D & 0 & \\
\hline $28 F E$ & 0000 & 142 & PFSX & $D$ & 0 & \\
\hline $28 F F$ & 0000 & 143 & PFSO & D & 0 & \\
\hline 2900 & 0000 & 144 & SAVE & D & 0 & \\
\hline 2901 & 0000 & 145 & TPF & $D$ & 0 & \\
\hline 2902 & 0001 & 146 & D1 & D & 1 & \\
\hline 2903 & 0002 & 147 & D2 & $D$ & 2 & \\
\hline 2904 & 0003 & 148 & D3 & $D$ & 3 & \\
\hline 2905 & 0004 & 149 & D4 & D & 4 & \\
\hline 2906 & 0010 & 150 & $x \perp 0$ & D & $x \cdot 10^{\circ}$ & \\
\hline 2907 & 0300 & 151 & $\times 300$ & $D$ & $x \cdot 300$ & \\
\hline 2908 & 1070 & 152 & $\times 1070$ & $D$ & $x^{\circ} 1070^{\circ}$ & \\
\hline 2909 & $289 F$ & 153 & DS MBH & $D$ & SMBH & \\
\hline $290 \mathrm{~A}$ & FFFO & 154 & XFFFO & $D$ & $X^{\circ} F F F 0^{\circ}$ & \\
\hline $290 B$ & 0400 & 155 & $\times 400$ & $D$ & $x^{\circ} 400^{\circ}$ & \\
\hline $290 \mathrm{C}$ & 0000 & 156 & IORET & $D$ & 0 & \\
\hline 2900 & $7 F F F$ & 157 & $\times 7 F F F$ & $D$ & $X^{\circ} 7 F F F^{\circ}$ & \\
\hline $290 E$ & $0 \perp F 0$ & 158 & $X \perp F 0$ & $D$ & $x \bullet 150^{\circ}$ & \\
\hline $290 F$ & $01 F F$ & 159 & $X \perp F F$ & $D$ & $X \bullet I F F$ & . \\
\hline 2910 & 1800 & 160 & $\times 1800$ & $D$ & $x \cdot 1800^{\circ}$ & \\
\hline 2911 & 0000 & 161 & WORD2 & $D$ & 0 & \\
\hline 2912 & 0000 & 162 & XDO & $D$ & $X^{\circ} D 0^{\circ}$ & \\
\hline 2913 & $008 D$ & 163 & CR & $D$ & $x^{\circ} 8 D^{\circ}$ & \\
\hline & & 164 & & END & & \\
\hline
\end{tabular}




$\begin{array}{llllllll}\text { CR } & 2913 & \text { DI } & 2902 & \text { D2 } & 2903 & \text { D3 } & 2904 \\ \text { D4 } & 2905 & \text { DSMBH } & 2909 & \text { INRR } & 28 F 4 & \text { INT } & 0007 \\ \text { IORET } & 290 C & \text { JMPH } & 28 C 1 & \text { NPF } & 2891 & \text { PFSO } & 28 F F \\ \text { PFSA } & 28 F D & \text { PFSX } & 28 F E & \text { POWF } & 2890 & \text { RETURN } & 28 F 0 \\ \text { SAVE } & 2900 & \text { SMBH } & 289 F & \text { TPF } & 2901 & \text { WAIT } & 28 E C \\ \text { WORD2 } & 2911 & \text { XIO } & 2906 & \text { XI07D } & 2908 & \text { X1800 } & 2910 \\ \text { XIFO } & 290 E & \text { XIFF } & 290 F & \text { X300 } & 2907 & \text { X400 } & 290 B \\ \text { X7FFF } & 290 D & \text { XDO } & 2912 & \text { XFFFO } & 290 A & & \end{array}$

PAS? 
29180082
$291 C 0000$
29100000
29150000
29150000
29200000
29210000

2922 OQ8A

292301.00

29249120

29257800

29269121

29277800

$2928818 E$

$2929718 D$

$292 A \quad 811 \mathrm{C}$

292B BI $8 F$

292C $718 \mathrm{C}$

292D 03F6

292E 8190

$292 F 0080$

29307015

29310080

29322083

$2933008 \mathrm{~A}$

2934 618A

29357189

$293602 F 2$

$2937718 B$

2938 OAOE

$2939 F 18 F$

293A 0860

293B 1141

293C 818B

293D E191

293E 9110
1. $10 / 31 / 7485$ MULT1.

2 ORIG $X^{\circ} 291 B^{\circ}$

3 MULTI $D$ X $X^{\circ}$.

4 NVAL D 0

5 JWIND D 0

6 JCOUNT D 0

7 JDONE D 0

8 JEROR D 0

9 JSKIP D 0

10 * MULTI. PROGRAM BRINGS IN WIND

11 - DATA AND CHI CH2 DATA FROM

12 * MUX FIFO SYSTEM VIA INTERRUPT

13 LEVEL 5 :

14 IN FORTRAN USE:

15 * CALL MULTI (K( 1 ), JWIND, JCOUNT, JDONE, JEROR, JSKIP)

16 * K(1) IS FIRST ELEMENT IN ARRAY

17 JWIND IS CURRENT WIND VALUE.

18 * JCOUNT INDICATES THE ARRAY

19 * ELEMENT CURRENTLY FILLED.

20 - JDONE=1 WHEN ARRAY IS FULL.

21 * JEROR = COUNT OF NUMBER OF BAD

22 * DATA VALUES

23 - JSKIP = NUMBER OF SAMPLES SKIPPED DUE

24 TO MISSING CHANNEL NUMBERS.

25 * IN FORTRAN SET JDONE, JSKIP, AND

26 JCOUNT = 0 BEFORE STARTING

27 * TO FILL ARRAY WITH DATA.

28

29

30

31

32

33

34

35

36

37

38

39

40

41

42

43

44

45

46

47

48

49

50

51

52

53

54

55

56

57
SMB S

CLR

LDX JEROR

STW 0 SET JEROR $=0$

LDX JSKIP

STV 0 SET JSKIP $=0$

LDW $=2$

STW SW SET SW $=2$

LDW NVAL

SUB $=$ I

STW $N$ SET $N=B E G I N N I N G$ OF ARRAY -

DOT 15.6 MASTER RESET TO MUX FIFO

LDW $=$ MULT 5

SME $\quad X \cdot 15^{\circ}$

STH $\quad x * 15^{\circ}$

SMB $\quad x^{\circ} 83^{\circ}$

JSX $x^{\circ} 83^{\circ}$

- INTERRUPT LEVEL 5

MULT5 SMB TX

STX TX

STV TA

DIN 15.2 BRING IN DATA FROM MUX FIFO

STU T

SRL 14

CMU $=1$

SEQ

JMP A

LDH T

AND $\quad X \circ 03 F F^{\circ}$ EXTRACT WIND DATA

LDX JWIND 


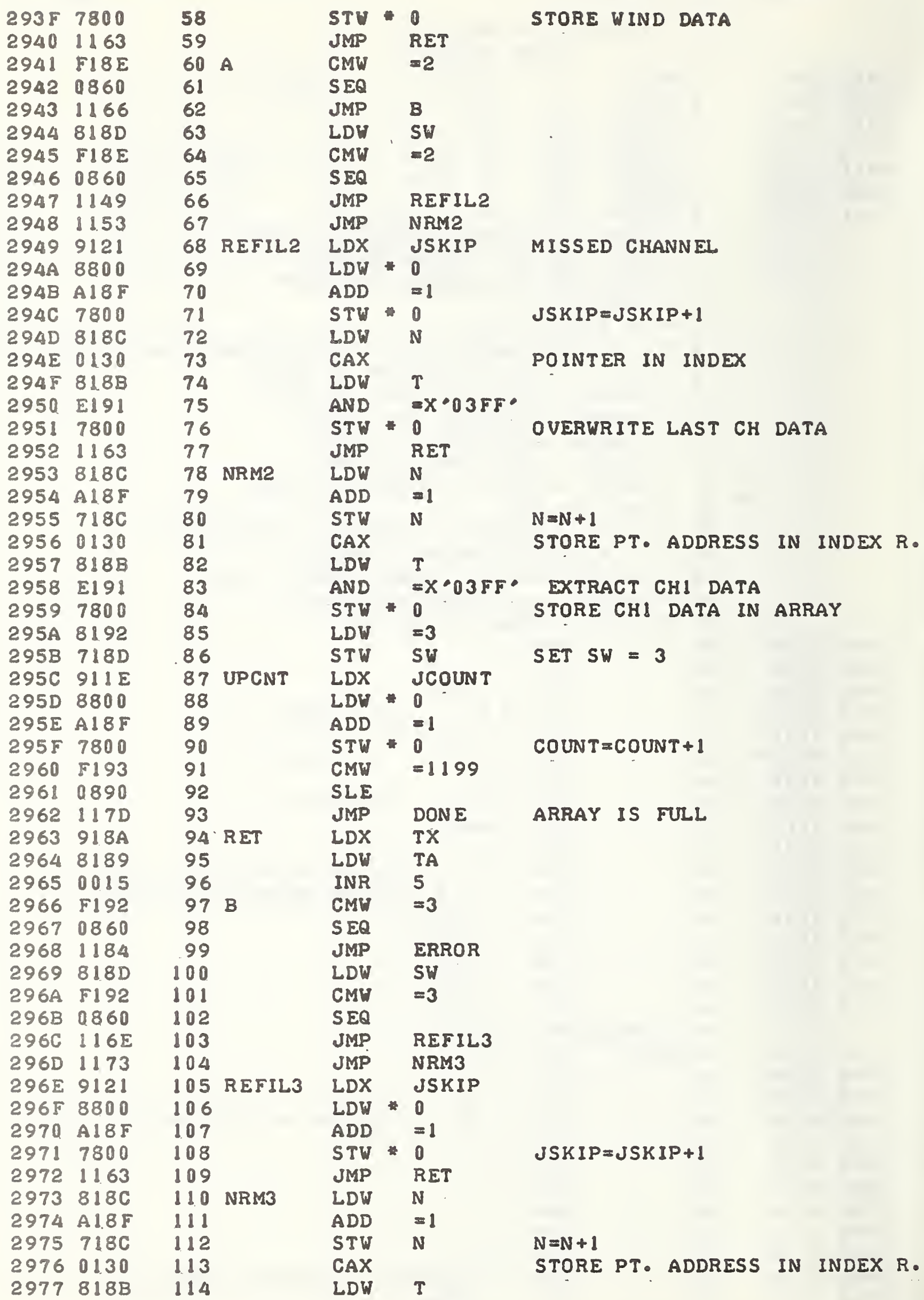




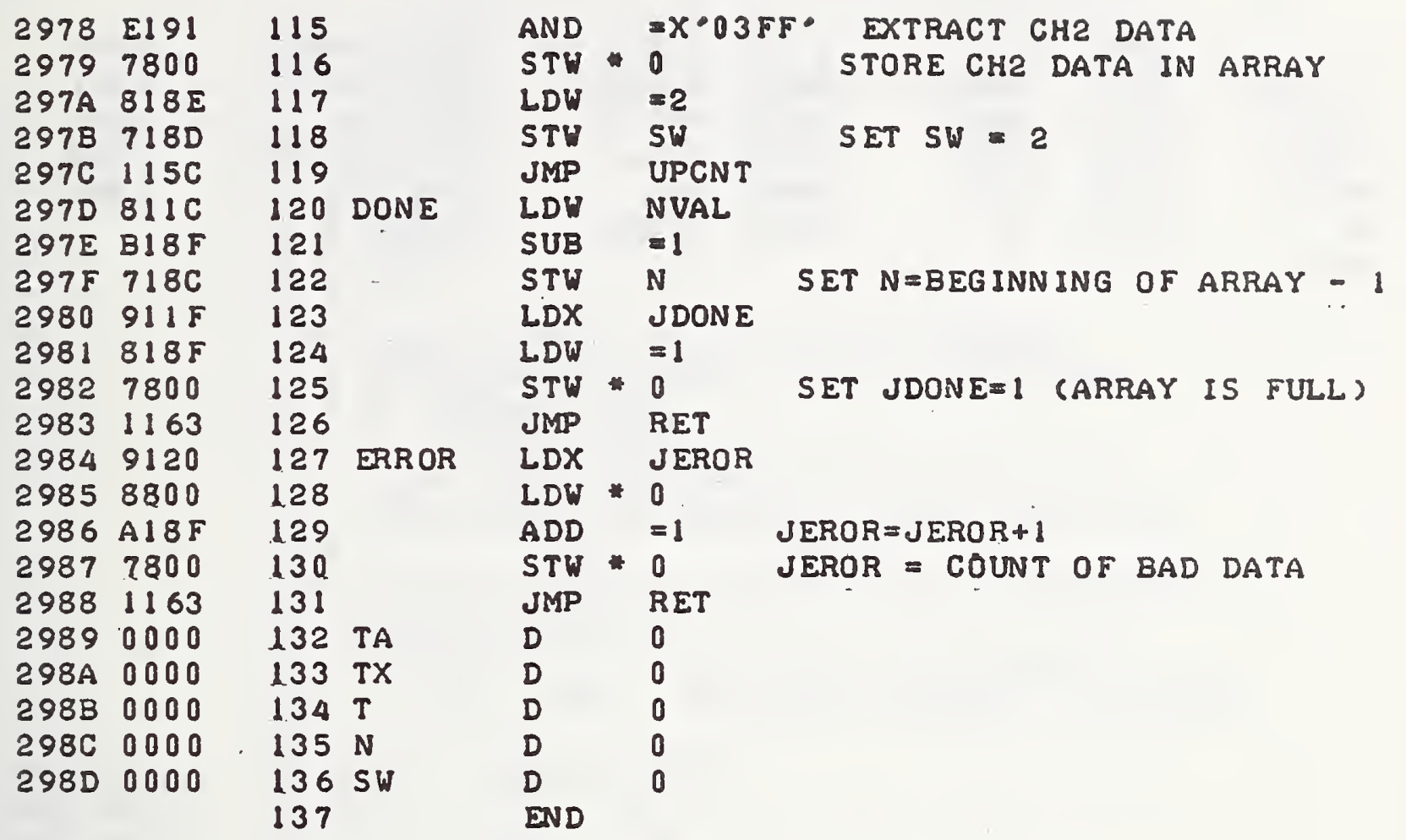

$298 E 0002$ $298 \mathrm{~F} 0001$

$2990 \quad 2933$

2991 O3FF

29920003

2993 O4AF

NO ERRORS 


$\begin{array}{llllllll}\text { A } & 2941 & \text { B } & 2966 & \text { DONE } & 297 D & \text { ERROR } & 2984 \\ \text { JCOUNT } & 291 E & \text { JDONE } & 2915 & \text { JEROR } & 2920 & \text { JSKIP } & 2921 \\ \text { JWIND } & 291 D & \text { MULTI } & 291 B & \text { MULT5 } & 2933 & \text { N } & 298 C \\ \text { NRM2 } & 2953 & \text { NRM3 } & 2973 & \text { NUAL } & 291 C & \text { REFIL2 } & 2949 \\ \text { REFIL3 } & 296 E & \text { RET } & 2963 & \text { SW } & 298 D & \text { T } & 298 B \\ \text { TA } & 2989 & \text { TX } & 298 A & \text { UPCNT } & 295 C & & \end{array}$

PAS? 


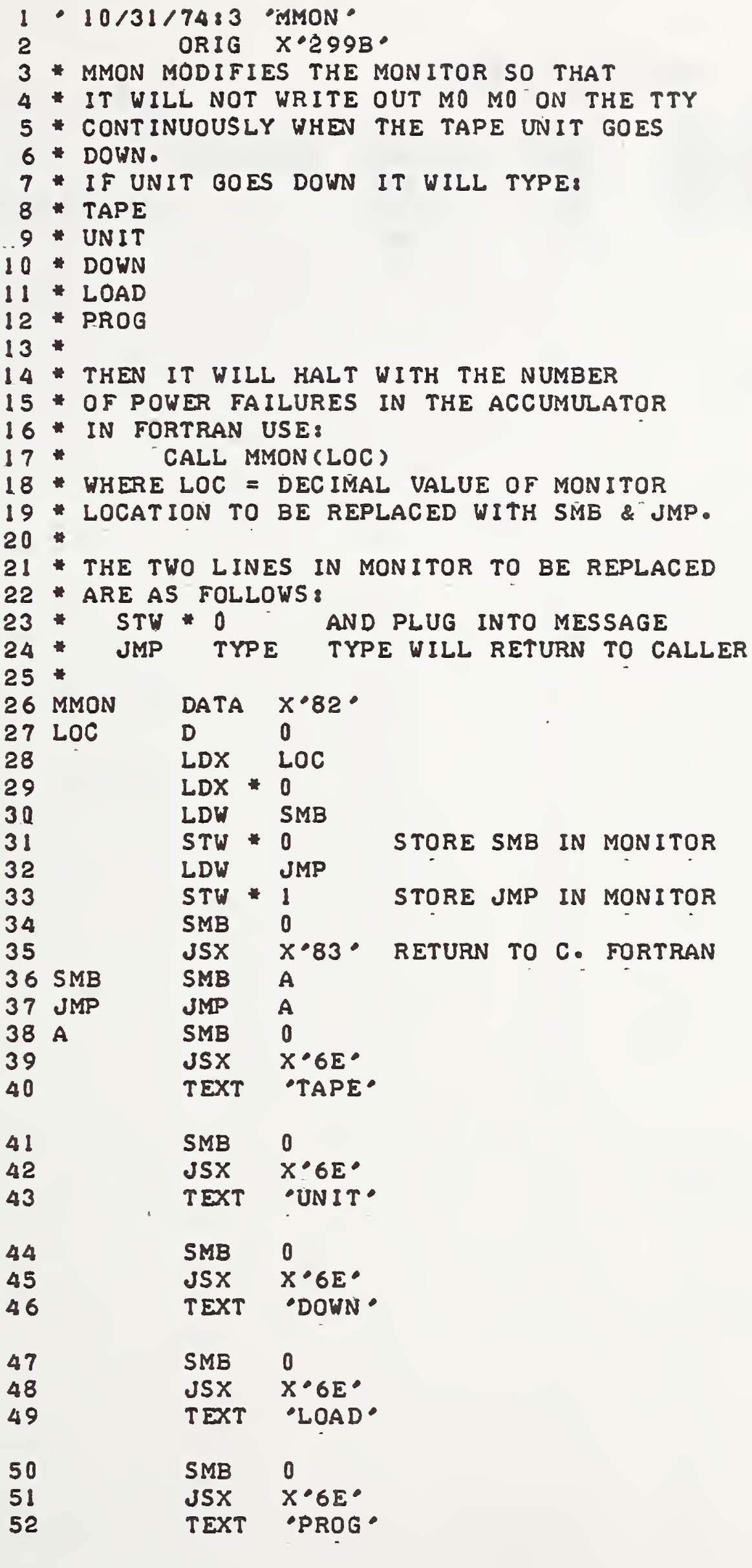




\begin{tabular}{|c|c|c|c|}
\hline $298 B$ & 0080 & 53 & SMB \\
\hline $29 B C$ & $804 D$ & 54 & LDW \\
\hline $298 D$ & $0 A 04$ & 55 & SRL \\
\hline $29 \mathrm{BE}$ & 0000 & $\begin{array}{l}56 \\
57\end{array}$ & HLT \\
\hline
\end{tabular}

RELOAD PROGRAM

NO ERRORS 
$10 / 31 / 7483$ 'MMON

A

SMB

PAS?
29A7 JMP

29A5
PAGE

3

299C MMON

$299 B$

$29 A 6$ LOC 


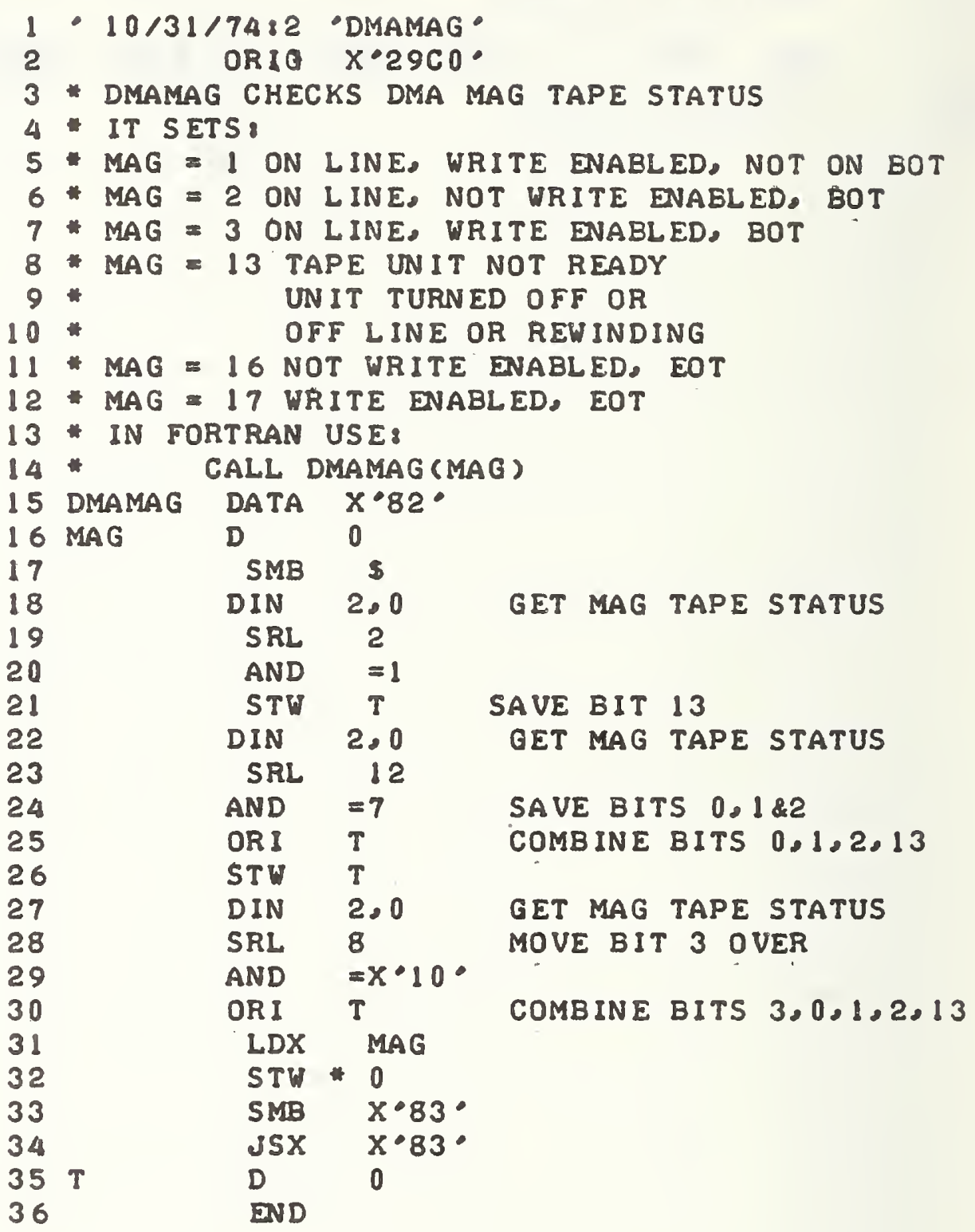

29050001

29060007

2907 0010

NO ERRORS 
$10 / 31 / 7482$ 'DMAMAG

PAGE 2

DMAMAG

2960 MAG

$29 \mathrm{Cl} \mathrm{T}$

2904

PAS? 
29E0 0082

29E1 0000 29E2 0000

29530080

29E4 8048

29E5 7210

29E6 91E2

$29 E 78800$

$29 E 8$ F21 4

29E9 0860

29EA $11 \mathrm{FF}$

$29 E B \quad 91 E 1$

29EC 8800

29ED F215

29EE 0890

29EF 0000

2950 C211

$29 \mathrm{Fl} \mathrm{71F2}$

29520030

$29 \mathrm{F3} 91 \mathrm{El}$

$29 F 48800$

$29 F 5 \quad C 212$

29567158

29578216

2958 0A40

$29 F 9$ E210

29FA 0080

$29 \mathrm{FB} 704 \mathrm{~B}$

$29 \mathrm{FC} 00 B 0$

29FD 0080

29FE 2083

29FF $00 A O$

$2 A 00$ 91El

$2 A 018800$

$2 A 02 \quad F 215$

$2 A 030890$

$2 A 040000$

$2 A 05 \quad C 213$

$2 A 067207$

$2 A 070020$

$2 A 0891 \mathrm{E} 1$

$2 A 098800$

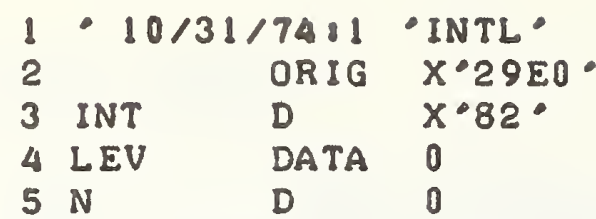

6 * INT PROGRAM DISABLES OR ENABLES

7 * INT ERRUPT LEVEL LEV

8 FOR $N=1$ DISABLE LEV

9 * FOR N $\Leftrightarrow 1$ ENABLE LEV

10 LOCATION X'4B. CONTAINS ENABLE

11 * STATUS FOR ALL 15 INTERRUPTS

12 * IE EIT $=1$ IF INTERRUPT IS ENABLED

13 * THIS STATUS WORD IS USED IN

14 * POWERFAIL SAFE PROGRAMS TO REENABLE

15 * THE PROPER INTERRUPTS.

16 * IN FORTRAN USE:

17 CALL INTL (LEV,N)

18 WHERE LEV $=0$ TO 15

19 SMB $X^{\circ} 4 B^{\circ}$

20

21

22

23

24

25

26

27

28

29

30

31

32

33

$34 \mathrm{~B}$

35

36

37

38

39

$40 \mathrm{C}$

41

$42 R$

43

44

45

46

$47 \mathrm{~A}$

48

49

50

51

52

53

54

$55 \mathrm{D}$

56

57

STW STAT
LDW $X^{\circ} 4 B^{\circ}$

LDX N

LDW * 0

$\mathrm{CMW}=1$

$S E Q$

JMP A

LDX LEV

LDW 0

$\mathrm{CMW}=15$

SLE

HLT

ORI

STW

DSB 0

LOAD INTERRUPT ENABLE STATUS

LDX LEV

LDW * 0

ORI G

STW C MODIFY SRC INSTRUCTION

LDW $=X^{\circ} 7$ FFF॰

SRC 0 SHIFT O ALONG

AND STAT SET BIT LEV $=0$

SMB

STW

UNM

$S M B$

JSX

MSK

LDX

LDW *

CMW $=15$

SLE

HLT

ORI

STW D

ENB 0

LDX LEV

LDW * 0
BAD LEV VALUE

MODIFY DSB INSTRUCTION

DISABLE LEV INTERRUPT

$X \cdot \Delta B^{\circ}$

$X \bullet 4 B^{\circ}$

$x \cdot 83^{\circ}$

$x \cdot 83^{\circ}$

LEV

0

15

BAD LEV VALUE

RESTORE INT ENAELE STATUS

UNMASK POWERFAIL SAFE

MASK POWERFAIL SAFE

MODIFY ENB INSTRUCTION

DNABLE LEV INTERRUPT 


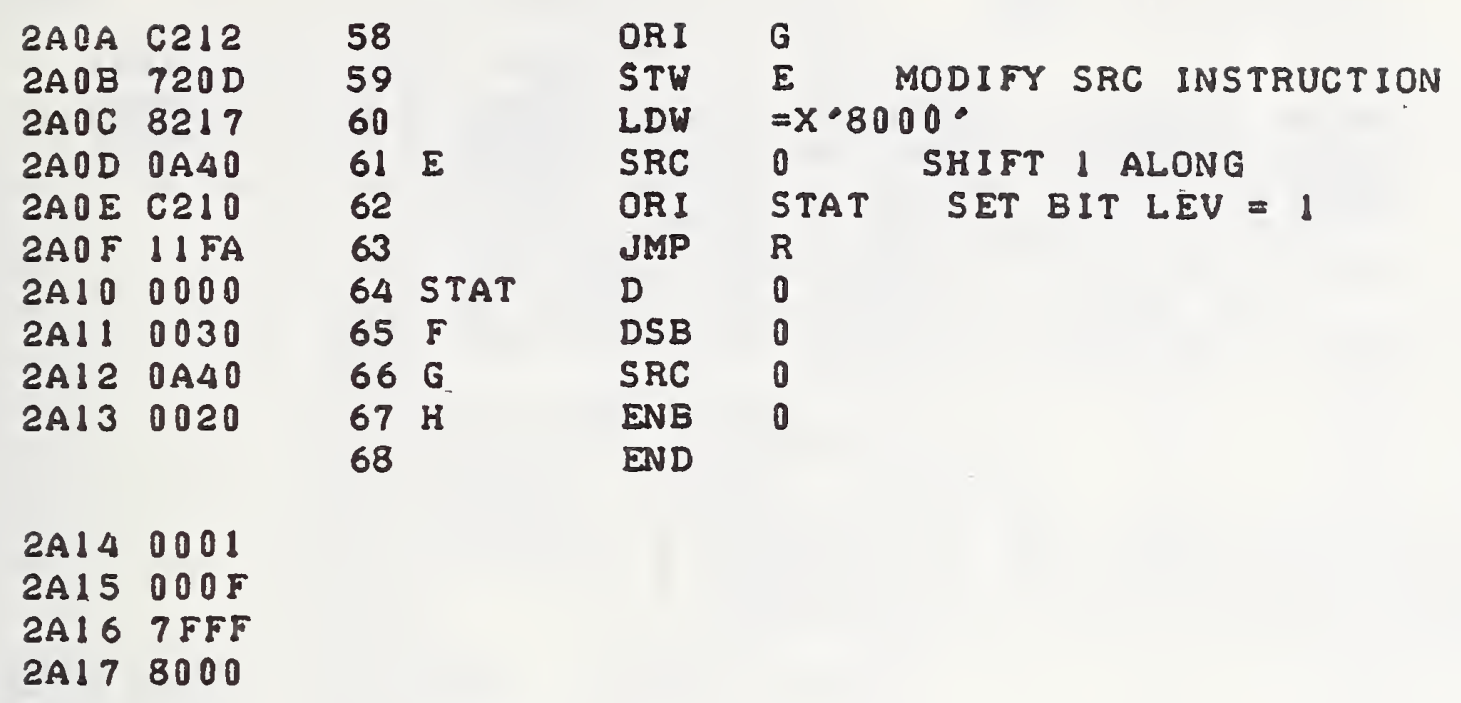

NO ERRORS 
$10 / 31 / 74: 1$ INTL.

$\begin{array}{llllllll}\text { A } & 29 F F & B & 29 F 2 & C & 29 F 8 & D & 2 A 07 \\ \text { E } & 2 A O D & F & 2 A 11 & G & 2 A 12 & H & 2 A 13 \\ \text { INT } & 29 E 0 & \text { LEV } & 29 E I & N & 29 E 2 & R & 29 F A \\ \text { STAT } & 2 A 10 & & & & & & \\ \text { PAS? } & & & & & & \end{array}$

PAGE

3 982 AI 1

A 13

$95 A$ 


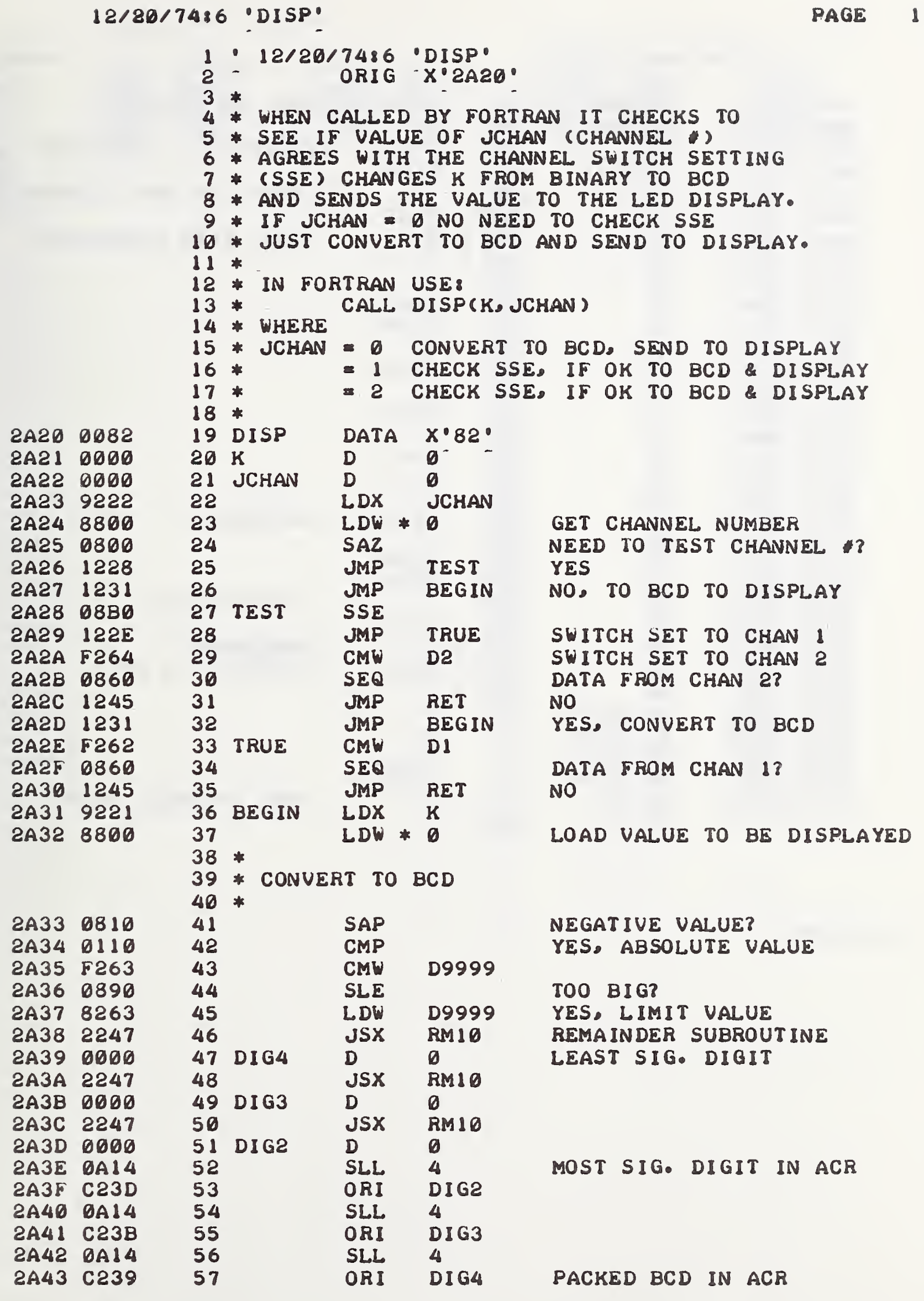


$12 / 20 / 7486$ 'DISP!

PAGE 2

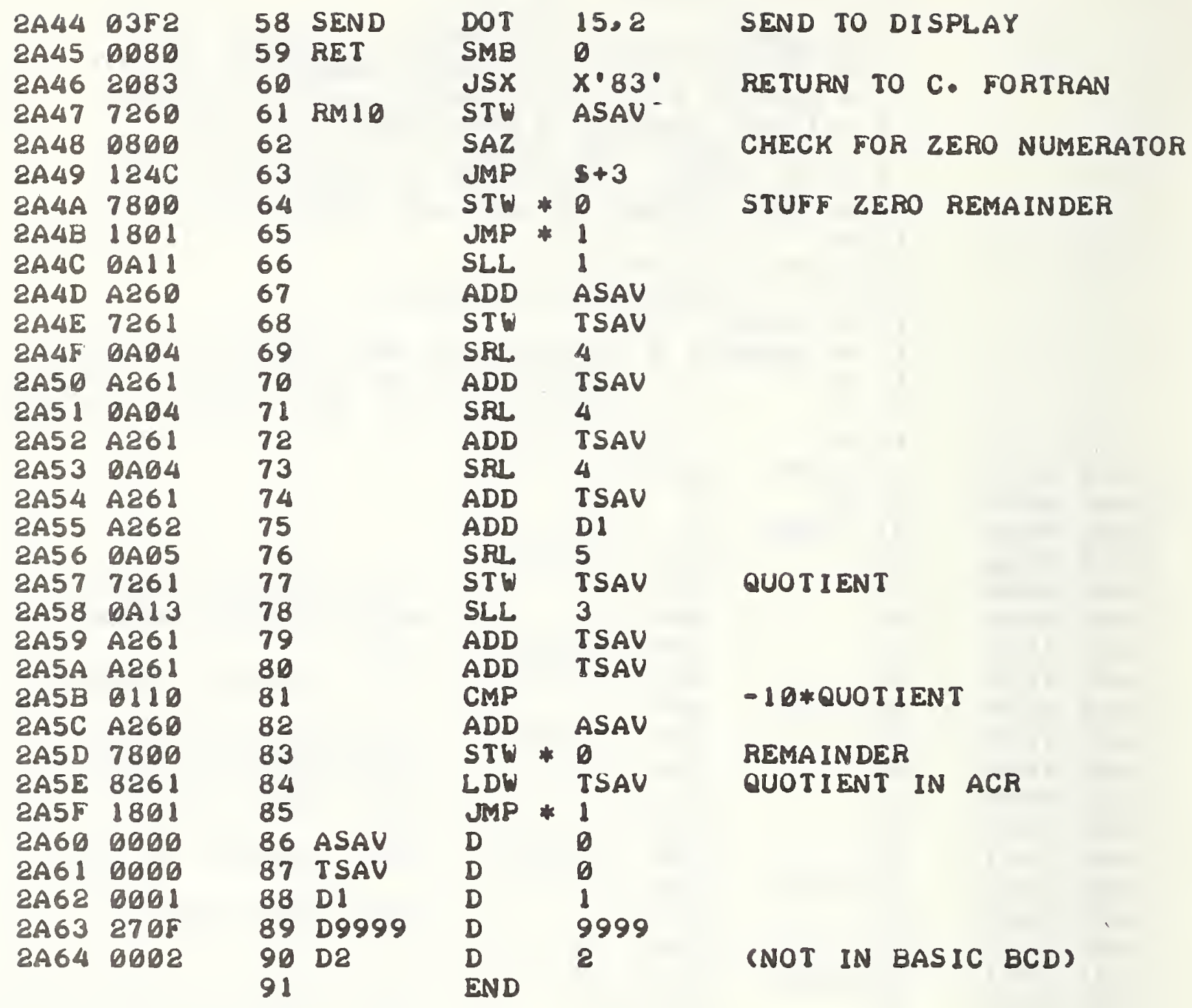

N O ERRORS 
18/80/7486 'DISP!

PAGE 3

\begin{tabular}{|c|c|c|c|c|c|c|c|}
\hline $\begin{array}{l}\text { A SAV } \\
\text { D } 9999 \\
\text { DISP } \\
\text { RMIO } \\
\text { T SAV }\end{array}$ & $\begin{array}{l}2 A 60 \\
2 A 63 \\
2 A 20 \\
8 A 47 \\
2 A 61\end{array}$ & $\begin{array}{l}\text { BEGIN } \\
\text { DIGE } \\
\text { JCHAN } \\
\text { SEND }\end{array}$ & $\begin{array}{l}2 A 31 \\
8 A 3 D \\
8 A 88 \\
8 A 44\end{array}$ & $\begin{array}{l}\text { DI } \\
\text { DIG3 } \\
\text { K } \\
\text { TEST }\end{array}$ & $\begin{array}{l}2 A 62 \\
2 A 3 B \\
8 A 21 \\
2 A 28\end{array}$ & $\begin{array}{l}\text { D2 } \\
\text { DIGA } \\
\text { RET } \\
\text { TRUE }\end{array}$ & $\begin{array}{l}2 A 64 \\
2 A 39 \\
2 A 45 \\
\text { 2A2E }\end{array}$ \\
\hline
\end{tabular}


1 - $12 / 11 / 7488^{\circ} L E A D R \cdot$

2 ORIG $X^{\circ} 2 A 80^{\circ}$

3 * PUNCHES PAPER TAPE LEADER WHEN CALLED

4 * BY MAIN PROGRAM.

$5 *$

6 * IN FORTRAN USE:

$7 *$ CALL LEADR

$8 *$

$2 A 200082$ 0005

$2 A 210080$

9 LEADR

DATA $X^{\circ} 82^{\circ}$

10 UNIT EQU $5^{-}$

11

OPEN F,BUF, WC, UNIT, $X^{\prime} E^{\prime}, 1$

S $2 A 222042$

$2 A 23 \quad 2 A 37$

$2 A 242 A 40$

$2 A 25$ 2A3F

$2 A 260005$

$2 A 27000 E$

$2 A 288001$

$2 A 29$ 823D

12

LDW

$F+6$

2A2A C236

13

ORI $\quad \mathrm{B} 8000$

14

STW

$F+6$

$2 A 2 C 0080$

DO 10

$F$, BUF, WC

$S$ 2A2D 2044

ZA2E $2 A 37$

$2 A 2 F \quad 2 A 40$

$2 A 30$ AA3F

$2 A 310080$

$S \quad 2 A 32 \quad 2046$

$2 A 33$ AA37

$2 A 340080$

$2 A 352983$

$2 A 368000$

$2 A 37$

2A3F D023

$2 A 40$

15

16

STAT F

17

18

$19 \times 8000$

205

$21 W C$

22 BUF

23 OPEN

24 DOIO

25 STAT

26

$\begin{array}{ll}\text { SMB } & 0 \\ \text { JSX } & x^{\circ} 83^{\circ} \\ \text { D } & x^{\prime} 8000^{\circ} \\ \text { RES } & 8^{-} \\ \text {DATA } & 35 \\ \text { RES } & 35 \\ \text { EQU } & 66 \\ \text { EQU } & 68 \\ \text { EQU } & 70 \\ \text { END } & \end{array}$

SET SPECIAL FORMAT

RETURN TO C. FORTRAN

N O ERRORS 
$18 / 11 / 7488$ 'LEADR'

$B \cup F$

$O P E N$

$\times 8000$

PAS?

2A36
2A40 DOIO

0042 STAT

00445

0046 UNIT
PAGE

e

2A37 LEADR

0005 WC

$2 A 20$

2A3F 


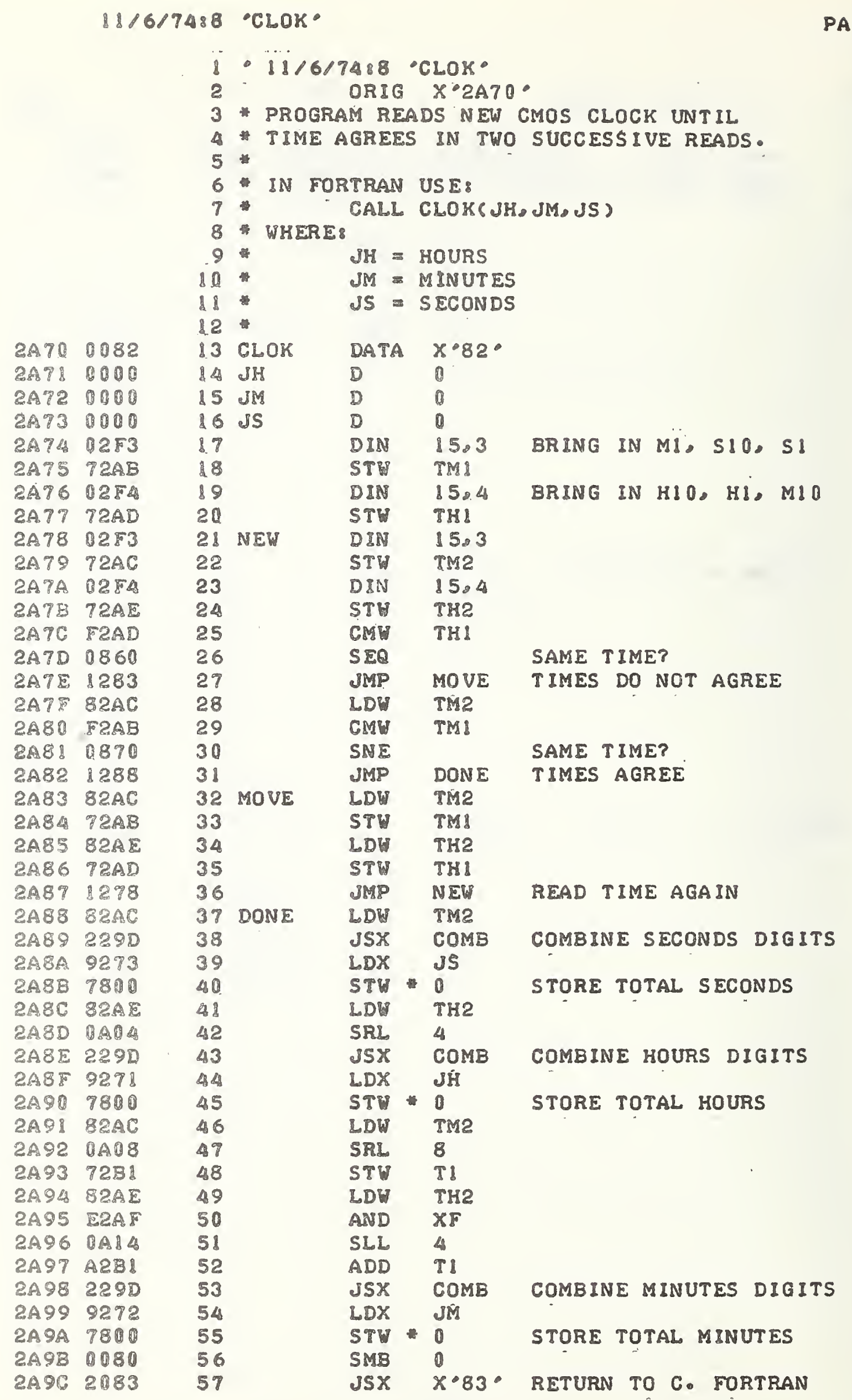




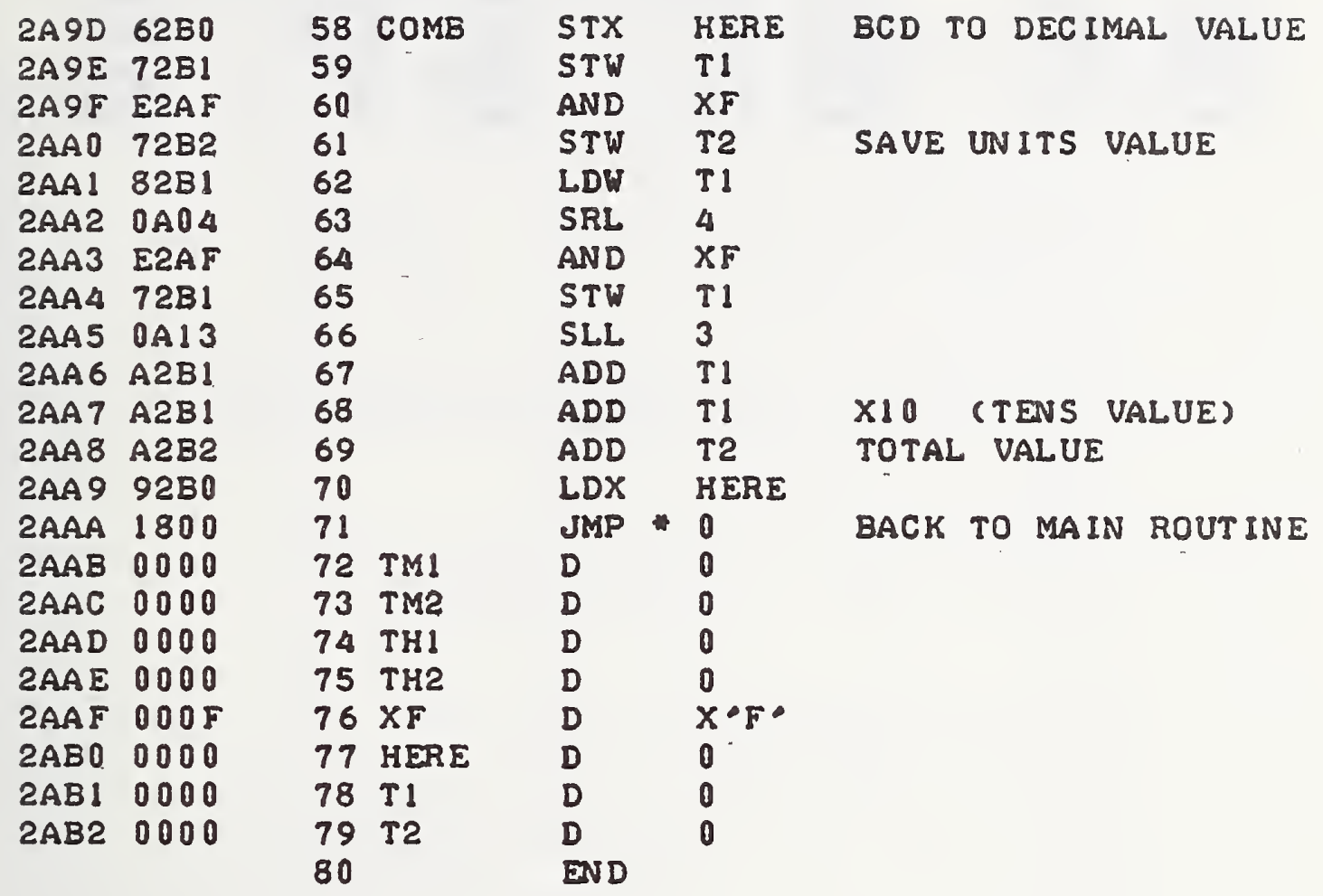

NO ERRORS 


$\begin{array}{llllllll}\text { CLOK } & 2 A 70 & \text { COMB } & \text { 2A9D } & \text { DONE } & \text { 2A88 } & \text { HERE } & \text { 2ABO } \\ \text { JH } & 2 A 71 & \text { JM } & 2 A 72 & \text { JS } & \text { 2A73 } & \text { MOVE } & \text { 2A83 } \\ \text { NEW } & 2 A 78 & \text { TI } & \text { 2AB1 } & \text { T2 } & \text { 2AB2 } & \text { TH } & \text { 2AAD } \\ \text { TH2 } & \text { 2AAE } & \text { TML } & \text { 2AAB } & \text { TM2 } & \text { 2AAC } & \text { XF } & \text { 2AAF } \\ \text { PAS? } & & & & & & & \end{array}$


7. APPENDIX C. PROGRAM LISTINGS FOR INTERFACE TEST PROGRAMS AND REALTIME ANALYZER ASSEMBLY LANGUAGE DRIVER

Appendix C contains program listings for "MINOSI", TCLOK", TRTAI", and "RTAI". 
$1800 \quad 0086$

18010050

$1802806 \mathrm{E}$

18030080

18047015

$1805 \square 356$

$1806 \quad 803 \mathrm{C}$

$1807 \quad 3 F 2$

18080025

18091009

180A 9035

$180 \mathrm{~B} 0501$

$180 \mathrm{C} \quad 100 \mathrm{~B}$

$180 \mathrm{D}$ BRFE

$180 E \quad 7037$

$180 F \quad 08 D 0$

18101029

1811 D8EO

18121025

1813 DAOE

$1814 \mathrm{~F} 06 \mathrm{~F}$

18150860

18161028

18178037

$1818 \mathrm{Eg} 3 \mathrm{~B}$

$181908 \mathrm{00}$

$181 \mathrm{~A} 1022$ $11^{\circ} 11 / 26 / 7484^{\circ} M I N O S 1^{\circ}$

2 ORIG $x^{\circ} 1800^{\circ}$

3 * MINIMAL TEST OF COMMUNITY NOISE SYSTEM.

4 * CHANGE LOC B TO GIVE DIFFERENT DELAY

5 * TIME BETWEEN INTERRUPT AND THE DIN IN.

6 * USE SSI AND SSE TO GIVE THE FOLLOWING

7 * values on external display 8

$8 *$

9 * WIND SSI. SSE DOWN (ID $=A$ )

10 * CHI SSI UP (ID $=B$ )

11 * CH2 SS2 UP (ID $=C$ )

$12 *$

13 * EXIERNAL SENSE UP FOR DECIMAL DISPLAY

14 * EXTERNAL SENSE IOWN FOR HEX DISPLAY

15 * (IN HEX MODE MOST SIGNIFICANT DIGIT

$16 *$ IS ID)

$17 *$

18 * PUT SSO UP TO HALT AFTER DISPLAY

19 * PUT SS3 UP TO GIVE MASTER RESET

20 * AFTER DISPLAY

$21 *$

$22 *$

23 * IF THE WORD 'FACE' REMAINS ON THE DISPLAY

$24 *$ IT SAYS THAT

$25 *$

$26 *$

$27 *$

$28 *$

$29 *$

$30 *$

31 START SMB \$

32

33

34

35

36

37

38

39

40 A

41 IT

$42 \mathrm{C}$

43

44

45

46

47

48

49

50

51

52

53

54

55

56

57
1) DISPLAY IS WORKING

2) LEVEL 5 DATA INTERRUPT FROM INTERFACE IS MISSING OR CPU INTERRUPT

CARD IS MALFUNCTIONING

LDW $=I T$

SMB 0

STW $x^{\circ} 15^{\circ}$

DOT $15,6^{\circ}$

LDW FACE

DOT 15.2 SEND FACE TO DISPLAY

ENB 5

JMP A

LDX B

DXS 1

JMP C

DIN 15,2

STW T

SSI

JMP

SS2

JMP S2

SRL 14

SEQ WIND DATA?

JMP RETA NO

LDW T

AND X3FF

SSE

JMP
WANT HEX OR DECIMAL? DEC IMAL
$\mathrm{CMW} \equiv 1$ 


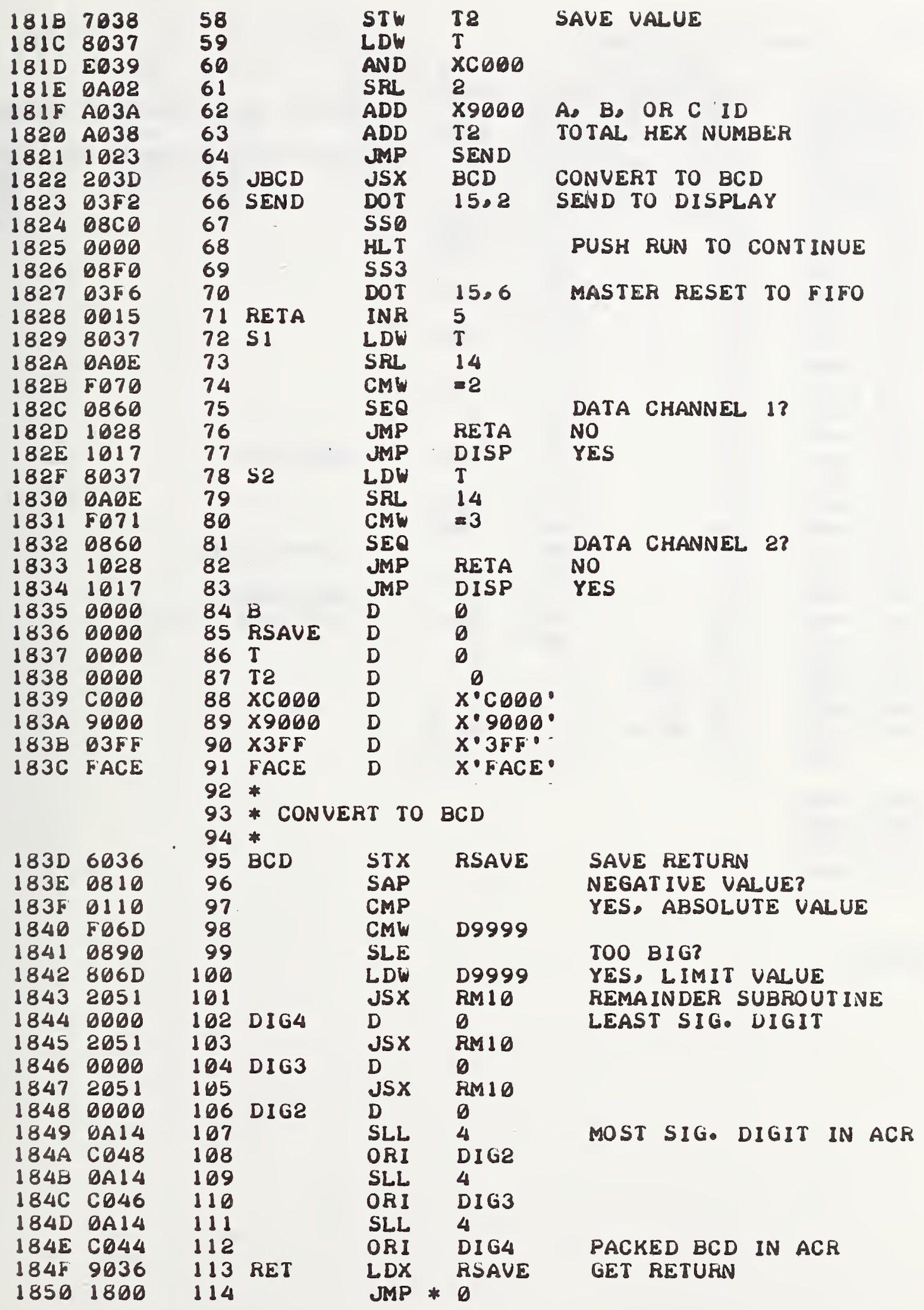




\begin{tabular}{|c|c|c|c|c|c|c|c|}
\hline $\begin{array}{l}1851 \\
1852\end{array}$ & $\begin{array}{l}706 A \\
9800\end{array}$ & $\begin{array}{l}115 \\
116\end{array}$ & $R M \perp 0$ & $\begin{array}{l}\text { STW } \\
\text { SAZ }\end{array}$ & & ASAV & CHECK FOR ZERO NUMERATOR \\
\hline 1853 & 1056 & 117 & & JMP & & $5+3$ & 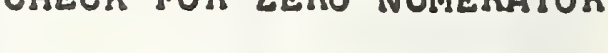 \\
\hline 1854 & 7800 & 118 & & STW & * & 0 & STUFF ZERO REMAINDER \\
\hline 1855 & 1801 & 119 & & JMP & * & $\downarrow$ & \\
\hline 1856 & $D A \perp 1$ & 120 & & SLL & & 1 & \\
\hline 1857 & $A D 6 A$ & 121 & & $A D D$ & & ASAV & \\
\hline 1858 & $706 B$ & 122 & & STW & & TSAV & \\
\hline 1859 & $\triangle A O 4$ & 123 & & SRL & & 4 & ( \\
\hline $185 \mathrm{~A}$ & $A D 6 B$ & 124 & & ADD & & TSAV & \\
\hline 1858 & $D A D 4$ & 125 & & SRL & & 4 & \\
\hline $185 C$ & $A \oslash 6 B$ & 126 & & $A D D$ & & TSAV & \\
\hline $185 D$ & $D A O 4$ & 127 & & SRL & & 4 & \\
\hline $185 E$ & $A 96 B$ & 128 & & $A D D$ & & TSAV & \\
\hline $185 \mathrm{~F}$ & $\mathrm{AD} 6 \mathrm{C}$ & 129 & & $A D D$ & & DI & \\
\hline 1860 & DAOS & 130 & & SRL & & 5 & f \\
\hline 1861 & $706 B$ & 131 & & STW & & TSAV & QUOT IENT \\
\hline 1862 & DA 13 & 132 & & SLL & & 3 & \\
\hline 1863 & $A D 6 B$ & 133 & & $A D D$ & & TSAV & \\
\hline 1864 & $A D 6 B$ & 134 & & $A D D$ & & TSAV & \\
\hline 1865 & 0110 & 135 & & CMP & & & $-10 * Q U O T$ IENT \\
\hline 1866 & $A \emptyset 6 A$ & 136 & & $A D D$ & & ASAV & \\
\hline 1867 & 7800 & 137 & & STW & * & & REMAINDER \\
\hline 1868 & $806 \mathrm{~B}$ & 138 & & LDW & & TSAV & QUOTIENT IN ACR \\
\hline 1869 & 1801 & 139 & & JMP & $*$ & 1 & \\
\hline $186 \mathrm{~A}$ & 0000 & 140 & ASAV & D & & 0 & \\
\hline 1868 & 0000 & 141 & TSAV & D & & 0 & \\
\hline $186 \mathrm{C}$ & 0001 & 142 & DI & D & & 1 & \\
\hline $186 D$ & $\begin{array}{l}2705 \\
1800\end{array}$ & $\begin{array}{l}143 \\
144\end{array}$ & D9999 & $\begin{array}{l}\text { D } \\
\text { END }\end{array}$ & & $\begin{array}{l}9999 \\
\text { START }\end{array}$ & \\
\hline $186 E$ & $180 \mathrm{~A}$ & & & & & & \\
\hline 1861 & 0001 & & & & & & \\
\hline 1870 & 0002 & & & & & & \\
\hline 1871 & 0003 & & & & & & \\
\hline
\end{tabular}

NO ERRORS 
$11 / 86 / 7484$ 'MINOS1'

A

C

D IG3

I T

RMIO

$S$ END

T SAV

PAS?

$\begin{array}{llll}1809 & \text { ASAV } & 186 A & \text { B } \\ 1868 & \text { DI } & 186 C & \text { D9999 } \\ 1846 & \text { DIG4 } & 1844 & \text { DISP } \\ 180 A & \text { JBCD } & 1822 & \text { RET } \\ 1851 & \text { RSAVE } & 1836 & \text { S1 } \\ 1823 & \text { START } & 1800 & \text { T } \\ 186 B & \text { X3FF } & 183 B & \text { X9600 }\end{array}$

$1835 \mathrm{BCD}$

1830

1848

$183 \mathrm{C}$

1828

1825

1838

1839 


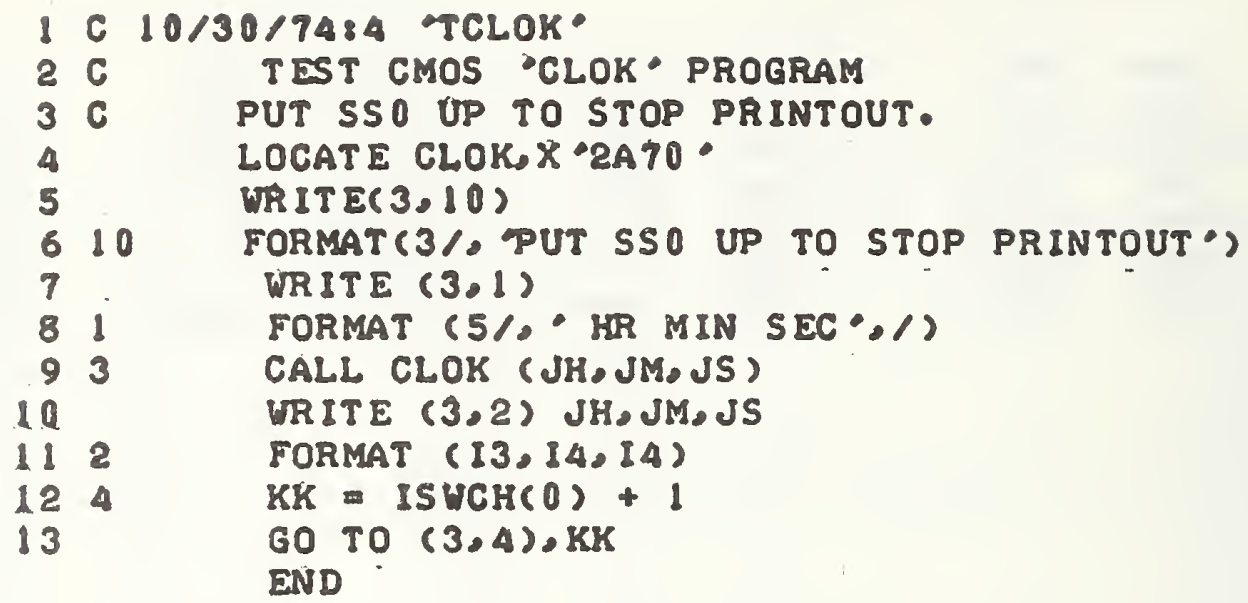




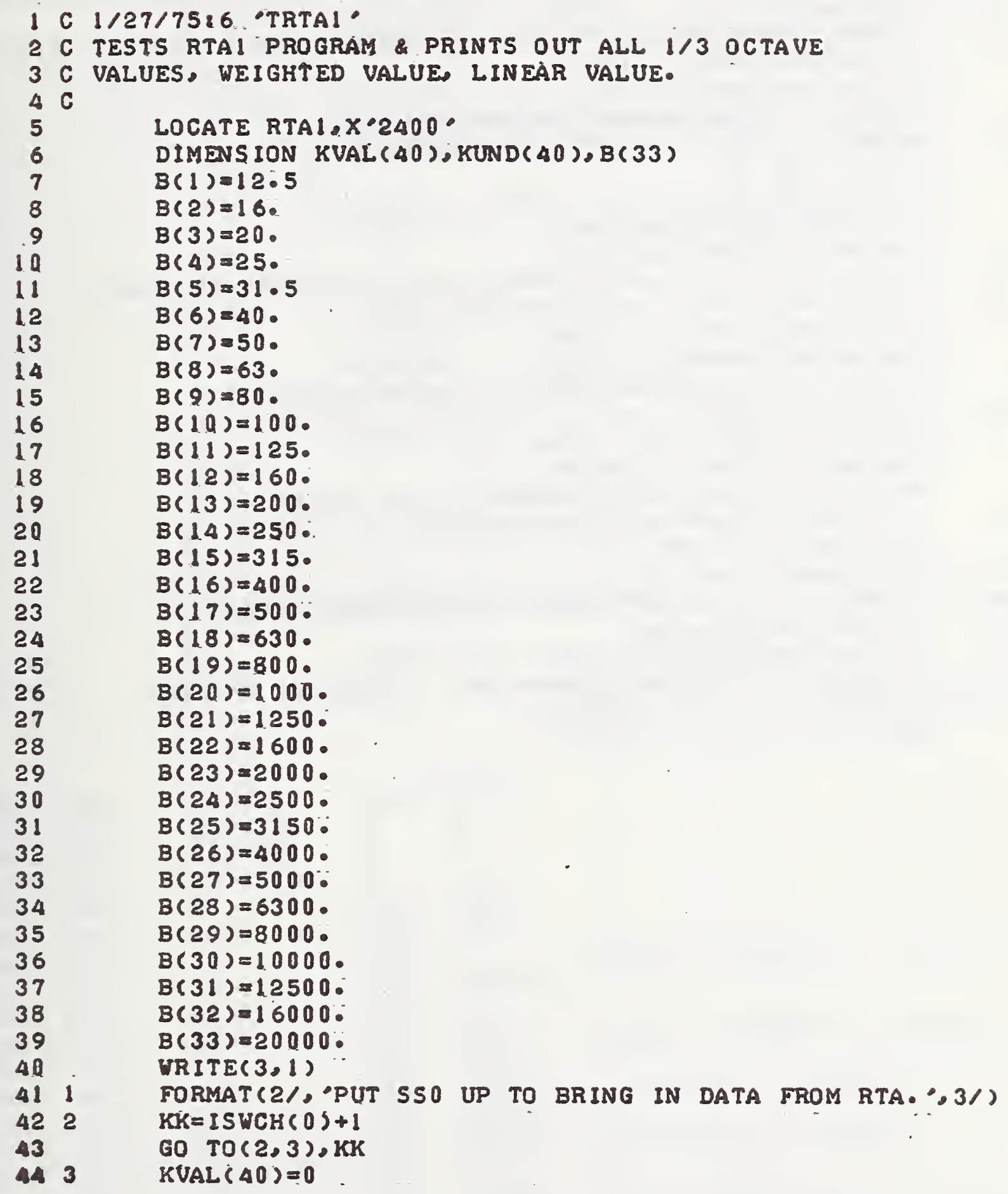




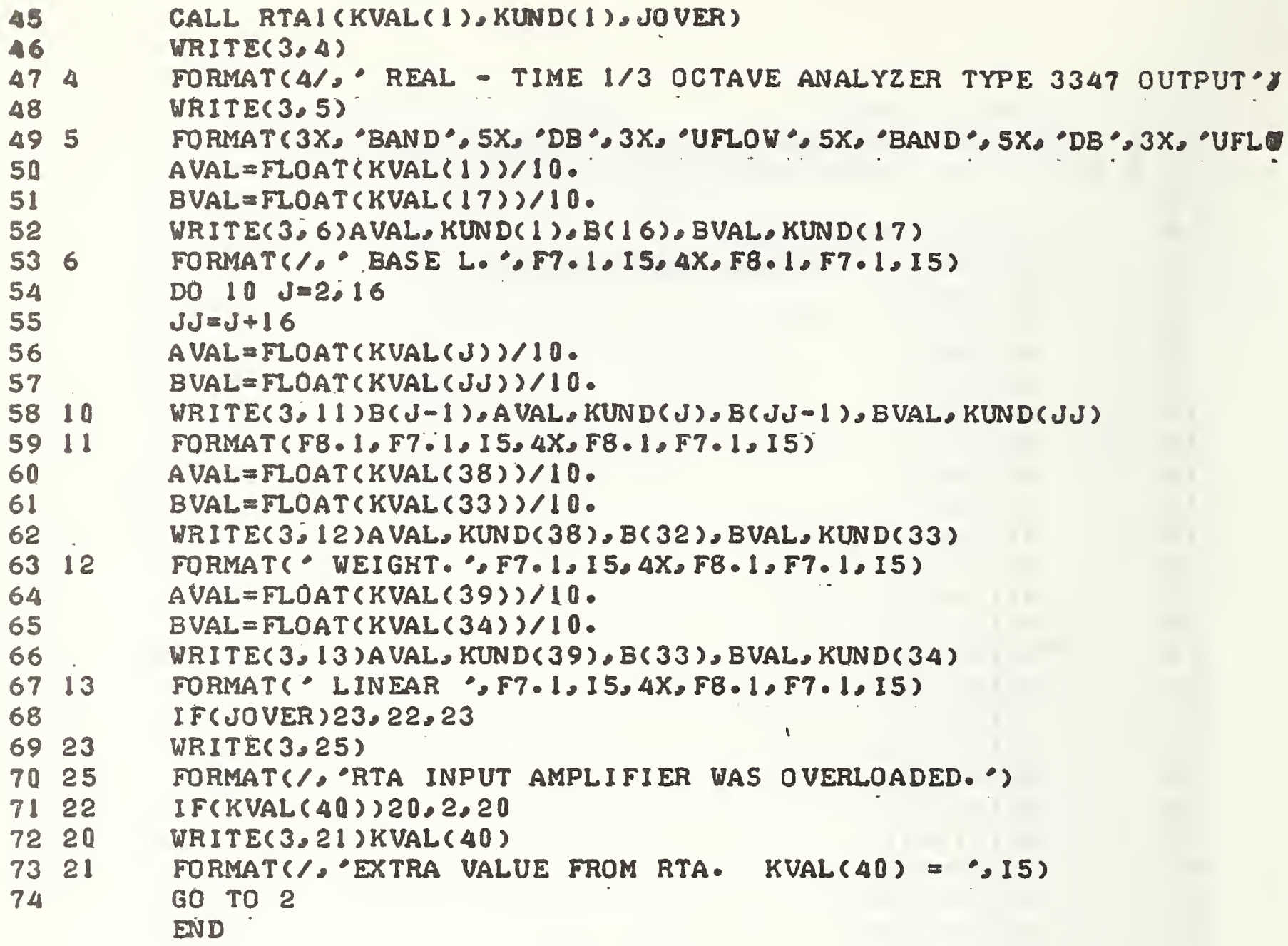




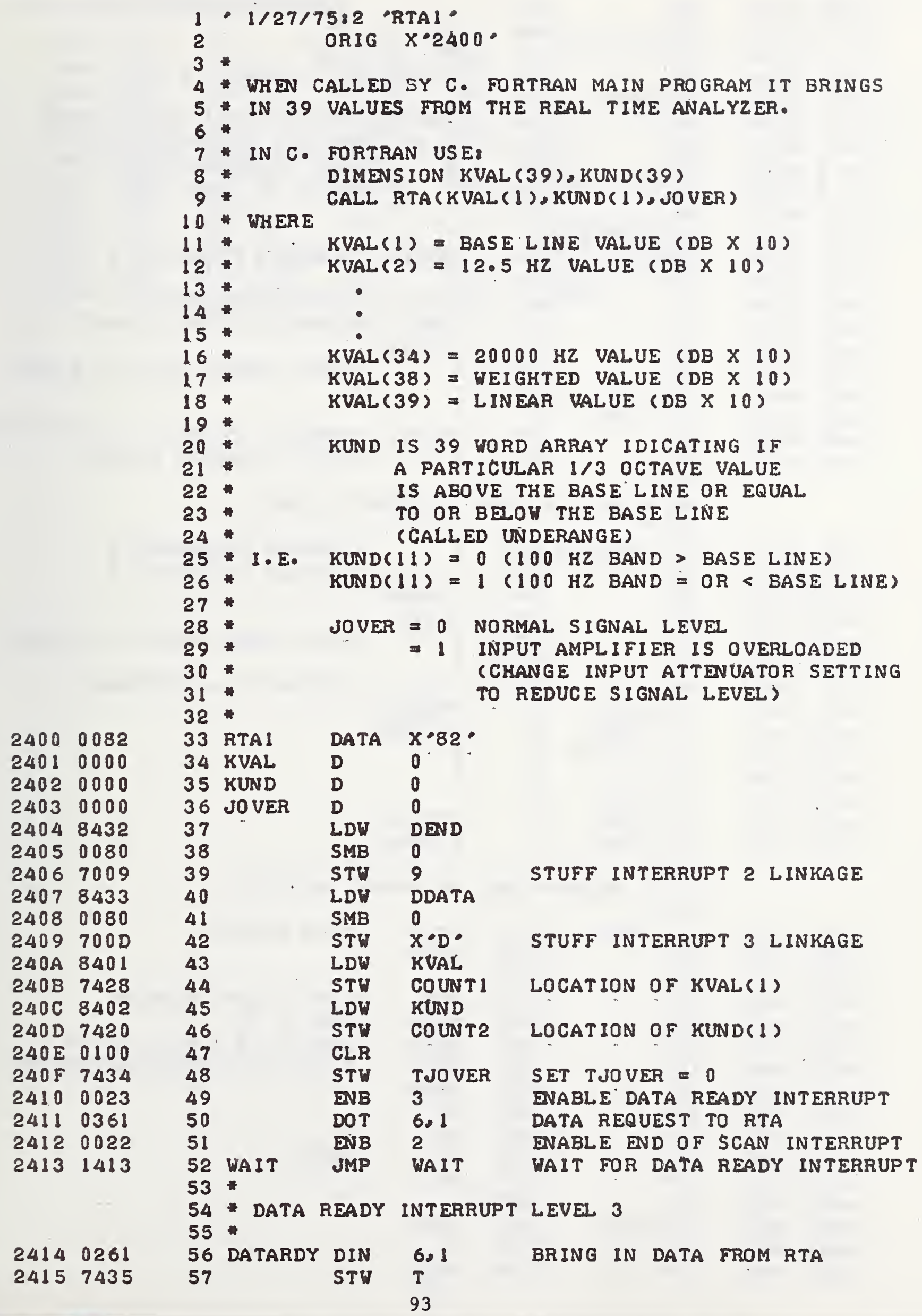

STW COUNTI LOCATION OF KVAL( 1 )

STW COUNTE LOCATION OF KUND(1)

STUFF INTERRUPT 2 LINKAGE

STUFF INTERRUPT 3 LINKAGE

WAIT FOR DATA READY INTERRUPT 


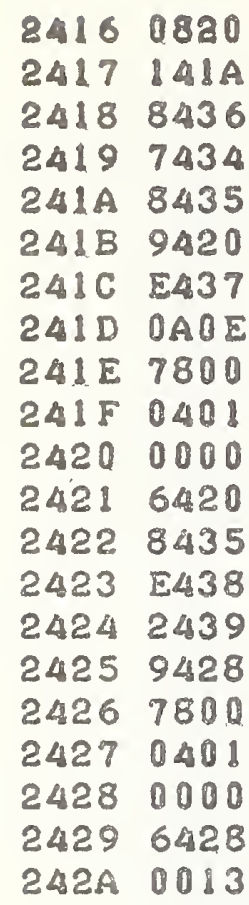

$242 B \quad 0033$

$242 C \quad 0032$

$242 D 8434$

242E 9403

$242 F 7800$

24300080

243 ! 2083

$2432242 B$

24332414

24340000

24350000

24360001

24374000

$24383 F F$
24396451

243A 7452

$243 B \quad 0100$

243C 7453

243D 2446

$243 E 2446$

$243 \mathrm{~F} 2446$

$2440 \quad 8452$

24410.54

$2442 \quad 2454$

$2443 \quad A 453$

24449451

$2445 \quad 1800$

24468452

24470.54

$2448 \quad 7452$
58

59

60

61

62

63

64

65

66

67

68

69

70

71

72

73

74

75

76

77

78

79

80 .

81

82 ENDSCAN

83

84

85

86

87

88

89

90

91

\section{2}

93 on

$94 \times 4000$

95 X3FFF

$96 *$

97 * CONVER $98 *$

99 BCDB

100

101

102

103

104

105

106

107

108

109

110

111

$112 \mathrm{MB} 10$

113

114

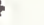
$C D B$
SAM

JMP

LDW

STW

LDW

LDX

AND

SRI

STW * 0

IXS 1

D

STX

LDW

AND

JSX

LDX

STW * 0

IXS 1

D

STX

INR

$\mathrm{T}$

0

3

\section{CONT}

ONE

TJO VER

COUNT2 IX POINTS TO KUND ELEMENT $\times 4000$

14

1

COUNT2 COUNT2 $=$ COUNT2 +1

X3FFF EXTRACT BCD DATA

$B C D B$

COUNT 1

CONVERT ECD TO BINARY

STORE BINARY IN KVAL ARRAY

COUNT 1 COUNT $1=$ COUNT $1+1$

DATA INTERRUPT RETURN NO

YES

EXTRÁCT UNDERANGE BIT

MOVE UNDERRANGE BIT

STORE IN KUND ARRAY

INPUT AMPLIFIER OVERLOADED?

SCAN INTERRUPT LEVEL 2

DSB 3

DISABLE INTERRUPT 3

DSB 2

LDW TJOVER

LDX JOVER

STH * 0

SMB 0

JSX $X \cdot 83^{\circ}$ RETURN TO C. FORTRAN

DEND $D$ ENDSCAN

DISABLE INTERRUPT 2

.83.
ENDSCAN
DATARDY

PASS JOVER VALUE TO FORTRAN

D DATARDY

D 0

D 0

D 1

D $x^{\circ} 4000^{\circ}$

D $\quad x^{\circ} 3 F F=$

0

$x^{\circ} 4000^{\circ}$
$x^{-3 F F 5}$

BCD TO EINARY ROUTINE

STX RT

STW BCDN

CLR

STW TOT

JSX MBIO

JSX MBIO

JSX MBIO

LDH BCDN

SLC 4

AND $X F$

$A D D$ TOT

LDX RT

JMP $* 0$

LDW BCDN

SLC 4

STU BCDN
SAVE RETURN

ZERO BINARY NUMBER

DIGI $X 10$

DIG2 X $10+D I G 1 \times 100$

$D I G 3 \times 10+D I G 2 \times 100+D I G 1 \times 1000$

$+D I G 4$ 


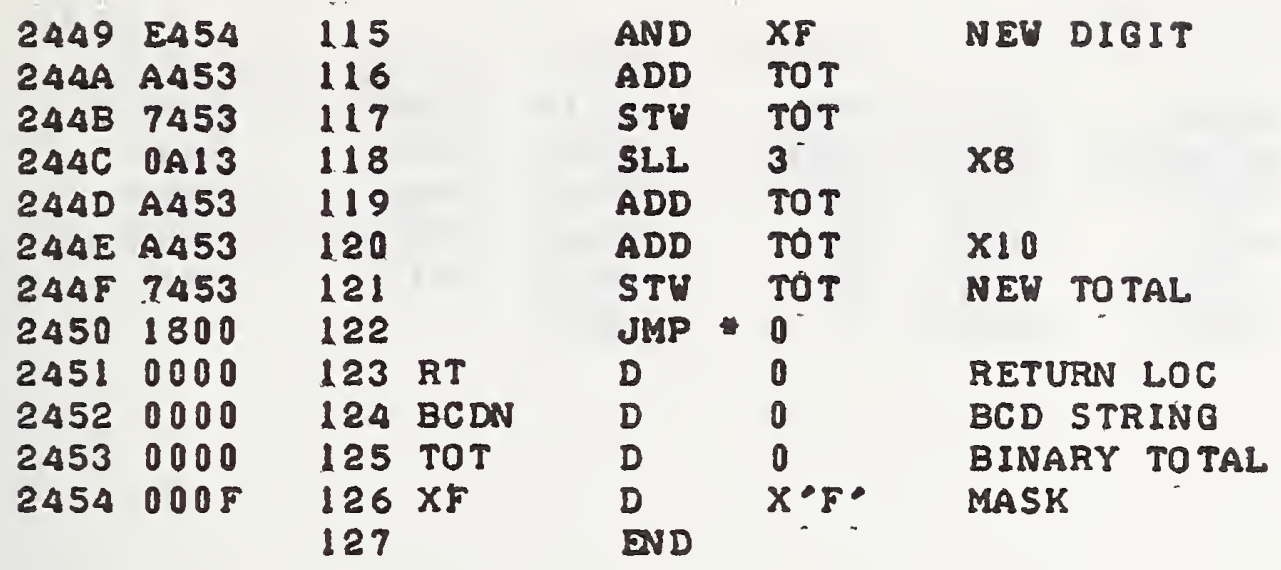

NO ERRORS 
i/27/75:2 'RTA1.

$\begin{array}{llllllll}\text { BCDB } & 2439 & \text { BCDN } & 2452 & \text { CONT } & 241 A & \text { COUNTI } & 2428 \\ \text { COUNT2 } & 2420 & \text { DATARDY } & 2414 & \text { DDATA } & 2433 & \text { DEND } & 2432 \\ \text { ENDSCAN } & 242 B & \text { JOVER } & 2403 & \text { KUND } & 2402 & \text { KVAL } & 2401 \\ \text { MB10 } & 2446 & \text { ONE } & 2436 & \text { RT } & 2451 & \text { RTAI } & 2400 \\ \text { T } & 2435 & \text { TJOVER } & 2434 & \text { TOT } & 2453 & \text { WAIT } & 2413 \\ \text { X3FTF } & 2438 & \text { X4000 } & 2437 & \text { XF } & 8454 & & \\ \text { PAST } & & & & & & \end{array}$

PAGE 4 
8. APPENDIX D. FORTRAN SOFTWARE LISTINGS FOR THE ANALYSIS OF COMMUNITY NOISE DATA

Appendix D contains program listings for Tape Read Program and Calcomp Plot Program. 
C PROGRAM TO READ 24 MOURS OF DATA AND PLOT LI ETC. LEQ EACH HOUR.

OIMENSION IOAY (5), LINE $(?, 6)$

DIMENSION SPLF $(24,6,2)$, SPECS 1351

DIMENSION YF(ION), XF (100), FITIS)

INTEGER DAYST,HRST

UIMENSIIN NRIN 100,2$), 1 C 2(2), 33(2,10001$

COMMON J1(2C:D),J2(10001

ENIIVALENCE $(J 1(1), J 311,1)$

UATA $(F 1 T(J), J=1,5) / 1 ., 10 . .50 .00 .09 . /$

C READ IN AEGINNING,FND,DELTA FOR BIN - E.G, $40,80,2$ MEANS BIN IN 20 BINS FROM

C 4 T TO RO DB WITH 2 DA EIN WIDTH.

READ(5,1) IBIEG, IFND, IDEL

C FORMATI) MEANS FREF FORMAT, ALL NUMRERS SEPARATED HY COMMAS. E.G $40,80,2$

I FORMAT ( ) NUM $=(I F N D-I P E G) / \triangle D E L$

WRITE(6,7) NUM, I BEG, IEND, IOFL

2 FORMATIIH), 'FOLLOMING DATA IS FOR, I3, BINS FROM.,13, TO,.13,

- odr in., 13, tor stFps.i

C READ IN STARTIIIG DAY,HR, NUM DF HRS KEAT $(5,9)$ DAYST, HRST, NHR

9 FORMAT(316)

READ(O, 10)ITAY(?), IDAY(4)

10 FORMAT( $>$ A 6$)$

IDAY $(1)=0$ DAY"

I $A Y Y(3)=0$ HUUR.

IDAY $(5)=-0$

50 CALL RMIINPK(7,L 2$)$

IF(JIIIZOI).EO.DAYST.ANR.JI(I2C.2).EQ.HRSTIGO TO II

Go TO 50

$110010 ? 11=1, N H R$

CALL NTPAN $7,7,-1)$

DD $15 \mathrm{~J}=1.2$

$1(2(J)=C$

on $151=1.160$

$15 N A I N(I, J)=0$

17 IHR =J।(1?0?)

13 CALL KUIJNFKI7,L?

C L 2 IJEGATIVF MFAIIS RFAD FRROR. IGNDRE RLOCK ANU CONTINUE

IFIL):LT:C) Gก TD 13

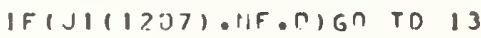

IFIJI()?OZI.NF. IHRIGN TO 16

C TO 30 IINS TATA IN GIVFN RANGE. IGNMRE DATA UUTSIOE KANGE.

C DATA GDEATER THAN OR ERUAL TO 40 ANO LFSS THAN 4 I PUT IN 4 TDB BIN.

on $30 \mathrm{~J}=1.2$

DD $30 \quad 1=1,6 \cap 0$

IF J J J,II/IU..LT.IPFG.DR.J3/J,II/IO.GT.IENDI GD TO 30

$1(?)=1(2)=1$

SPLF $(11,6, J)=\operatorname{SPLF}(11,6, J)+10 \cdot(\mathrm{J} 3(\mathrm{~J}, 11 / 100.1$

Dก $20 K=1, N U H$

TEST $=I A E G+Y \cdot I D E L$

$2 C \mid F(J 3(J, 1) / 10 . L T$. TEST) GO TO 2 I

$21 N B \backslash N(K, J)=N R I N(K, J)+1$

30 CONTINUE

$60 T 017$

$16 \quad 0040 \quad \mathrm{~J}=1.2$

IF(IC2(J).EQ.C) GO TO 40

SPLF $(11,6, J)=10 * A L O G I 0(S P L F(11,6, J) / 1(2(J) !$

$X F(1)=N B ! N(N \cup M, J)$

DO $31 K=2$, IUM

$J 4=N U M-K+1$

$31 X F(K)=X F(K,-1)+N B I N(J 4, J 1$

DD $41 K=1$, N $11 M$

$X F(K)=X F(K), 1(2,(\mathrm{~J}) \cdot 100$.

$41 Y F(K)=1 E N D+1-K$

34.

65.

66.

67.

69.

INTERPOLATE TO CALCULATE LI.LIO ETC. DO $53 L=1.5$

53 SPLF I ),L,J) = AITINT(XF, YF,NUM,FIT(L), 2,TI)

40 CONTINUF- 


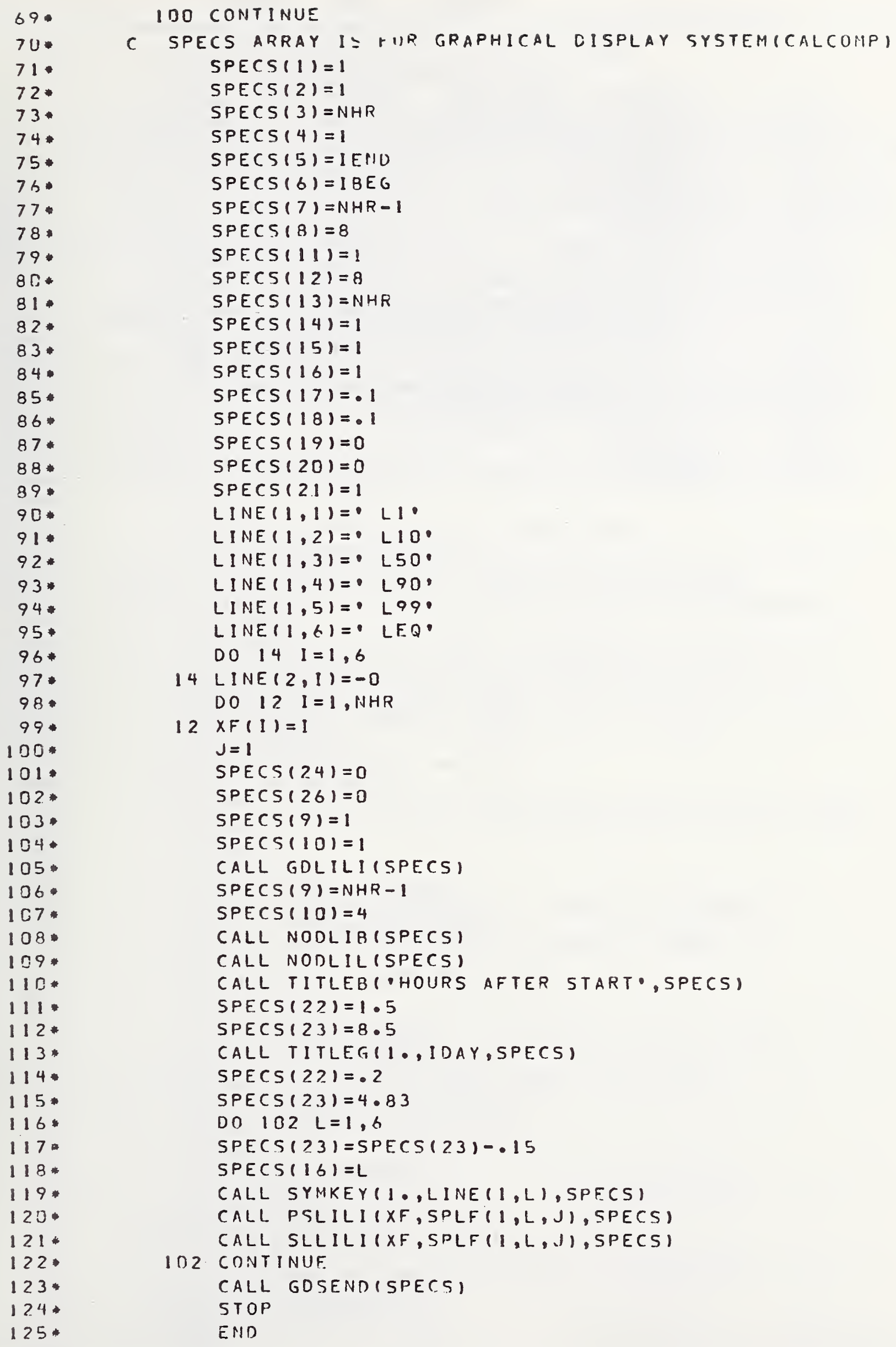




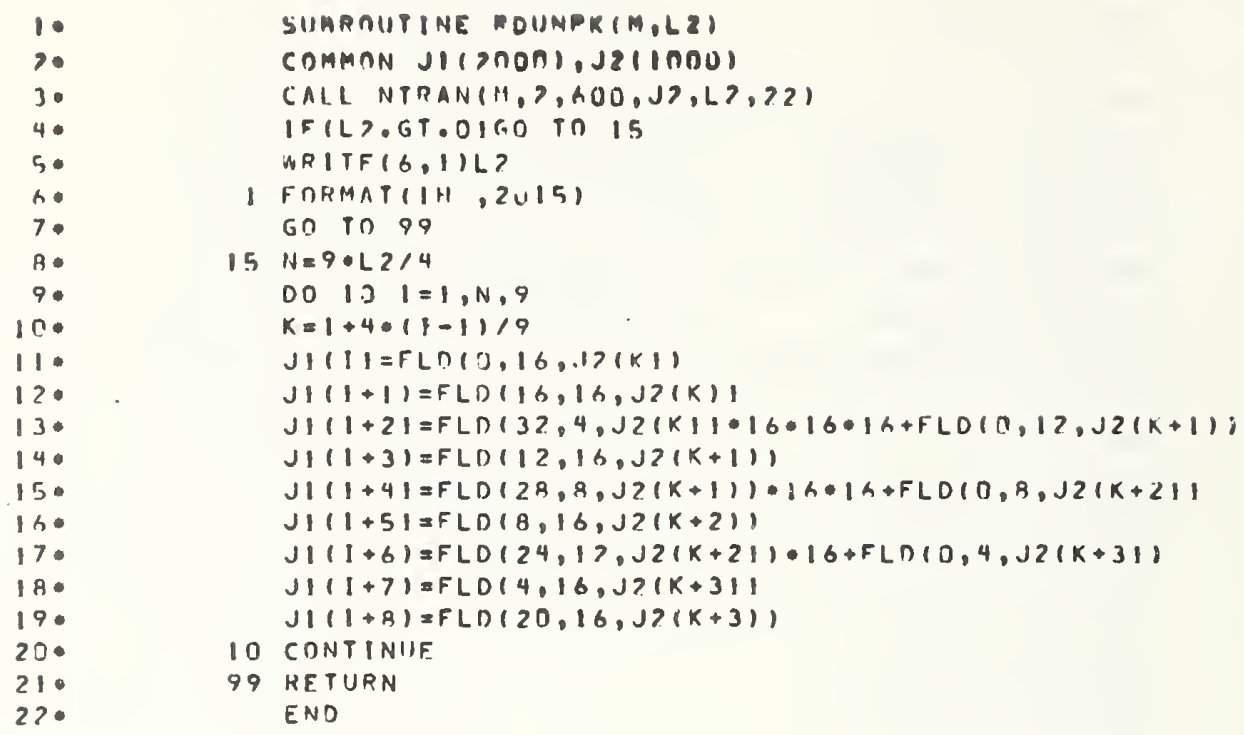




\section{Calcomp Plot rrogram}

C PROGRAM TO READ DATA,BIN,CALCULATE L1,10,50,90,99,LEG AND LIST. DIMENSIDN YF (ION),XF(IUJ), FIT (5), SPLF (S), XLEGI2I

INTEGER DAYST,HRST,MINST, OAYFIN,HRFIN,MINFIN

DIMENSIDN NEIN $(100,2), I C 2(2), J 3(2,600 I$ COMMON J1(1215),J2(1000)

EQUIVALENCE $(J 111), J 3(1,1) 1$

UATAIFITIJ),J=1,5)/1, ID, $1050,090, .99,1$

C.REAO IN BEGINNING,END,DELTA FDK BIN - E.G. $40.80,2$ MEANS BIN IN 20 BINS FROM

C $\quad 4 O$ TO $8 O$ OB WITH 2 DB BIN WIOTH. KEAD(5,I) IBEG, IEND, IOEL

C FORMATI) MEANS FREE FORMAT, ALL NUMRERS SEPARATEO BY COMMAS. E.G 40, HO, 2

I FDRMAI() $N U H=(|E N D-| B E G) / \mid D E L$

WRITE $(6,2)$ NUM, IBEG, IENO, IDEL

2 FORMATIIHI, 'FOLLOMING DATA IS FOR,.13,0BINS FROM1,13, TD0.13, - OOB IN?,I3,. DB STEPS,I

C READ IN SIARTING DAY,HR, MIN AND FINISHING DAY,HR,MIN. READIS, I) OAYST, HRST, MINST, DAYFIN,HRFIN, MINFIN READIS,IIICTRL

50 CALL RDUNPK\$7.L2I

IF (JI(1201),EQ.OAYST.ANO.JI(1202) EQ.HRST.AND.JI(I2O3),GE.MINSTIGD -TD 11

GO TO 50

II CALL NTRAN17,7,011

13 CALL ROUNPK17,L 2 I

C L 2 NEGATIVE MEANS REAO ERROR. IGNDRE BLDCK AND CONTINUE IF (LZ.LT.O) GO TO 13

$I C I=I C I+I$

IF (ICTRL.EQ.I) WRITE(6,10) (JI(J),J=1201,1215I

IF (ICTRL.EU.2) MRITE $(6,10) \mathrm{J} I$

IO FOKMATIIH 2015 I

C TD 30 BINS DATA IN GIVEN RANGE. IGNDRE DATA OUTSIDE RANGE.

C DATA GREATER THAN DR EQUAL TO 40 AND LESS THAN 4 I PUT IN $400 B$ BIN.

DO $30 \quad J=1,2$

$00 \quad 30 \quad 1=1.600$

$J 3(J, 1)=J 3(J, 11+10$

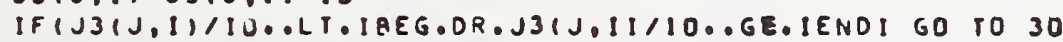

$I(2)=\mid(2|J|+\mid$

$x L E G(J)=x L E G(J)+10 \cdots(J 3(J, 11 / 100)$,

DO $20 K=1$, NUM

TEST $=I B E G+K \bullet I O E L$

20 IFIJ3IJ,I)/IOELT. TESTI GO TO 21

$2 I N B \backslash N(K, J)=N B \backslash N(K, J I+I$

30 CONTINUE

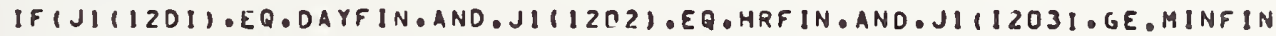

-) GD $10 \quad 12$

GO TD 13

$12|C|=60 U \cdot I C I$

WRITE (6,3) DAYST, HRST, MINST

3 FDKMATIIH, 'DATA STARTS DN DAY, I I, HDUR, I3, MINUTE, I3)

HRITE $(6,4)$ DAYFIN, HRFIN,MINFIN

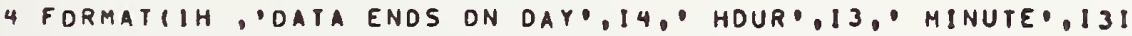

HRITE $(6,5 I I C)$

5 FORMATIIH, "TOTAL POINTS READ $=0,110 I$

DO $40 \mathrm{~J}=1,2$

HRITE (6,6) J,IC21JI

6 FDRMATIIHO, 'FOR CHANNEL, I $2, "$ TOTAL POINTS BINNEO IN RANGE $=0,1101$ IFIICZ(J),EQ.0) GO TO 40

WRITE $(6,7)$

7 FORMATIIH, XLEO LI LIO L5O L9O L99 I

$X L E G(J)=I D A A L D G I D(X L E G(J) / I C Z I J I I$

$X F(1)=N B I N(N U M, J I$

$0031 K=2$, NUM

$J 4=N U M=K+1$

$31 X F(X)=X F(K-1 I+N B ! N(J 4, J !$

$0041 K=1, N U M$

$X F(K)=X F(K) / 1(2) J) \cdot 100$.

$41 Y F(X)=\mid E N O+1-K$

C IHTERPDLATE TO CALCULATE LI,LIO ETC. DO $S 3 \quad L=1, S$

53 SPLF(L) =AITINTIXF, YF, NUM,FITILI, 2, TI) WRITE(6.8) XLFG(J), SPLF

8 FORMATIIH, IOFG.1I

40 CONTINUE

STOP

ENO 


\section{ACKNOWLEDGEMENTS}

The authors wish to express their appreciation to $\mathrm{Dr}$. Robert Joseph at the U. S. Army Environmental Hygiene Agency, Aberdeen Proving Ground, Maryland for the loan of the Bio-Acoustic Division's minicomputer system during interface development and for his helpful suggestions at the time of software development.

We wish to thank Mr. James Heinen, Miss Toni Savoy and Mr. Mitchell Tarica for the many hours they spent constructing the interface hardware.

We want to express our gratitude to Mrs. Marilyn Cadoff for her aid in compiling this report.

We also thank Mrs. Janet Russell and Mrs. Margaret Hildebrand for lending their typing skills to the preparation of this document.

Finally, we wish to thank Mr. William Haight for his judicious review and commentary on this report. 
NBS. II AA (REV. 7.73)

\begin{tabular}{|c|c|c|c|}
\hline $\begin{array}{l}\text { U.S. DEPT. OF COMM. } \\
\text { BIBLIOGRAPHIC DATA } \\
\text { SHEET }\end{array}$ & $\begin{array}{l}\text { 1. PUBLICATION OR RE.PORT NO. } \\
\text { NBSIR } \$ 5-692\end{array}$ & $\begin{array}{l}\text { 2. Gov't Accession } \\
\text { No. }\end{array}$ & 3. Recipient's Accession No. \\
\hline \multirow{2}{*}{\multicolumn{3}{|c|}{$\begin{array}{l}\text { 4. TITLE AND SUBTITIE } \\
\text { A Minicomputer-Based System for the Measurement and Analy- } \\
\text { o1s of Community Nolse }\end{array}$}} & $\begin{array}{l}\text { 5. Publication Date } \\
\text { Apr11 } 1975\end{array}$ \\
\hline & & & 6. Performing Organization Code \\
\hline \multicolumn{3}{|c|}{$\begin{array}{l}\text { 7. AUTHOR(S) } \\
\text { R. L. Fisher, D. S. Blomquist, J. S. Forrer, and D. M. Corley }\end{array}$} & $\begin{array}{l}\text { 8. Performing Organ. Report No. } \\
\text { NBSIR } 75-692\end{array}$ \\
\hline \multirow{2}{*}{\multicolumn{3}{|c|}{$\begin{array}{l}\text { 9. PERFORMING ORGANIZATION NAME AND ADDRESS } \\
\text { NATIONAL BUREAU OF STANDARDS } \\
\text { DEPARTMENT OF COMMERCE } \\
\text { WASHINGTON, D.C. } 20234\end{array}$}} & $\begin{array}{l}\text { 10. Project/Task/Work Unit No. } \\
2130454\end{array}$ \\
\hline & & & 11. Contract/Grant No. \\
\hline \multirow{2}{*}{\multicolumn{3}{|c|}{$\begin{array}{l}\text { 12. Sponsoring Organization Name and Complete Address (Street, City, State, ZIP) } \\
\text { Bioacoustics Division } \\
\text { U.S. Army Environmental Hygiene Agency } \\
\text { Aberdeen Proving Ground, Maryland } 21010\end{array}$}} & $\begin{array}{l}\text { 13. Type of Report \& Period } \\
\text { Covered Final } \\
5 / 74-2 / 75\end{array}$ \\
\hline & & & 14. Sponsoring Agency Code \\
\hline
\end{tabular}

15. SUPPLEMENTARY NOTES

16. ABSTRACT (A 200word or less factual summary of most significant information. If document includes a significant bibliography or literature survey, mention it here.)

An operating system for the measurement and analysis of community noise was turned over to the Army for their use in February 1975, thus accomplishing the transfer of technology developed by NBS to the Bioacoustics Division, U. S. Army Environmental Hygiene Agency. This report documents the hardware and software packages prepared by NBS in support of this system.

17. KEY WORDS (six to twelve entries; alphabetical order; capitalize only the first letter of the first key word unless a proper name; separated by semicolons)

Community noise; computer interface; instrumentation; minicomputer; noise.

18. AVAILABILITY

[ For Official Distribution. Do Not Release to NTIS

$\square$ Order From Sup. of Doc., U.S. Government Printing Office

Washington, D.C. 20402, SD Cat. No. C13

X Order From National Technical Information Service (NTIS) Springfield, Virginia 22151

\begin{tabular}{|l|c|}
\hline $\begin{array}{c}\text { 19. SECURITY CLASS } \\
\text { (THIS REPURT) } \\
\text { UNCL ASSIFIED }\end{array}$ & 21. NO. OF PAGES \\
\hline $\begin{array}{c}\text { 20. SECURITY CLASS } \\
\text { (THIS PAGE) } \\
\text { UNCLASSIFIED }\end{array}$ & 22. Price \\
\hline
\end{tabular}


